INSTITUTO DE PESQUISAS ENERGÉTICAS E NUCLEARES

Autarquia Associada à Universidade de São Paulo

\title{
DETERMINAÇÃO DE ELEMENTOS EM SANGUE DE HAMSTER DOURADO USANDO AAN
}

\author{
Rodrigo Oliveira de Aguiar
}

Dissertação apresentada como parte dos requisitos para obtenção do Grau de Mestre em Ciências na Área de Tecnologia Nuclear - Aplicações.

Orientadora:

Dra. Cibele Bugno Zamboni

São Paulo 2009 
"A mente que se abre a uma nova idéia jamais voltará ao seu tamanho original."

(Albert Einstein)

Dedico com muito amor este trabalho à minha filha Beatriz 


\section{Agradecimentos}

Gostaria de agradecer primeiramente a Deus pela força que depositou em mim, e um conjunto infinito de pessoas que me ajudaram muito:

À Dra. Cibele Bugno Zamboni, pela orientação, incentivo e apoio, indispensáveis para a realização deste trabalho.

Aos colegas do grupo, Agostinho, Ilca, Fred, Guilherme, Laura, Luciana, Roberto, Sabrina, Tatyana e Wagner pela amizade e auxílio no desenvolvimento deste trabalho.

Aos colegas Cláudio e Fábio pela colaboração e amizade.

Ao corpo técnico do reator IEA-R1 e Proteção Radiológica pelo pronto atendimento nas irradiações.

Ao pessoal da CPG pela colaboração.

Ao IPEN/CNEN por possibilitar a realização deste trabalho.

Ao Governo do Estado de São Paulo, pelo apoio financeiro.

À Bianca Torres pela organização no suporte financeiro.

Às diretoras Célia Paschoal e Léia Soares de Abreu, pelo apoio e colaboração.

À Beatriz que me deu muita alegria nos momentos difíceis.

Aos meus pais e irmã pelo carinho e apoio em todos os momentos.

À Priscila pelo companheirismo.

À Nina pela motivação.

Aos meus avôs Geraldo e José Arnaldo “Em Memória”

Às minhas avós Andrelina e Esmeralda.

Ao Vagner, Valéria e Enzo pela força.

Ao Gilson e toda minha família e meus amigos que torceram por mim. 


\title{
DETERMINAÇÃO DE ELEMENTOS EM SANGUE DE HAMSTER DOURADO USANDO AAN
}

\author{
Rodrigo Oliveira de Aguiar
}

\section{RESUMO}

No presente estudo a técnica de analise por ativação com nêutrons foi utilizada para a determinação simultânea da concentração de elementos, de relevância em clínica, em sangue total de Hamster Dourado. O limite de normalidade obtido para $\mathrm{Br}, \mathrm{Ca} \mathrm{Cl}$, $\mathrm{Mg}$, $\mathrm{Na}$ e $\mathrm{S}$ considerando $2 \sigma$ (Dois Desvios Padrão), foi de 0,011 - 0,047 gL ${ }^{-1}(\mathrm{Br}) ; 0,11-0,35 \mathrm{gL}^{-1}$ (Ca); 2,11 - 3,75 gL $\mathrm{gL}^{-1}(\mathrm{Cl}) ; 1,35-2,79 \mathrm{gL}^{-1}(\mathrm{~K}), 0,026-0,090 \mathrm{gL}^{-1}(\mathrm{Mg}), 1,03-2,51 \mathrm{gL}^{-1}(\mathrm{Na}) \mathrm{e}$ $0,97-2,01 \mathrm{gL}^{-1}(\mathrm{~S})$. O conhecimento desses limites viabiliza o uso de sangue total em investigações clínicas deste modelo animal.

A comparação com as estimativas de normalidade em sangue total em seres humanos (Hamster \& humano) permitiu verificar as similaridades ou diferenças fisiológicas, dados importantes em experimentos utilizando este modelo animal. 


\title{
DETERMINATION OF ELEMENTS IN BLOOD OF GOLDEN HAMSTER BY NAA
}

\section{Rodrigo Oliveira de Aguiar}

\begin{abstract}
In the present study Neutron Activation Analysis technique has been used to determine, simultaneously, some element concentrations of clinical relevance in whole blood samples of Golden Hamster. The normal range for $\mathrm{Br}, \mathrm{Ca}, \mathrm{Cl} \mathrm{K}, \mathrm{Mg}$, Na and $\mathrm{S}$ considering $2 \sigma$ (Two Standard deviations) was $0.011-0.047 \mathrm{gL}^{-1}(\mathrm{Br}) ; 0.11-0.35 \mathrm{gL}^{-1}(\mathrm{Ca}) ; 2.11-3.75 \mathrm{gL}^{-1}(\mathrm{Cl})$; $1.35-2.79 \mathrm{gL}^{-1}(\mathrm{~K}), 0.026-0.090 \mathrm{gL}^{-1}(\mathrm{Mg}), 1.03-2.51 \mathrm{gL}^{-1}(\mathrm{Na})$ e $0.97-2.01 \mathrm{gL}^{-1}(\mathrm{~S})$. The knowledge of these limits became possible to perform clinical investigation in this animal model using whole blood.
\end{abstract}

The comparison with the results from human being whole blood estimation (Hamster \& human) became possible to check the similarities or physiologic differences, an important data for animal experimentation . 


\section{SUMÁRIO}

Página

INTRODUÇÃO

MOTIVAÇÃO

OBJETIVO

CAPÍTULO 1: A IMPORTÂNCIA DOS ELEMENTOS NO ORGANISMO _....................... 5

1.1 PRINCIPAIS CARCTERÍSTICAS DOS ELEMENTOS \& RELEVÂNCIA..........6

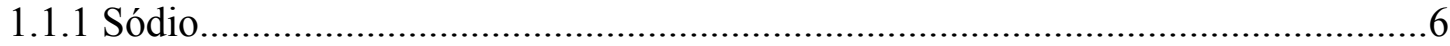

1.1.2 Potássio

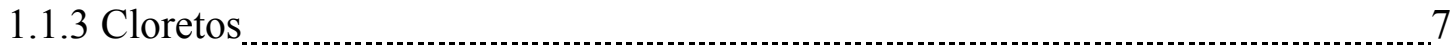

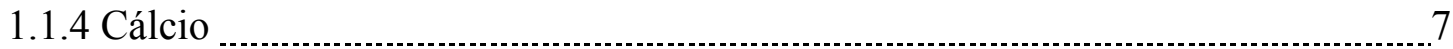

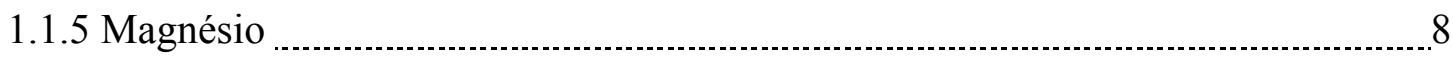

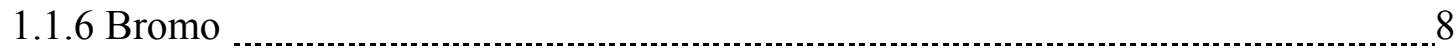

1.1.7 Enxofre

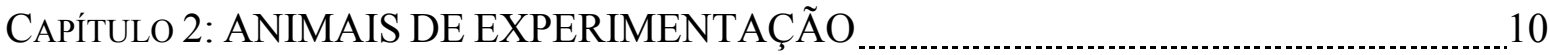

CAPÍTULO 3: HAMSTERS

3.1 Hamster Dourado

CAPÍTULO 4: METODOLOGIA NUCLEAR

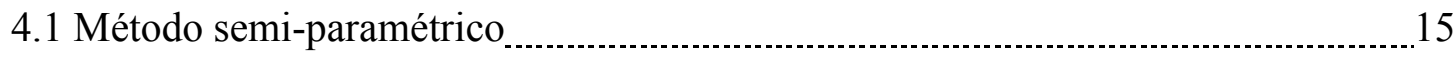

4.2 Método instrumental

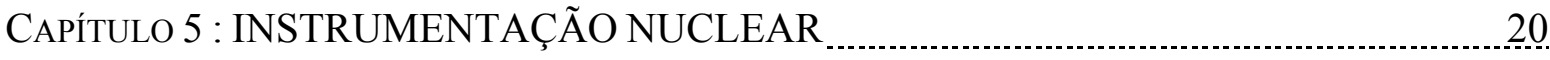

CAPÍTULO 6 : PROCEDIMENTO EXPERIMENTAL _ 23

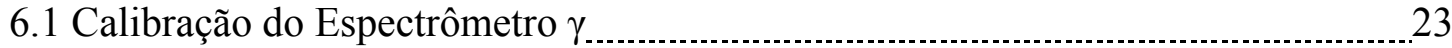

6.2 Coleta e Preparo das Amostras Biológicas _...................................................... 24

6.3 Irradiação utilizando o método semi-paramétrico de AAN ..................................24

6.4 Irradiação utilizando o método Instrumental de AAN .........................................24

6.5 Material de Referência

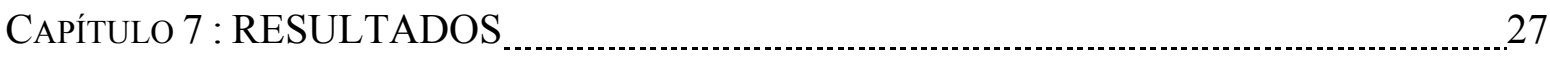

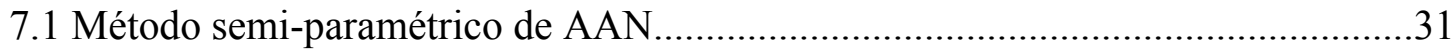




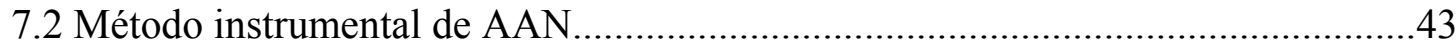

CAPÍTUlo 8 : DISCUSSÃO

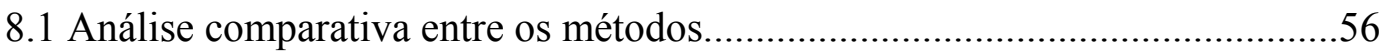

8.2 Análise comparativa: Hamster \& Humanos................................................60

CAPÍTULO 9 : CONCLUSÕES

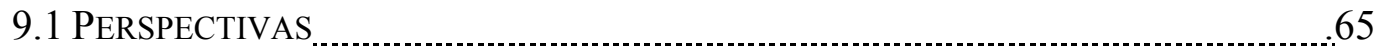

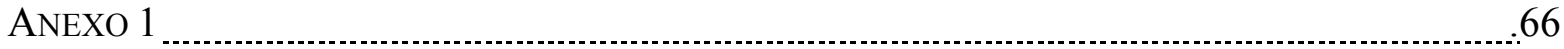

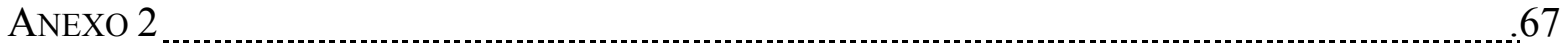

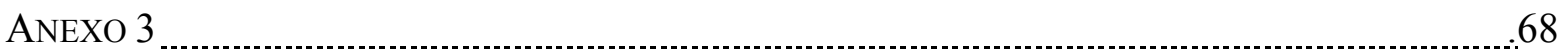

ANEXO 4

REFERÊNCIAS BIBLIOGRÁFICAS 


\section{LISTA DE FIGURAS}

Página

Figura 1: Esquema ilustrativo do projeto multidisciplinar.....................................................4

Figura 2: Hamster Dourado macho....................................................................................14

Figura 3: Hamster Dourado fêmea ......................................................................................14

Figura 4: Instrumental nuclear utilizado no LEER.............................................................20

Figura 5: Arranjo com detetor de Germânio hiperpuro (HPGe)...........................................21

Figura 6: Esquema simplificado do arranjo eletrônico.......................................................22

Figura 7: Função ajustada e eficiência de fotopico experimental ......................................... 23

Figura 8: Espectro parcial de raios $\gamma$ de sangue total de Hamster Dourado irradiado por 5

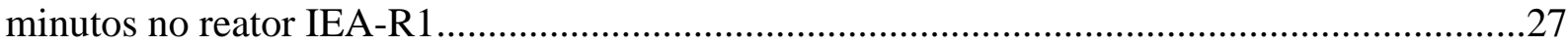

Figura 9: Espectro parcial de raios $\gamma$ de sangue total de Hamster Dourado irradiado por 5

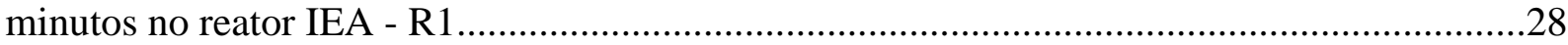

Figura 10: Espectro parcial de raios $\gamma$ de sangue total de Hamster Dourado irradiado por 5

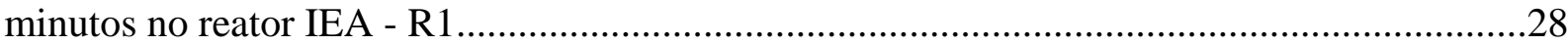

Figura 11: Espectro parcial de raios $\gamma$ de sangue total de Hamster Dourado irradiado por 5 minutos no reator IEA - R1

Figura 12: Espectro parcial de raios $\gamma$ de sangue total de Hamster Dourado irradiado por 5 minutos no reator IEA - R1.

Figura 13: Concentração do $\mathrm{Br}$ em amostras de sangue total 33

Figura 14: Concentração do Ca em amostras de sangue total .33

Figura 15: Concentração do $\mathrm{Cl}$ em amostras de sangue total................................................34

Figura 16: Concentração do K em amostras de sangue total................................................34

Figura 17: Concentração do Mg em amostras de sangue total..............................................35

Figura 18: Concentração do Na em amostras de sangue total..............................................35

Figura 19: Concentração do S em amostras de sangue total...................................................36

Figura 20: Histograma das concentrações do Br em sangue total de Hamster Dourado e ajuste da função gaussiana 
Figura 21: Histograma das concentrações do Ca em sangue total de Hamster Dourado e ajuste da função gaussiana.

Figura 22: Histograma das concentrações do $\mathrm{Cl}$ em sangue total de Hamster Dourado e ajuste da função gaussiana.

Figura 23: Histograma das concentrações do K em sangue total de Hamster Dourado e ajuste da função gaussiana. .38

Figura 24: Histograma das concentrações do Mg em sangue total de Hamster Dourado e ajuste da função gaussiana. 38

Figura 25: Histograma das concentrações do Na em sangue total de Hamster Dourado e ajuste da função gaussiana. .39

Figura 26: Histograma das concentrações do S em sangue total de Hamster Dourado e ajuste da função gaussiana. .39

Figura 27: Representação via Box-plot para Br. 40

Figura 28: Representação via Box-plot para Ca... .41

Figura 29: Representação via Box-plot para Cl.. 41

Figura 30: Representação via Box-plot para K. 42

Figura 31: Representação via Box-plot para Mg. .42

Figura 32: Representação via Box-plot para Na... .43

Figura 33: Representação via Box-plot para S .43

Figura 34: Concentração do Br em amostras de sangue total de Hamster Dourado pela técnica de AANI.. 45

Figura 35: Concentração do Ca em amostras de sangue total de Hamster Dourado pela técnica de AANI.. 45

Figura 36: Concentração do $\mathrm{Cl}$ em amostras de sangue total de Hamster Dourado pela técnica de AANI. .46

Figura 37: Concentração do K em amostras de sangue total de Hamster Dourado pela técnica de AANI. . .46

Figura 38: Concentração do Mg em amostras de sangue total de Hamster Dourado pela técnica de AANI.

Figura 39: Concentração do Na em amostras de sangue total de Hamster Dourado pela técnica de AANI...... 
Figura 40: Histograma das concentrações do Br em sangue total de Hamster Dourado e ajuste da função gaussiana obtidos pela técnica de AANI. 48

Figura 41: Histograma das concentrações do Ca em sangue total de Hamster Dourado e ajuste da função gaussiana obtidos pela técnica de AANI. .48

Figura 42: Histograma das concentrações do $\mathrm{Cl}$ em sangue total de Hamster Dourado e ajuste da função gaussiana obtidos pela técnica de AANI.

Figura 43: Histograma das concentrações do K em sangue total de Hamster Dourado e ajuste da função gaussiana obtidos pela técnica de AANI.

Figura 44: Histograma das concentrações do Mg em sangue total de Hamster Dourado e ajuste da função gaussiana obtidos pela técnica de AANI. .50

Figura 45: Histograma das concentrações do Na em sangue total de Hamster Dourado e ajuste da função gaussiana obtidos pela técnica de AANI. 50

Figura 46: Histograma das concentrações do S em sangue total de Hamster Dourado e ajuste da função gaussiana obtidos pela técnica de AANI. .51

Figura 47: Representação via Box-plot para Br pela técnica AANI.......................................52

Figura 48: Representação via Box-plot para Ca pela técnica AANI......................................52

Figura 49: Representação via Box-plot para $\mathrm{Cl}$ pela técnica AANI.......................................53

Figura 50: Representação via Box-plot para K pela técnica AANI.......................................53

Figura 51: Representação via Box-plot para Mg pela técnica AANI.....................................54

Figura 52: Representação via Box-plot para Na pela técnica AANI.....................................54

Figura 53: Representação via Box-plot para S pela técnica AANI.........................................55

Figura 54: Concentração de Br em amostras de sangue total de Hamster Dourado................ 57

Figura 55: Concentração de $\mathrm{Cl}$ em amostras de sangue total de Hamster Dourado................ 57

Figura 56: Concentração de K em amostras de sangue total de Hamster Dourado................. 58

Figura 57: Concentração de Br em amostras de sangue total de Hamster Dourado................ 58

Figura 58: Concentração de $\mathrm{Br}$ em amostras de sangue total de Hamster Dourado via método instrumental, comparada com o intervalo de confiança de $\mathrm{Br}$ via método semiparamétrico. 59

Figura 59: Concentração de Ca em amostras de sangue total de Hamster Dourado via método instrumental, comparada com o intervalo de confiança de Ca via método semiparamétrico. 59 
Figura 60: Concentração de $\mathrm{Cl}$ em amostras de sangue total de Hamster Dourado via método instrumental, comparada com o intervalo de confiança de $\mathrm{Cl}$ via método semi-

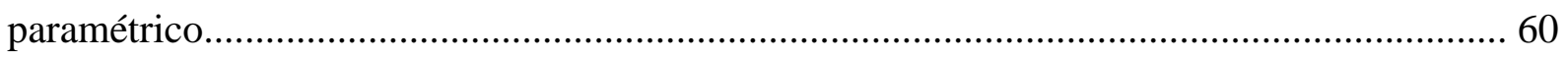

Figura 61: Concentração de K em amostras de sangue total de Hamster Dourado via método instrumental, comparada com o intervalo de confiança de $\mathrm{K}$ via método semi-

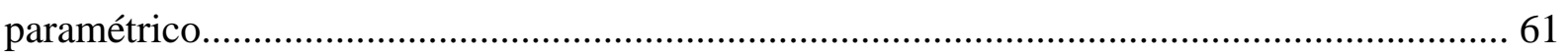

Figura 62: Concentração de Mg em amostras de sangue total de Hamster Dourado via método instrumental, comparada com o intervalo de confiança de $\mathrm{Mg}$ via método semi-

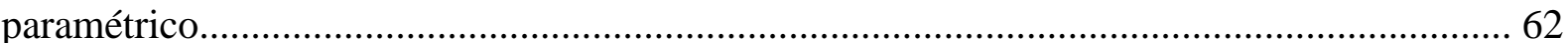

Figura 63: Concentração de Na em amostras de sangue total de Hamster Dourado via método instrumental, comparada com o intervalo de confiança de $\mathrm{Na}$ via método semi-

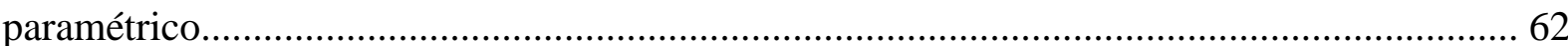

Figura 64: Concentração de S em amostras de sangue total de Hamster Dourado via método instrumental, comparados com o intervalo de confiança de $\mathrm{S}$ via método semiparamétrico 


\section{LISTA DE TABELAS}

Página

Tabela 1: Composição elementar aproximada do corpo de um homem de $70 \mathrm{~kg}$....................9 Tabela 2: Concentração dos elementos obtidos na análise do material de referência (NIST 8414) empregando o método semi-paramétrico de AAN....................................................26

Tabela 3: Elementos identificados no sangue total de Hamster Dourado e energia selecionada

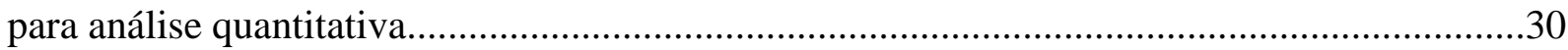

Tabela 4: Resultado das análises bioquímicas em sangue de Hamster Dourado pelo método

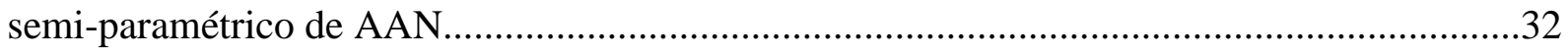

Tabela 5: Valores da média, mediana e moda das concentrações do $\mathrm{Br}, \mathrm{Cl}, \mathrm{K}, \mathrm{Mg}$, $\mathrm{Na}$ e S obtidas pelo método semi-paramétrico de AAN...............................................................40 Tabela 6: Resultado das análises bioquímicas em sangue de Hamster Dourado pela técnica Instrumental (AANI) e Semi-Paramétrica (SP AAN) .....................................................44

Tabela 7: Valores da média, mediana e moda das concentrações do $\mathrm{Br}, \mathrm{Cl}, \mathrm{K}, \mathrm{Mg}$ e $\mathrm{Na}$ obtidas pelo método instrumental de AAN.......................................................................51 


\section{INTRODUÇÃO}

Vários estudos destinam-se a elucidar o metabolismo dos organismos vivos, tanto em condições de normalidade (organismo saudáveis) como em situações de disfunções (organismos com patologia). Os constituintes majoritários da composição sanguínea, principalmente os metais $\mathrm{K}$, $\mathrm{Na}$ e íons de $\mathrm{Cl}$, por exemplo, são imprescindíveis à vida e, portanto, o conhecimento quantitativo desses elementos no sangue permite uma avaliação clínica quanto ao bom funcionamento das várias funções que regulam a fisiologia dos órgãos. Dessa forma, alterações (excesso ou deficiência) desses elementos no sangue estão normalmente associadas a algum tipo de patologia em curso.

Por outro lado, a busca pela formulação de novos medicamentos, vacinas, uso de anestésicos, de suplementos alimentares e outros produtos de interesse na área médica, necessita de vários testes em organismos in vivo para o acompanhamento clínico das funções reguladoras dos organismos com relação à resposta (reação) geradas por seu uso, viabilizando ou não sua utilização em seres humanos.

Usualmente, esses testes in vivo são realizados primeiramente em animais de pequeno porte (tais como: camundongos, ratos, coelhos) e posteriormente em humanos. A escolha do animal de experimentação leva em conta tanto a disfunção em questão, como a composição do produto a ser testado (isso é, vacinas, anestésicos, etc) bem como o material biológico a ser analisado (sangue, soro, urina, dentes, órgãos, etc) e suas similaridades com humanos. Outros fatores também relevantes na escolha dos animais, dizem respeito às implicações legais e custos.

Particularmente, em pesquisas na área médica que utilizam animais de experimentação, a realização de vários exames clínicos é uma necessidade. Usualmente, nesses experimentos são realizadas análises bioquímicas em soro e urina, mas em função da dificuldade em coletar quantidades necessárias para os procedimentos clínicos 
convencionais (da ordem de alguns mililitros de soro e/ou urina), em muitos casos o procedimento é realizado somente ao término do estudo (após o sacrifício) ou em períodos muito longos (quando o experimento permite) o que pode aumentar o estresse do animal, fator que pode alterar o resultado do exame.

Desta forma, justifica-se a busca de métodos que forneçam uma análise quantitativa dos elementos constituintes dos fluídos corpóreos nesses animais de forma ágil e principalmente minimizando o estresse dos mesmos. Além disso, a maior aproximação entre as funções e os constituintes fisiológicos entre as espécies e o homem bem como o acompanhamento sistemático das funções biológicas desses animais é também de grande importância para o sucesso dessas pesquisas.

Com base nisto, nos últimos anos o Laboratório de Espectroscopia e Espectrometria das Radiações (LEER) do Centro do Reator de Pesquisas (CRPq/IPEN) tem utilizado a técnica de Análise por Ativação com Nêutrons (AAN) como alternativa para análise de órgãos, ossos e fluídos corpóreos de animais de pequeno e médio porte [1-10], simplificando etapas tanto no manuseio como no preparo das amostras alem de fornecer uma análise quantitativa precisa de vários elementos de interesse em bioquímica clínica simultaneamente. Recentemente, a análise de $\mathrm{Cl}$, $\mathrm{K}$ e Na em soro humano permitiu validar esta metodologia nuclear para uso em análises bioquímicas, pois os resultados obtidos [1114] encontram-se em acordo com o estabelecido pela clínica convencional [15].

\section{MOTIVAÇÃO}

O presente estudo é dedicado à caracterização da composição sanguínea de Hamster Dourado, com ênfase na quantificação de elementos de relevância para pratica clínica. A utilização desse procedimento (AAN) apresenta um diferencial importante no que se refere às análises bioquímicas convencionais, a saber: utilização de sangue total, que reduz significativamente a quantidade de material biológico necessário para sua execução. Esta simplificação leva também à redução nos custos dos experimentos, pois 
dispensa o uso de reagentes, além de apresentar facilidades no armazenamento da amostras (não necessita de refrigeração).

\section{OBJETIVO}

No presente estudo serão analisados os elementos $\mathrm{Br}, \mathrm{Ca}, \mathrm{Cl}, \mathrm{K}, \mathrm{Mg}, \mathrm{Na}$ e $\mathrm{S}$ em sangue total de Hamster Dourado, pois pequenas oscilações nesses eletrólitos são indicadores importantes de sua condição clínica. Pretende-se estabelecer o índice de normalidade desses elementos no sangue compondo dados relevantes para sua monitoração clínica, principalmente porque este modelo animal é largamente empregado em testes de medicamentos, vacinas, etc.

As medidas serão realizadas utilizando o método semi - paramétrico de AAN (AAN SP). Como procedimento alternativo, para comparação dos resultados, será empregado o método Instrumental de AAN (AANI).

Este estudo faz parte de um projeto multidisciplinar denominado "Estudo da Distribuição de Metais em Amostras Biológica via Metodologia Nuclear: Determinação de Valores de Referência", atualmente em desenvolvimento no Laboratório de Espectroscopia e Espectrometria das Radiações (LEER) do IPEN, em colaboração com Universidades e Centros de Pesquisa de várias regiões do Brasil.

Na Figura 1 é apresentado um esquema ilustrativo do projeto multidisciplinar no qual o presente estudo está inserido. 
ESTUDO DA DISTRIBUIÇÃO DE METAIS EM AMOSTRAS BIOLÓGICAS

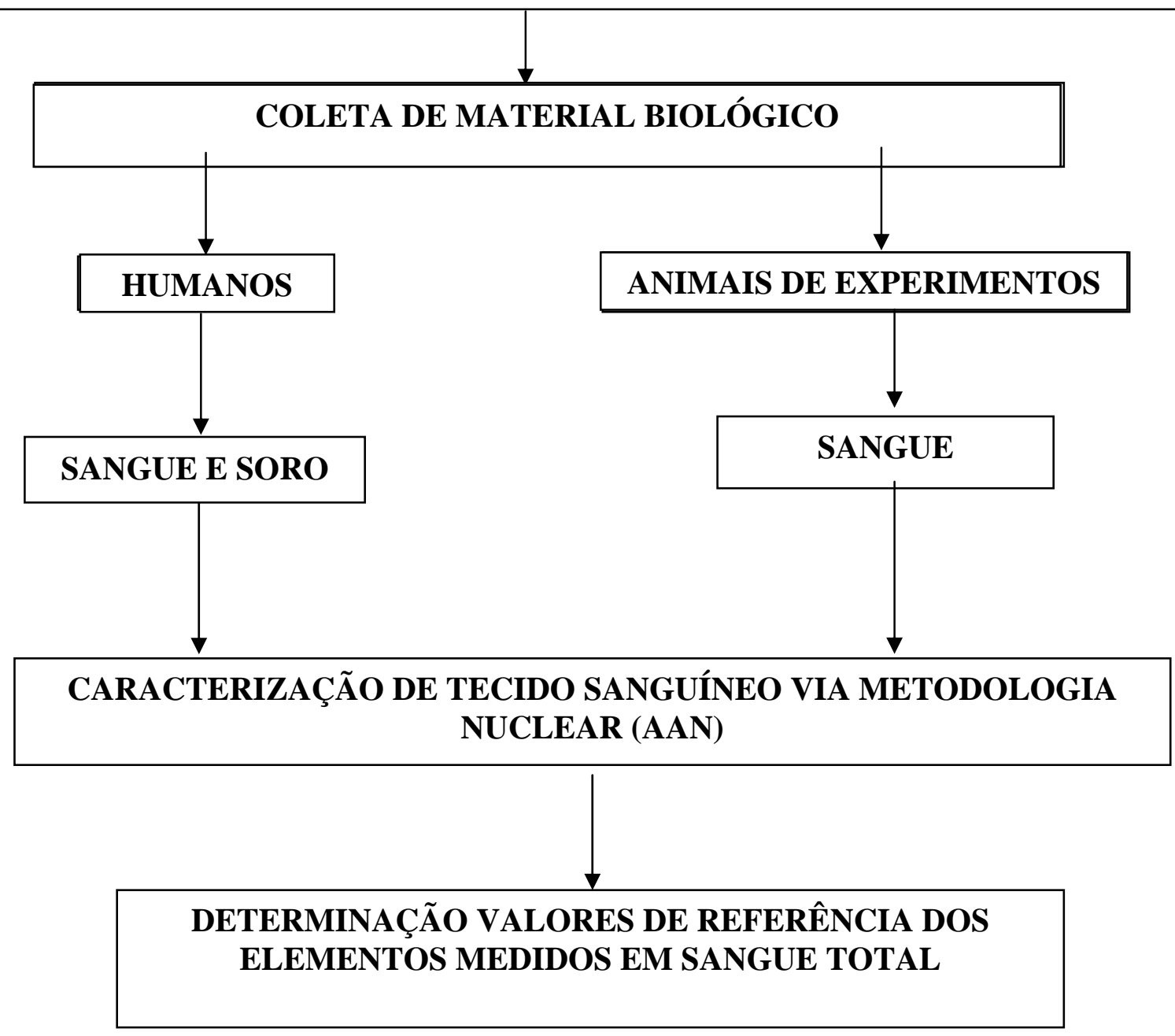

FIGURA 1 - Esquema ilustrativo do projeto multidisciplinar. 


\section{CAPÍTULO 1. A IMPORTÂNCIA DOS ELEMENTOS NO ORGANISMO}

Dos mais de 90 elementos naturalmente existentes, somente 26 são conhecidos como sendo necessário a ratos. [16]

Os elementos mais abundantes no organismo, oxigênio, carbono, hidrogênio e nitrogênio, constituem $96 \%$ do peso corpóreo total de um mamífero compondo a água, as proteínas, os ácidos nucléicos, as gorduras e os carboidratos. Em menor concentração temse o cálcio, fósforo, potássio, enxofre, sódio, cloro e magnésio que constituem quase $4 \%$, sendo que os demais elementos, em quantidade total combinada no corpo dos mamíferos, constituem da ordem de $0,01 \%$ da massa corpórea. [16]

O cloro, potássio e o sódio são elementos constituintes dos fluídos e tecidos moles. O sódio e o cloro são encontrados em abundância fora da célula, ao contrário do potássio, cuja concentração maior está no interior celular. O sódio e o potássio atuam numa função denominada transporte ativo regulando a entrada e saída de líquidos e nutrientes na célula. Atuam também, em conjunto com o cálcio, na contração muscular e transmissão de impulsos nervosos. Esses elementos, bem como magnésio, manganês, bromo e enxofre, dentro outros, são também potentes modificadores do $\mathrm{pH}$ nos líquidos corporais, funcionando como instrumentos de manutenção da saúde celular, alcalinizam ou acidificam os fluidos corpóreos, conforme a necessidade do organismo: enquanto os sais de cálcio, magnésio, sódio, potássio e manganês são predominantemente alcalinizantes e atuam como elementos energizantes e neutralizadores, os sais que contêm enxofre, cloro, bromo são agentes mais acidificantes. Portanto, alem de essenciais à saúde necessitam estar em equilíbrio para manutenção do $\mathrm{pH}$.[16] 


\subsection{PRINCIPAIS CARACTERÍSTICAS DOS ELEMENTOS \& RELEVÂNCIA CLÍNICA}

\subsubsection{Sódio (Na)}

Os íons sódio são os principais cátions do líquido extracelular representando aproximadamente $90 \%$ dos cátions inorgânicos por litro de plasma em humanos [17].

As principais funções biológicas do íon sódio são:

- Manter a pressão osmótica do fluído extracelular;

- Controlar a retenção de água nos espaços tissulares;

- Auxiliar na manutenção da pressão sanguínea;

- Regular a irritabilidade dos nervos e tecidos musculares e do coração.

\subsubsection{Potássio (K)}

O potássio é o cátion intracelular mais abundante e sua influência se faz sentir em vários processos metabólicos da célula. A concentração extracelular do potássio é pequena, entretanto, as repercussões clínicas de pequenas variações são, no entanto, de grave repercussão no organismo podendo gerar lesões cardíacas.

Cabe ao rim grande parte da responsabilidade pelo controle da concentração desse eletrólito [18]: o potássio ingerido é filtrado nos glomérulos, e quase completamente reabsorvido nos túbulos proximais, sendo depois secretado nos túbulos distais. A diminuição da taxa de filtração glomerular leva a carência de potássio, sendo típica da insuficiência renal [17].

As principais funções dos íons K no corpo relacionam-se com a manutenção de:

- Pressão osmótica das células;

- Potencial elétrico das células;

- Tamanho das células; 
- Contração adequada do coração;

- Transmissão adequada dos impulsos nervosos [19].

\subsubsection{Cloretos}

O cloreto é o principal ânion extracelular e representa a maior fração da concentração total de ânions inorgânicos do plasma humano [17]. Em geral, o cloreto é afetado pelas mesmas condições que afetam o sódio [19].

Uma das principais funções do $\mathrm{Cl}$ é como um componente do ácido clorídrico gástrico. O íon cloreto desempenha também uma importante função no transporte de oxigênio e dióxido de carbono no sangue [19]. Também está significativamente envolvido na manutenção da distribuição de água, da pressão osmótica e do equilíbrio entre ânions e cátions no compartimento líquido extracelular.

Os íons de cloreto no alimento são quase completamente absorvidos no tubo digestivo, filtrados pelos glomérulos e sofrem reabsorção passiva, junto com $\mathrm{Na}^{+}$[17].

\subsubsection{Cálcio (Ca)}

O cálcio é um nutriente vital para uma correta mineralização óssea. A sua carência poderá resultar em graves problemas na estrutura óssea. É nos ossos que praticamente todo o cálcio está localizado, cerca de 99\%, com o restante nos dentes e nas células sanguínea. Os íons cálcio são necessários para contração muscular e auxiliam na coagulação sanguínea alem de controlar a passagem de fluídos através das paredes celulares. [17]

O cálcio é essencial na dieta de animais, pois proporciona rigidez aos dentes, fundamental em roedores. [17] 


\subsubsection{Magnésio (Mg)}

Cerca de $70 \%$ do magnésio do organismo encontra-se no esqueleto, enquanto o restante se distribui pelos vários líquidos e tecidos moles. Sua principal função no organismo esta na formação do esqueleto, mas é também um elemento indispensável para muitas reações bioquímicas pois esta presente em ambos os compartimentos (extra e intracelular).[18]

Os sintomas gerais de deficiência de magnésio incluem lesões de pele, hiperirritabilidade, disfunção muscular, calcificação de tecidos moles, ossos e dentes defeituosos e crescimento retardado. Apesar de ser essencial no organismo, ainda há poucos estudos sobre a participação e quantificação ideal para cada animal. [18]

\subsubsection{Bromo $(\mathrm{Br})$}

O Bromo é encontrado em níveis de traço em humanos. É considerado um elemento químico essencial, entretanto ainda não se conhece exatamente as funções que realiza. Muitos compostos de bromo têm uma ação fisiológica importante, por isso são utilizados como sedativos, anestésicos e anti-sépticos. $\mathrm{O}$ Br embora não seja majoritário em sangue sua avaliação também é útil para o acompanhamento clínico, em animais de experimentação, por estar presente em medicamentos, tais como antidepressivos e soníferos, muito utilizados pela população brasileira. [17]

Sua monitoração clínica esta normalmente relacionada a intoxicação por medicamentos. [17]

\subsubsection{Enxofre (S)}

O enxofre é um constituinte importante de alguns aminoácidos portanto, não pode faltar para perfeita produção de proteínas. Na maioria dos seres vivos, moléculas com átomos desse elemento, atuam como cofator ("estimulador") de reações químicas 
promovidas por enzimas. Além disso, o enxofre ajuda o fígado na secreção da bílis além de participar da síntese do colágeno no organismo.[18]

Em sua forma inorgânica, o enxofre encontra-se no sangue, na saliva e como um dos componentes das cartilagens. Embora sua avaliação clínica não seja usual sua ingestão pode ser intensa no organismo: esta presente em medicamentos (principalmente em laxantes), em vitaminas, além de ser muito utilizado como conservantes em bebidas alcoólicas.[18]

Na tabela 1 é apresentada Composição elementar aproximada do corpo humano.

TABELA 1.- Composição elementar aproximada do corpo de um homem de 70 kg. [16]

\begin{tabular}{c|c|c}
\hline \hline Elemento & Peso $(\mathrm{kg})$ & \% do peso corpóreo \\
\hline Oxigênio & 45,5 & 65,0 \\
\hline Carbono & 12,6 & 18,0 \\
\hline Hidrogênio & 7,0 & 10,0 \\
\hline Nitrogênio & 2,1 & 1,93 \\
\hline Cálcio & 1,35 & 1,12 \\
\hline Fósforo & 0,785 & 0,35 \\
\hline Potássio & 0,245 & 0,25 \\
\hline Enxofre & 0,175 & 0,15 \\
\hline Sódio & 0,105 & 0,15 \\
\hline Cloro & 0,105 & 0,05 \\
\hline Magnésio & 0,035 & 100,00 \\
\hline \hline Total & 70,00 & 15 \\
\hline \hline
\end{tabular}




\section{CAPÍTULO 2. ANIMAIS DE EXPERIMENTAÇÃO}

Existe registro do uso de modelo animal desde a antiguidade. Por volta de $500 \mathrm{aC}$ anatomistas realizavam vivissecções animais com o objetivo de entender o funcionamento dos órgãos: eram realizados estudos comparativos entre órgãos de humanos e de animais, com mesma patologia, para fins didáticos. Acredita - se que a primeira pesquisa cientifica tenha sido realizada por William Hervey sob o título: "Exercitatio anatômica de motucordis et sanguinis in animalibus" publicada em 1638, no qual são relatados os resultados obtidos sobre fisiologia da circulação em dezenas de espécies animais. Entretanto na realização desses experimentos não havia uma conduta ética bem definida com relação a proteção e cuidado dos animais. [20]

Vários filósofos, entre eles René Descartes (1596-1650), acreditavam que tanto o pensamento como a sensibilidade fazia parte da alma e como, em sua concepção, os animais não tinham alma, não sentiam dor [20]. Somente em 1789 com a publicação do livro "Introduction to the principles of morals and legislation", por Benthan, as questões relacionadas aos cuidados com animais foi devidamente avaliada.

Nos anos seguintes surgiram as primeiras sociedades protetoras dos animais e em 1876, no Reino Unido, foi estabelecida a primeira lei a regulamentar o uso de animais em pesquisa. [20]

Um marco importante na humanização do trato com animais vem do estabelecimento dos três "Rs" na pesquisa com animais: "Replace, Reduce e Refine", publicado em 1959 por Russell \& Burch mas, somente em 1978 a UNESCO estabeleceu a Declaração Universal dos Diretos dos Animais [20-22]. Hoje as áreas de criação atendem as normas internacionais de instalação: Current Good Manufacturing (CGM); World Health Organization (WHO) garantindo o padrão "SPF” (Specific Pathogens Free).

No Brasil, a produção, o manejo e o descarte obedecem ao código de ética animal e aos princípios dos três "Rs". Alem disso, vários órgãos regem as atividades didático cientifica com modelo animal: o Colégio Brasileiro de Experimentação Animal (COBEA) 
que aborda o assunto pelo seu aspecto ético e o Conselho Nacional de Controle de Experimentação Animal (CONCEA) pelo aspecto legal. Portanto a criação/utilização de animais em ensino/pesquisa fica restrita as instituições credenciadas pelo CONCEA e devem seguir os normativos estabelecidos pelo COBEA. Como recurso fiscalizador tem-se a criação das Comissões de Ética no uso de Animais (CEUA) que deve se constituir por um médico veterinário, um representante da Sociedade Protetora dos Animais (SPA) e por pesquisadores [21-22]. 


\section{CAPÍTULO 3. HAMSTERS}

A denominação Hamster é atribuída a roedores da família Cricetidae encontrados na África e Ásia. É também a denominação popular dado ao roedor nativo da Síria cuja denominação cientifica é Mesocricetus arautus.[23]

Existem diferentes espécies de Hamsters espalhados pelo mundo. Pode - se dividir as espécies de Hamster em duas categorias: selvagens e domesticados, de acordo com sua a possibilidade ou não da criação em cativeiro. De acordo com este critério têm 12 espécies selvagens e 5 domesticáveis: [23]

Selvagens

Cricetus crucetus - Hamster do Campo Europeu

Mesocricetus newtoni - Hamster Romeno

Mesocricetus brandti - Hamster Turco

Mesocricetus raddei - Hamster Ciscaucasiano

Cricetulus alticola - Hamster Ladak

Cricetulus barabensis - Hamster Listrado Chinês

Cricetulus kamensis - Hamster Tibetano

Cricetulus longicaudatus - Hamster de Cauda Longa (menor)

Cricetulus migratorius - Hamster Armeno

Cricetulus triton

Cricetulus obscurus

Cricetulus pseudogriseus - Hamster de Cauda Longa (maior)

Domesticáveis

Mesocicetus auratus (Hamster dourado) que compõe a espécie mais comum criada em cativeiro sendo utilizado como animal de experimentação e que será estudado neste trabalho.

Phodopus campbelli - Hamster Anão Russo de Campbell

Phodopus sungorus - Hamster Anão Russo Siberiano 
Cricetulus griseus - Hamster Chinês

Phodopus roborovski - Hamster Roborovski

\subsection{Hamster Dourado}

Em 1931 exemplares desta espécie (Mesocricetus arautus) foram achados na Síria e enviados para Inglaterra, onde passaram a ser utilizado como cobaias. Em 1938 chegam aos Estados Unidos e somente em 1960 ao Brasil. Por muito tempo esta espécie serviu apenas de cobaia, mas hoje é muito procurada como animal de estimação.[23]

O Hamster Dourado é um pequeno roedor, de tamanho oscilando de 8 a 12 centímetros e pesando, quando adultos, de $108 \mathrm{~g}$ (machos) a $120 \mathrm{~g}$ (fêmeas), em média. São animais limpos que apresentam pouco odor. Sua pelagem é densa e lustrosa, de um profundo dourado. A pele do abdômen, embora originalmente cinza claro esta se tornando muito clara nos Hamsters de hoje em dia, enquanto que a cabeça, originalmente estreita, está cada vez mais reduzida graças à seleção de reprodutores. As bochechas possuem faixas escuras bem como no peito (larga e contínua). A cauda é curta e truncada, as orelhas grandes estão bem separadas e os olhos são brilhantes e escuros. De cada lado da face, estendendo-se da bochecha até o ombro, o Hamster possui uma bolsa elástica que pode carregar (suportar) até metade do seu peso em alimentos. A pele é bastante maleável, os pés da frente são como mãos e as pernas e os pés traseiros têm três funções: ajudar caminhar em terrenos tortuosos, suportar o peso do corpo quando sentado e permitir que ele se mova para trás. Os machos adultos são mais amigáveis, sendo animal de estimação bastante popular.[23]

A gestação é de aproximadamente 16 dias em média, e pode chegar até 18 dias, nascendo de 2 a 15 filhotes. Os jovens deixam a mãe depois de três a quatro semanas e após um descanso de três ou quatro dias, ela está pronta para se reproduzir novamente. Devido à curta gestação e ao fato de alcançarem a idade adulta em dois ou três meses, os Hamsters são animais de rápida procriação e crescimento; em decorrência são muito utilizados em experimentação animal. Embora sejam de hábitos noturnos $(90 \%$ de suas 
atividades são feitas no escuro) são facilmente acordados na presença de algum estímulo. De comportamento individualista, mesmo com a própria espécie, pode ser condicionado a aprender (realizar) alguns procedimentos por técnica de oferecer recompensas. [23]

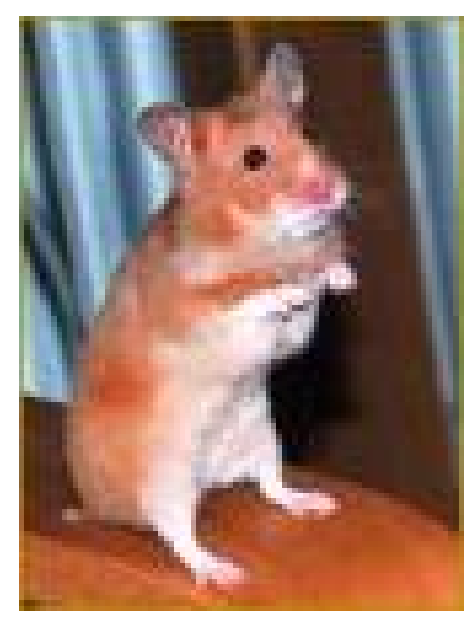

FIGURA 2 - Hamster Dourado macho.

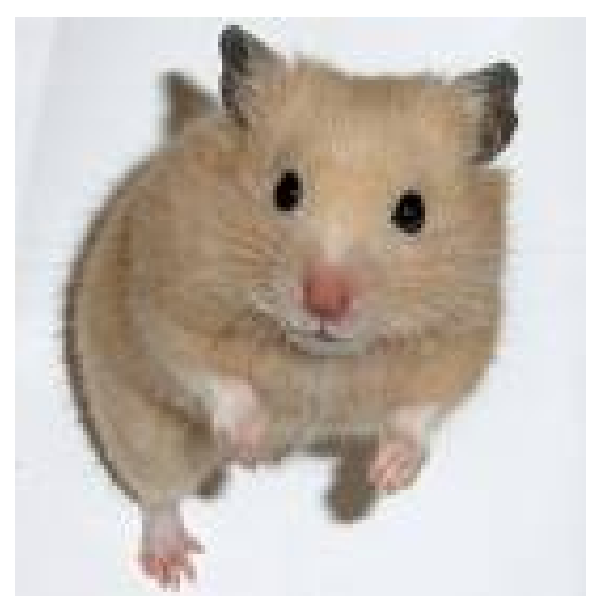

FIGURA 3 - Hamster Dourado fêmea. 


\section{CAPÍTULO 4. METODOLOGIA NUCLEAR: AAN}

O método nuclear a ser empregado denomina-se Análise por Ativação com Nêutrons (AAN). Utiliza-se feixe de nêutrons, a partir de um reator nuclear, para ativar a amostra em estudo, que induz reações nucleares nos núcleos dos elementos constituintes. Em decorrência, cada elemento (constituinte da amostra) ao tornar-se radioativo emite radiação $\gamma$ característica, processo este denominado desexcitação nuclear. A identificação dessas radiações utilizando propriedades nucleares associadas permite sua avaliação quantitativa.[24]

\subsection{Método semi - paramétrico}

Para a utilização deste método de análise é necessário o conhecimento do fluxo de nêutrons $\left(\phi_{\mathrm{n}}\right)$. Para a determinação do fluxo de nêutrons em reator térmico pode-se empregar a técnica de Razão de Cádmio [24]. A utilização deste método permite a determinação do fluxo utilizando detetores de ativação (por exemplo, folhas de ouro) por meio da relação:

$$
\phi_{n}=\frac{A^{a u} \cdot M}{m \cdot N_{A} \cdot \sigma \cdot K_{t}}\left(1-\frac{F_{c d}}{R_{c d}}\right)
$$

Onde:

$\phi_{n} \quad$ fluxo de nêutrons

$A^{a u} \quad$ atividade de saturação do detetor de ativação (folha de Ouro)

$M \quad$ peso atômico do ouro $(\mathrm{Au})$

$N_{A} \quad$ número de Avogadro

m massa do detetor de ativação (folha de $\mathrm{Au}$ ) 
$F_{c d} \quad$ fator de Cádmio (tabelado)

$R_{c d}$ razão obtida experimentalmente pela irradiação das folhas de $\mathrm{Au}$ (com e sem cobertura de $\mathrm{Cd}$ ).

$\sigma \quad$ seção de choque de ativação (tabelado)

$K_{t} \quad$ fator de perturbação do fluxo (tabelado)

A medida da atividade pode ser obtida por um sistema de contagem conhecendo-se a eficiência de deteção da transição $\gamma$ de interesse usando a expressão:

$$
A=\frac{C_{\gamma} \lambda}{\varepsilon_{\gamma} I_{\gamma}\left(1-e^{-\lambda T_{i}}\right) e^{-\lambda T_{e}}}
$$

Onde:
A atividade do isótopo radioativo;
$C \gamma$ área da transição gama discriminada;
$\lambda \quad$ constante de desintegração (tabelado);
$\varepsilon_{\gamma} \quad$ eficiência de deteção na energia da transição gama discriminada;
$I_{\gamma} \quad$ intensidade da transição gama discriminada (tabelada);
$T_{i} \quad$ tempo de irradiação (estabelecido);
$T_{e} \quad$ tempo de espera (intervalo de tempo que decorre entre o final da irradiação e o início da contagem da amostra);
$T_{c} \quad$ tempo de contagem (estabelecido).

A partir da determinação da atividade e de fluxo de nêutrons, obtém-se a concentração dos elementos ativados, nas amostras biológicas em questão, extraindo a fração massa do isótopo radioativo [Eq.3] em questão:

$$
F=\frac{\lambda \cdot M \cdot C_{\gamma} \cdot e^{\lambda \cdot T_{e}}}{m \cdot N_{A} \cdot \mathcal{E}_{\gamma} \cdot \sigma \cdot \phi \cdot I_{\gamma} \cdot\left(1-e^{-\lambda \cdot T_{i}}\right) \cdot\left(1-e^{-\lambda \cdot T_{c}}\right)}
$$


Onde:
A atividade do isótopo radioativo;
C $\gamma$ área da transição gama discriminada;
F fração do isótopo ativado;
$\phi \quad$ fluxo de nêutrons
$\lambda \quad$ constante de desintegração (tabelado);
$\sigma \quad$ seção de choque de ativação (tabelado)
$\varepsilon_{\gamma} \quad$ eficiência de deteção na energia da transição gama discriminada;
$I_{\gamma} \quad$ intensidade da transição gama discriminada (tabelada);
$T_{i} \quad$ tempo de irradiação (estabelecido);
$T_{e} \quad$ tempo de espera (intervalo de tempo que decorre entre o final da irradiação e o início da contagem da amostra);
$T_{c} \quad$ tempo de contagem (estabelecido).
m massa da amostra.
$N_{A} \quad$ número de Avogadro

\subsection{Método Instrumental}

Neste método a amostra e padrão são irradiados simultaneamente garantindo as mesmas condições. Desta forma, as concentrações dos elementos na amostra é obtida a partir do obter das concentrações estabelecidas no padrão:[24]

$$
A_{a m}=\sigma \phi \frac{N_{A} m_{a m} f}{M}\left(1-e^{-\lambda T i}\right)
$$

onde:

$\mathrm{A}_{\mathrm{am}} \quad$ atividade da amostra;

$\mathrm{N}_{\mathrm{A}} \quad$ número de Avogadro;

$\phi \quad$ fluxo de nêutrons;

$\sigma \quad$ seção de choque de ativação (tabelado)

$\mathrm{m}_{\mathrm{am}} \quad$ massa da amostra;

f fração do isótopo que irá sofrer a ativação;

$\mathrm{T}_{\mathrm{i}}$ tempo de irradiação;

M massa atômica do elemento; 
$\lambda$ constante de desintegração (tabelado).

$$
A_{p d}=\sigma \phi \frac{N_{A} m_{p d} f}{M}\left(1-e^{-\lambda T i}\right)
$$

onde:

$\mathrm{A}_{\mathrm{pd}} \quad$ Atividade do padrão

$\mathrm{N}_{\mathrm{A}} \quad$ número de Avogadro;

$\phi \quad$ fluxo de nêutrons;

$\sigma \quad$ seção de choque de ativação (tabelado)

$\mathrm{m}_{\mathrm{pd}} \quad$ massa do padrão;

f fração do isótopo que irá sofrer a ativação;

F fração do elemento ativado;

$\mathrm{T}_{\mathrm{i}}$ tempo de irradiação;

M massa atômica do elemento;

$\lambda \quad$ constante de desintegração (tabelado);

Dividindo a equação (4) pela equação (5) obtém-se:

$$
\frac{A_{a m}}{A_{p d}}=\frac{m_{a m}}{m_{p d}}
$$

onde:

A $\mathrm{am}_{\text {atividade da amostra; }}$

$\mathrm{A}_{\mathrm{pd}} \quad$ Atividade do padrão;

$\mathrm{m}_{\mathrm{am}} \quad$ massa do elemento na amostra;

$\mathrm{m}_{\mathrm{pd}} \quad$ massa do elemento no padrão.

A partir da atividade da amostra pode-se calcular a concentração do elemento utilizando a equação (7), inserindo um fator de correção devido à diferença de tempo entre a medida do padrão e da amostra. 


$$
C_{\text {amostra }}=\frac{A_{\text {amostra }} C_{\text {padrão }} M_{\text {padrão }} e^{\lambda\left(t_{a}-t_{p}\right)}}{A_{\text {padrão }} M_{\text {amostra }}}
$$

$C_{\text {amostra }} \quad$ concentração do elemento na amostra;

A amostra $\quad$ taxa de contagem da amostra;

$C_{\text {padrão }} \quad$ concentração do elemento no padrão;

$M_{\text {padrão }} \quad$ massa do padrão;

$T_{a} \quad$ tempo de decaimento da amostra;

$T_{p} \quad$ tempo de decaimento do padrão;

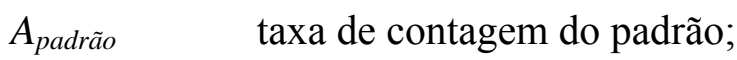

$M_{\text {amostra }} \quad$ massa da amostra. 


\section{CAPÍTULO 5. INSTRUMENTAÇÃO NUCLEAR}

A instrumentação nuclear utilizada na aquisição dos espectros da radiação $\gamma$ é constituída por um espectrômetro $\gamma$, eletrônica associada e sistema de aquisição de dados descritos a seguir. A FIGURA 4 ilustra o instrumental nuclear utilizado no LEER.

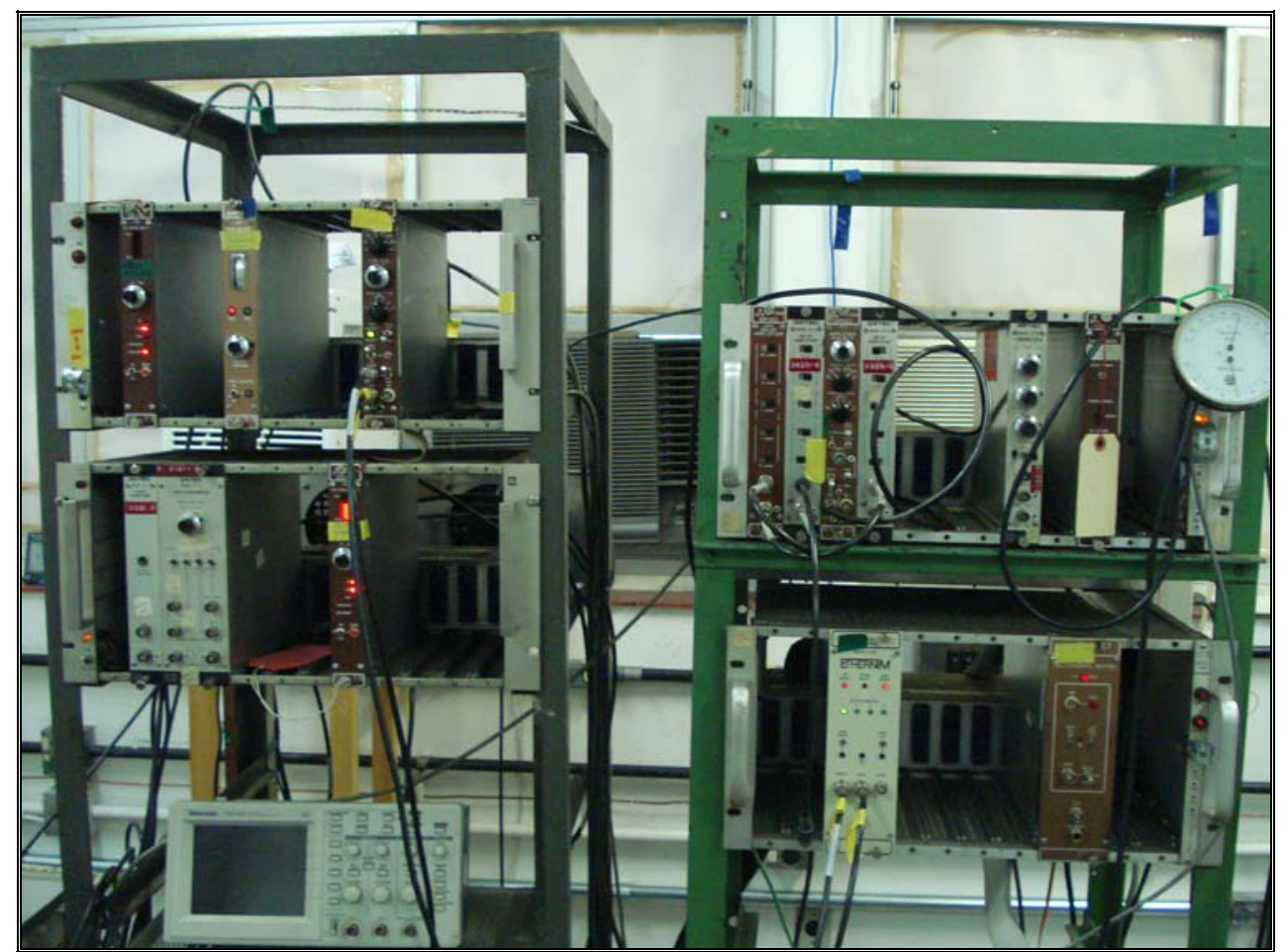

FIGURA 4 -Instrumentação nuclear utilizada no LEER.

O espectrômetro $\gamma$ é constituído por um detetor semicondutor de Germânio hiperpuro (ORTEC - modelo GEM-60195) montado no interior de uma blindagem de chumbo. Este tipo de blindagem minimiza a radiação de fundo do laboratório. Um suporte circular de lucite, centralizado sobre a face do detetor, sustenta a amostra (FIGURA. 5) 


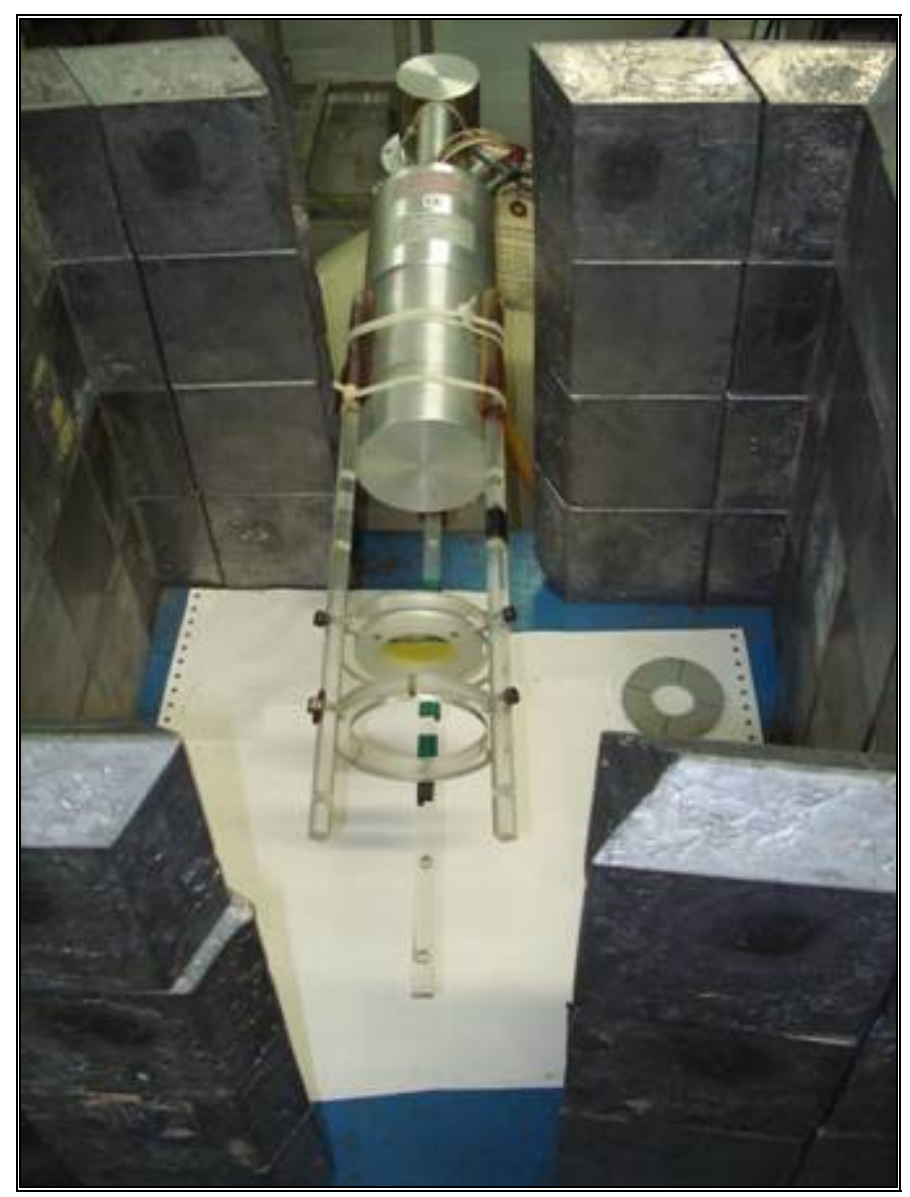

FIGURA 5- Arranjo com detetor de HPGe

O sistema de aquisição de dados consiste de um amplificador linear (ORTEC671) e um multicanal ADCAM, (ORTEC-918-A) controlado por um microcomputador PC. Na Figura 6 é apresentado um diagrama ilustrativo da instrumentação nuclear.

Para a realização deste estudo o espectrômetro foi calibrado em energia e eficiência utilizando-se fontes padrão [25]. 


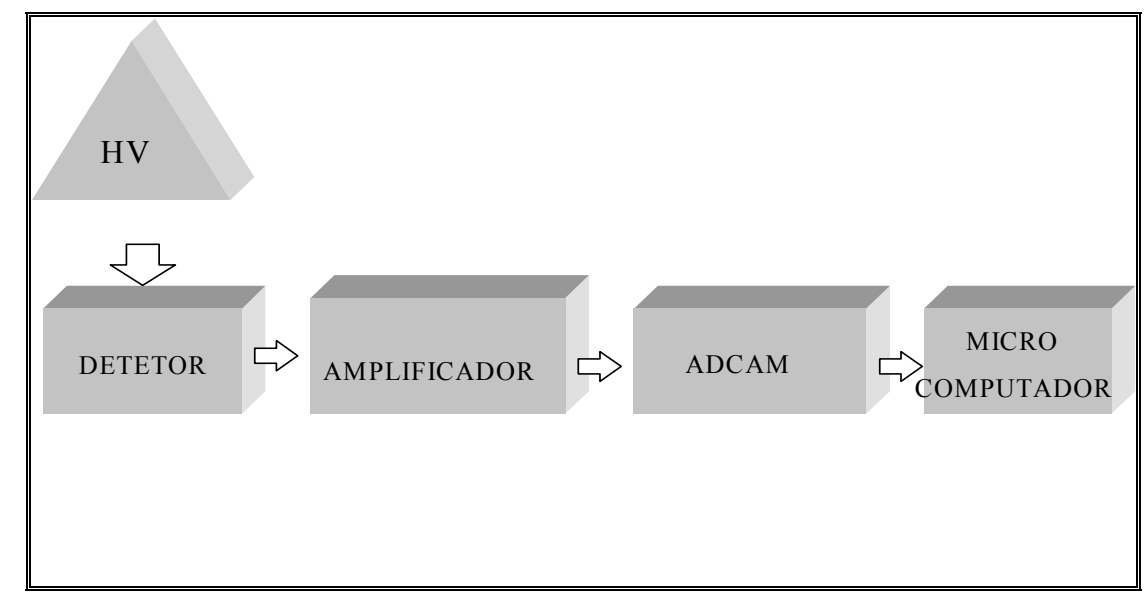

FIGURA 6 - Esquema simplificado do arranjo eletrônico. 


\section{CAPÍTULO 6. PROCEDIMENTO EXPERIMENTAL}

\subsection{Calibração do Espectrômetro $\gamma$}

Para a obtenção da curva de calibração em energia do espectrômetro $\gamma$ utiliza-se fontes padrão [25] de: ${ }^{60} \mathrm{Co},{ }^{109} \mathrm{Cd},{ }^{133} \mathrm{Ba},{ }^{137} \mathrm{Cs} \mathrm{e}{ }^{152} \mathrm{Eu}$, para que se possa associar a posição dos fotopicos das fontes padrão, ao longo dos 4096 canais, com suas respectivas energias.

A calibração de eficiência do detetor foi obtida a partir dos dados das fontes padrão de ${ }^{152} \mathrm{Eu} \mathrm{e}{ }^{57} \mathrm{Co}$, que possuem valores de intensidade obtidas na compilação da IAEA [25]. A curva obtida é apresentada na FIGURA 7 e a função é dada por:

$$
\varepsilon(E)=a \cdot e^{b . E}+c \cdot e^{d . E}
$$

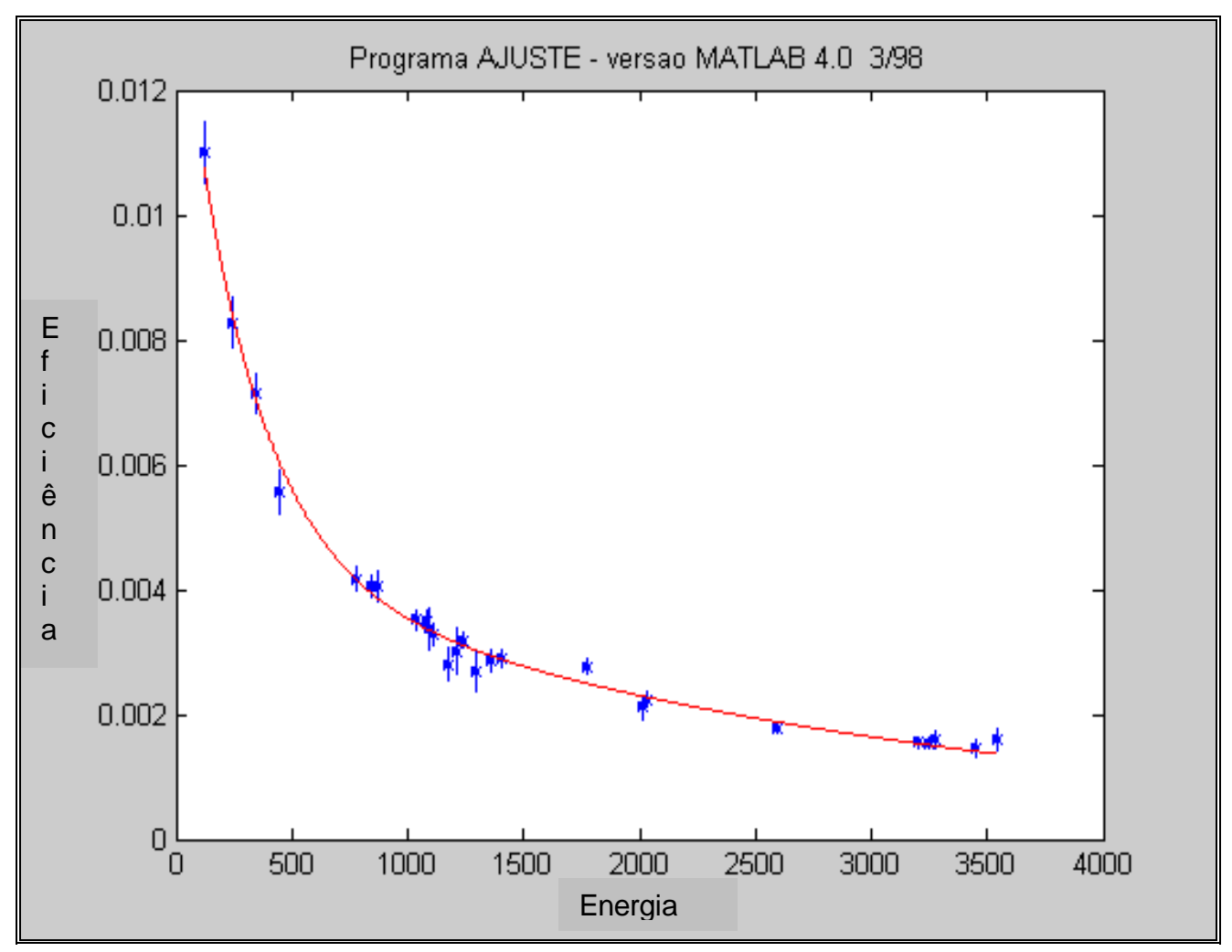

FIGURA 7 - Função ajustada e eficiência de fotopico experimental. 


\subsection{Coleta e Preparo das Amostras Biológicas}

Para o desenvolvimento deste estudo foi feita a coleta de 20 amostras de sangue de Hamster Dourado adultos, sem o uso de qualquer tipo de anticoagulante. Imediatamente após a coleta, antes do processo de coagulação, alíquotas $100 \mu \mathrm{L}$ foram pipetadas em papel de filtro Whatman, $\mathrm{n}^{\circ} 41(3,5 \times 4,0 \mathrm{~cm})$, em duplicata, e submetidas à secagem por alguns segundos utilizando luz infravermelho.

\subsection{Irradiação utilizando o método semi - paramétrico de AAN}

Para determinar simultaneamente a concentração dos elementos $\mathrm{Br}, \mathrm{Ca}, \mathrm{Cl}, \mathrm{K}, \mathrm{Mg}$ $\mathrm{Na}$ e $\mathrm{S}$, cada amostra biológica foi acondicionada em cápsula de polietileno, junto com os detetores de ativação (duas folhas metálicas de $\mathrm{Au}$ de $\leq 1 \mathrm{mg}$ nua e coberta com $\mathrm{Cd}$ ), usados para medida do fluxo de nêutrons [24] e irradiados por 5 minutos no reator do IPEN (IEA-R1, 2-4MW) num fluxo de $\sim 10{ }^{12} \mathrm{n} \cdot \mathrm{cm}^{-2} \cdot \mathrm{s}^{-1}$, permitindo a ativação simultânea desses materiais. Usando esse procedimento a atividade dos raios gama induzida na amostra de sangue e nos detetores de $\mathrm{Au}$, são obtidas sob as mesmas condições de irradiação.

Imediatamente após a irradiação, tempo de decaimento de 1 minuto, as amostras biológicas foram contadas por 10 minutos, permitindo o cálculo simultâneo dos elementos de interesse. Na seqüência, as amostras de $\mathrm{Au}(\mathrm{nu})$ e de $\mathrm{Au}$ coberto com $\mathrm{Cd}$ foram contadas no espectrômetro gama por um minuto, permitindo a identificação e cálculo da área da transição gama de $411 \mathrm{keV}$ do ${ }^{197} \mathrm{Au}$ para determinação da Razão de Cádmio e posteriormente cálculo do fluxo de nêutrons. O cálculo da área foi realizado utilizando o software IDFIX (apêndice I) e o cálculo da concentração utilizando o software Ativação (apêndice II, III e IV).

\subsection{Irradiação utilizando o método Instrumental de AAN}

As amostras biológicas foram irradiadas por 4 minutos juntas com o padrão de músculo bovino (NIST 8414) preparado seguindo o mesmo procedimento descrito no item 6.2. Após a ativação e tempo de espera de 2 minutos foram feitas aquisições de 5 minutos 
para o padrão e na seqüência para a amostra. O cálculo da área foi realizado utilizando o software IDFIX e o cálculo da concentração utilizando a equação (7).

A realização desta medida permite uma comparação dos resultados entre os dois procedimentos de AAN.

\subsection{Material de Referência}

Para verificar o desempenho do aparato experimental bem como para o controle de qualidade das medidas foi utilizado material de referência NIST 8414. Este material foi escolhido por apresentar valores certificados para todos os elementos medidos.

Para esta análise os valores das concentrações elementares medidas no material de referência foi comparada com os valores certificados usando o teste estatístico Z - Score [26]. Este teste permite avaliar o número de desvios padrão que o resultado experimental (E) está do valor esperado com dado certificado (C) :

$$
Z=\frac{|E-C|}{\sigma} \text { onde, } \sigma=\sqrt{\sigma_{E}^{2}+\sigma_{C}^{2}}
$$

Os resultados obtidos neste estudo para o procedimento semi - paramétrico de AAN são apresentados na Tabela 2. 
TABELA 2 - Concentração dos elementos obtidos na análise do material de referência (NIST 8414) empregando o método semi-paramétrico de AAN.

\begin{tabular}{c|c|c|c|c|c}
\hline \hline \multirow{2}{*}{ Elemento } & Presente & & Valores & \\
& estudo & DPR, & Certificados & ER, \% & $\mid$ Z-score \\
& $\mathrm{gL}^{-1}$ & & Media $\pm \mathrm{DP}$ & & \\
& & & $\mathrm{gL}^{-1}$ & & \\
\hline $\mathrm{Br}$ & $0,0014 \pm 0,0001$ & 7,1 & $0,0011 \pm 0,0002$ & 27,3 & 1,5 \\
\hline $\mathrm{Ca}$ & $0,164 \pm 0,015$ & 9,2 & $0,145 \pm 0,020$ & 13,10 & 0,95 \\
\hline $\mathrm{Cl}$ & $1,93 \pm 0,08$ & 4,8 & $1,88 \pm 0,15$ & 2,39 & 0,3 \\
\hline $\mathrm{K}$ & $14,76 \pm 1,05$ & 7,1 & $15,17 \pm 0,37$ & $-2,6$ & 1,1 \\
\hline $\mathrm{Mg}$ & $0,935 \pm 0,049$ & 5,2 & $0,960 \pm 0,095$ & $-2,7$ & 0,26 \\
\hline $\mathrm{Na}$ & $2,11 \pm 0,10$ & 4,7 & $2,10 \pm 0,08$ & 0,5 & 0,1 \\
\hline $\mathrm{S}$ & $6,97 \pm 0,72$ & 10,3 & $7,95 \pm 0,41$ & $-12,3$ & 2,4 \\
\hline \hline
\end{tabular}

ER: erro relativo

DPR: desvio padrão relativo medido

Considerando-se o intervalo de confiança de 95\% adotado para pratica clínica ( $\mid$ Zscore $\mid<2$ ) os dados encontram-se em boa concordância. 


\section{CAPÍTULO 7. RESULTADOS}

O resultado da análise espectroscópica da amostra de sangue total de Hamster, utilizando a instrumentação descrita na seção 5, é apresentado na TABELA 3. Esta análise permite a identificar e selecionar a energia da transição gama de interesse para cálculo da concentração.

Nas figuras 8 - 12 são apresentados os espectros parciais de raios $\gamma$ de sangue total de Hamster Dourado irradiado por 5 minutos com nêutrons no reator IEA - R1. As transições não identificadas compõem o espectro de fundo do laboratório.

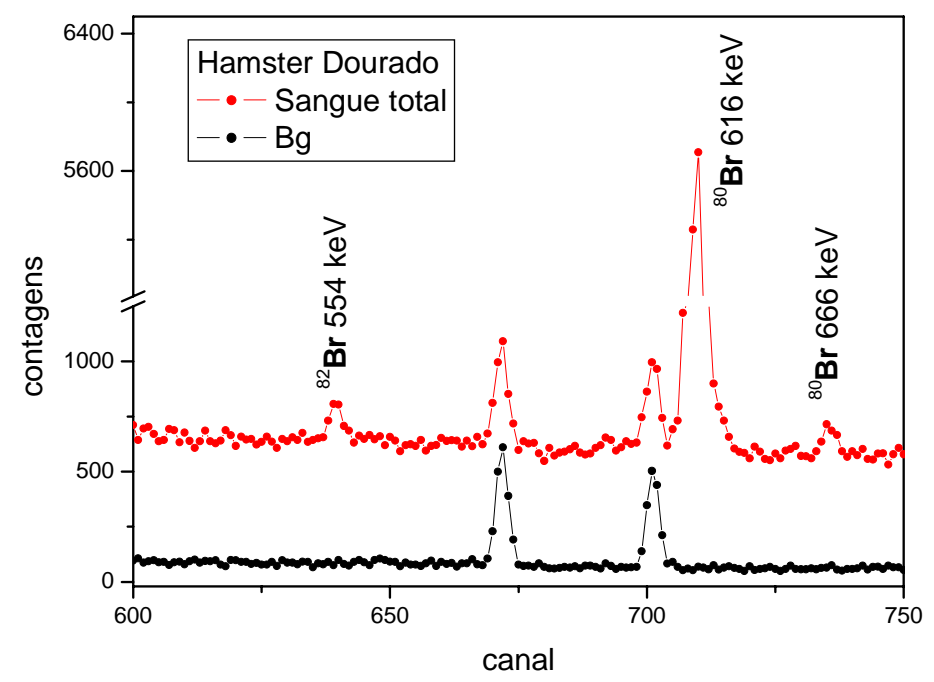

FIGURA 8 - Espectro parcial de raios $\gamma$ de sangue total de Hamster Dourado irradiado por 5 minutos no reator IEA-R1. 


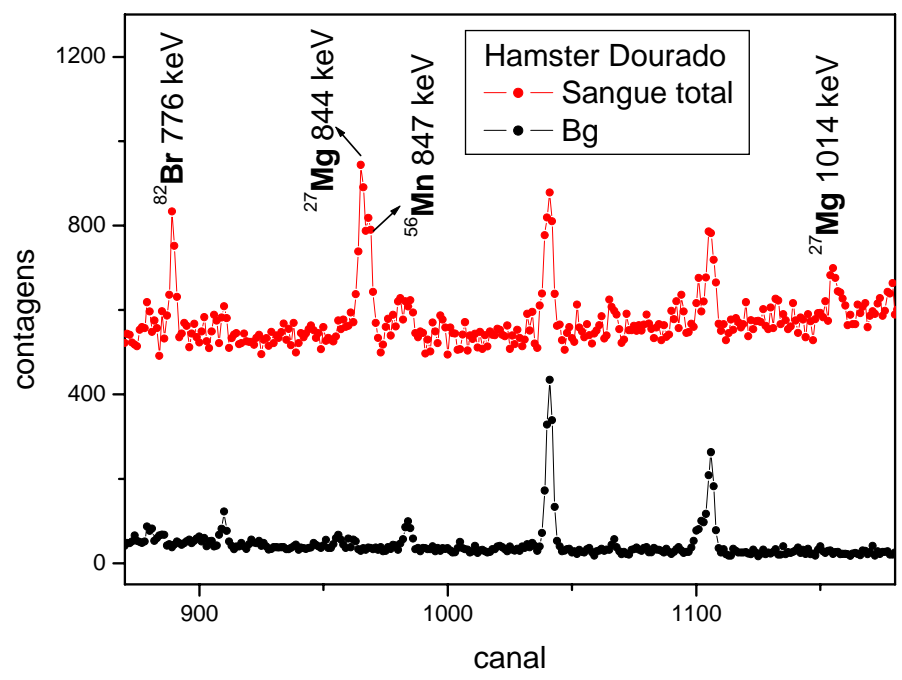

FIGURA 9 - Espectro parcial de raios $\gamma$ de sangue total de Hamster Dourado irradiado por 5 minutos no reator IEA - R1.

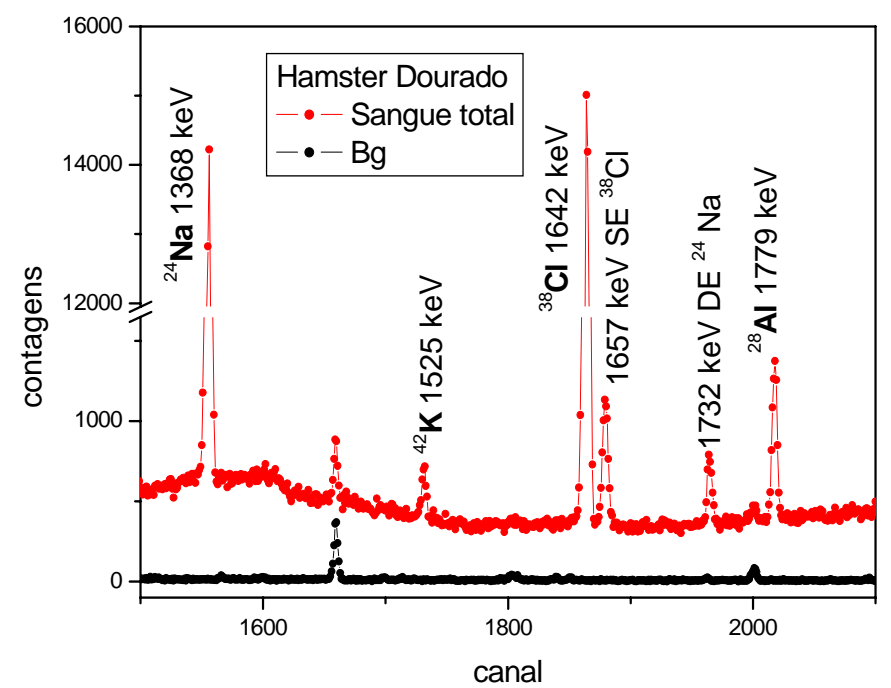

FIGURA 10 - Espectro parcial de raios $\gamma$ de sangue total de Hamster Dourado irradiado por 5 minutos no reator IEA - R1. 


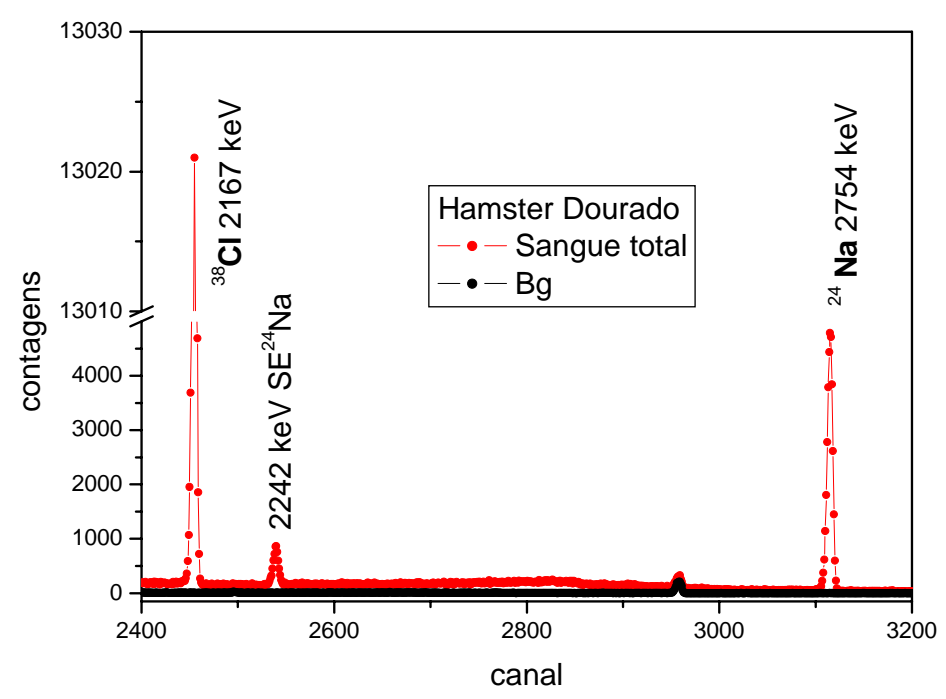

FIGURA 11 - Espectro parcial de raios $\gamma$ de sangue total de Hamster Dourado irradiado por 5 minutos no reator IEA - R1.

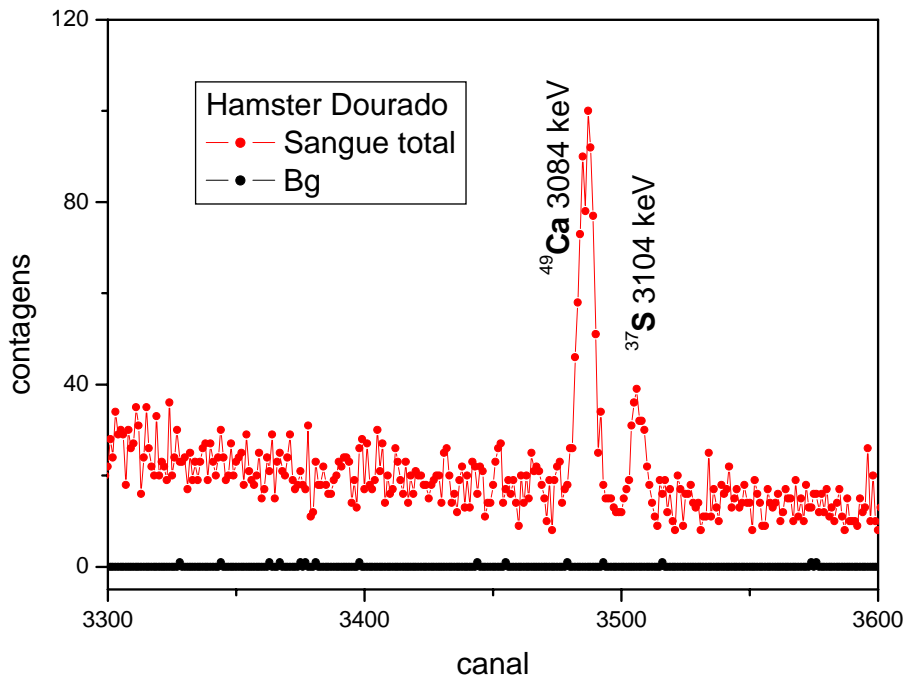

FIGURA 12 - Espectro parcial de raios $\gamma$ de sangue total de Hamster Dourado irradiado por 5 minutos no reator IEA - R1. 
TABELA 3. Elementos identificados no sangue total de Hamster (coluna 1) e energia selecionada para análise quantitativa (coluna 2) .

\begin{tabular}{c|c}
\hline \hline ELEMENTO & $\begin{array}{c}\text { CARACTERÍSTICAS DOS } \\
\text { RADIONUCLIDEOS } \\
\mathrm{T}_{1 / 2} ; \mathrm{E}_{\gamma}(\mathrm{keV})[24]\end{array}$ \\
\hline \hline Alumínio & ${ }^{28} \mathrm{Al}(2,24 \mathrm{~min}) ; 1779$ \\
\hline Bromo & ${ }^{80} \mathrm{Br}(17,68 \mathrm{~min}) ; 616$ \\
\hline Cálcio & ${ }^{49} \mathrm{Ca}(8,7 \mathrm{~min}) ; 3084$ \\
\hline Cloro & ${ }^{38} \mathrm{Cl}(37 \mathrm{~min}) ; 1642$ \\
\hline Magnésio & ${ }^{27} \mathrm{Na}(15 \mathrm{hg}) ; 1368$ \\
\hline Eódio & ${ }^{27} \mathrm{~S}(9.4 \mathrm{~m}) ; 843$ \\
\hline
\end{tabular}

Embora o Alumínio tenha sido identificado sua avaliação quantitativa não foi obtida em função da reação interferente ${ }^{31} \mathrm{P}(\mathrm{n}, \alpha){ }^{28} \mathrm{Al}$ causada pela presença de fósforo no sangue. Da mesma forma para o Manganês devido presença de ferro em sangue, ${ }^{56} \mathrm{Fe}$ (n, p) ${ }^{56} \mathrm{Mn}$. 


\subsection{Método semi - paramétrico de AAN}

As concentrações obtidas no presente estudo de $\mathrm{Br}, \mathrm{Ca}, \mathrm{Cl}, \mathrm{K}, \mathrm{Mg}$, $\mathrm{Na}$ e $\mathrm{S}$ em amostras de sangue total de Hamster Dourado estão na Tabela 4. Todos os resultados foram obtidos pela média das análises em duplicatas. Estes dados foram correlacionados com o intervalo de referência em sangue total de humanos [27]. A apresentação dos resultados encontra-se de acordo com o Guia para Expressão da Incerteza de Medição [28] que tem como objetivo estabelecer critérios e regras gerais, harmonizar métodos e procedimentos relacionados a expressão de incertezas associadas ao processo de medição.

As figuras 13 - 19 ilustram as concentrações de $\mathrm{Br}, \mathrm{Ca}, \mathrm{Cl}, \mathrm{K}, \mathrm{Mg}, \mathrm{Na}$ e $\mathrm{S}$, respectivamente, das amostras de sangue total do Hamster Dourado, onde o intervalo de referência obtido no presente estudo foi incluído considerando-se \pm 1 e \pm 2 DP (Desvio Padrão).

Nas figuras 20 - 26 são apresentados os histogramas com as curvas gaussianas para os elementos medidos. 
TABELA 4 - Resultado das análises bioquímicas em sangue de Hamster Dourado pelo método semi - paramétrico de AAN.

\begin{tabular}{|c|c|c|c|c|c|}
\hline Elemento & VM & V Mín. & V Máx. & 1 DP & $\begin{array}{l}\text { Intervalo de } \\
\text { Referência }\end{array}$ \\
\hline $\mathrm{Br}, g L^{-1}$ & 0,029 & 0,014 & 0,055 & 0,009 & $\begin{array}{c}0,020-0,038 \\
{[0,0067-0,026]^{*}}\end{array}$ \\
\hline $\mathrm{Ca}, g L^{-1}$ & 0,23 & 0,14 & 0,35 & 0,06 & $\begin{array}{c}0,17-0,29 \\
{[0,080-0,258]^{* *}, \mathrm{a}}\end{array}$ \\
\hline $\mathrm{Cl}, g L^{-1}$ & 2,93 & 2,05 & 3,5 & 0,41 & $\begin{array}{c}2,52-3,34 \\
{[2,54-3,5]^{*}}\end{array}$ \\
\hline $\mathrm{K}, g L^{-1}$ & 2,07 & 1,51 & 2,98 & 0,36 & $\begin{array}{c}1,71-2,43 \\
{[1,33-1,89]^{*}}\end{array}$ \\
\hline $\mathrm{Mg}, g L^{-1}$ & 0,058 & 0,041 & 0,088 & 0,016 & $\begin{array}{c}0,042-0,074 \\
{[0,027-0,0455] * *, b}\end{array}$ \\
\hline $\mathrm{Na}, g L^{-1}$ & 1,77 & 1,02 & 2,58 & 0,37 & $\begin{array}{c}1,40-2,14 \\
{[1,48-2,06]^{*}}\end{array}$ \\
\hline $\mathrm{S}, g L^{-1}$ & 1,49 & 1,15 & 2,09 & 0,26 & $\begin{array}{c}1,23-1,75 \\
{[0,10-0,74] * *, a}\end{array}$ \\
\hline
\end{tabular}

* Valor de referência para sangue total de humanos [27].

** [Valor mínimo - Valor máximo]

${ }^{\mathrm{a}}$ [ref. 29]

${ }^{\mathrm{b}}$ [ref. 30]

VM - Valor médio

1 DP - 1 Desvio padrão. 


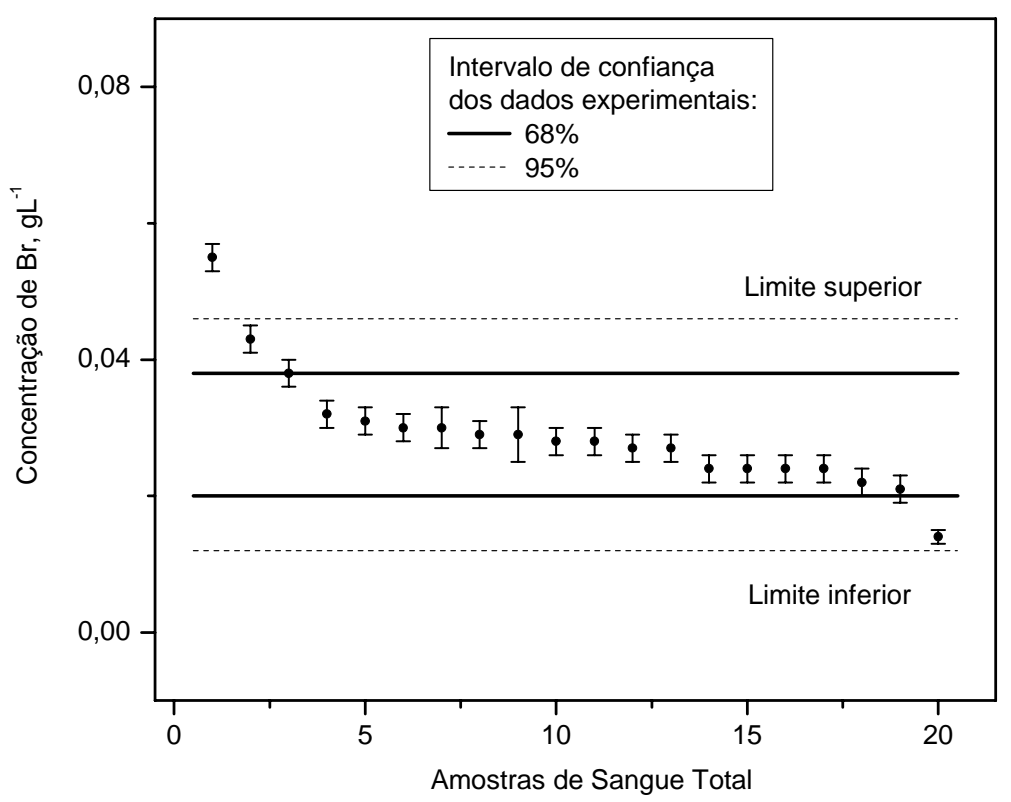

FIGURA 13- Concentração de Br em amostras de sangue total.

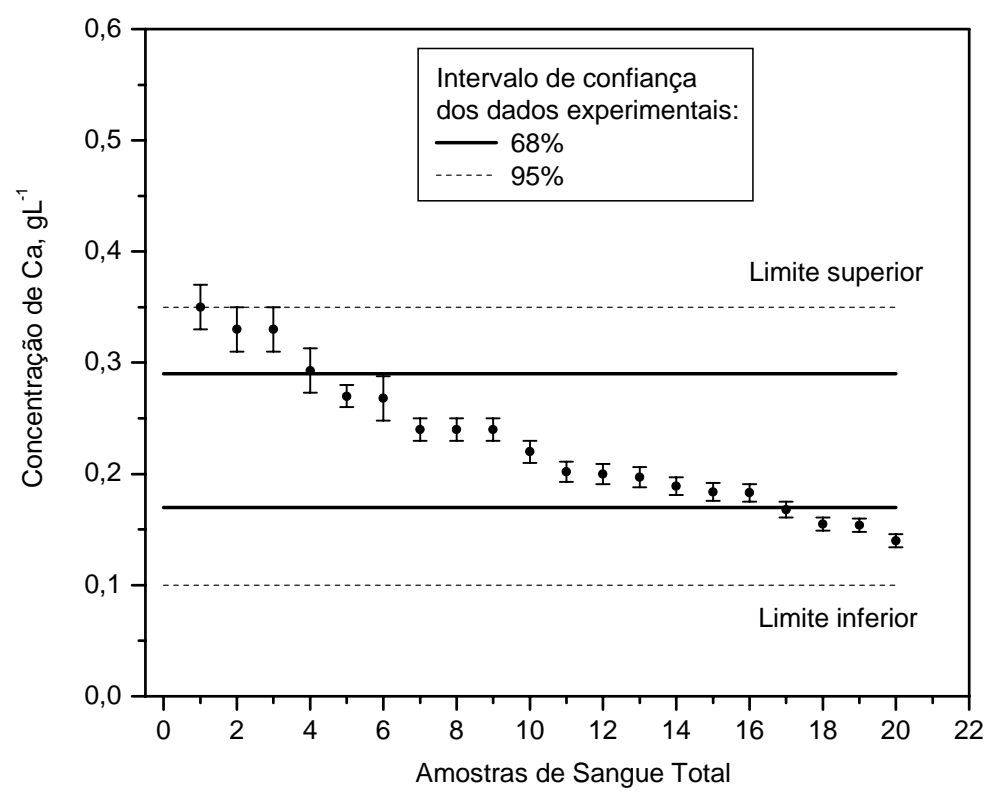

FIGURA 14 - Concentração de Ca em amostras de sangue total. 


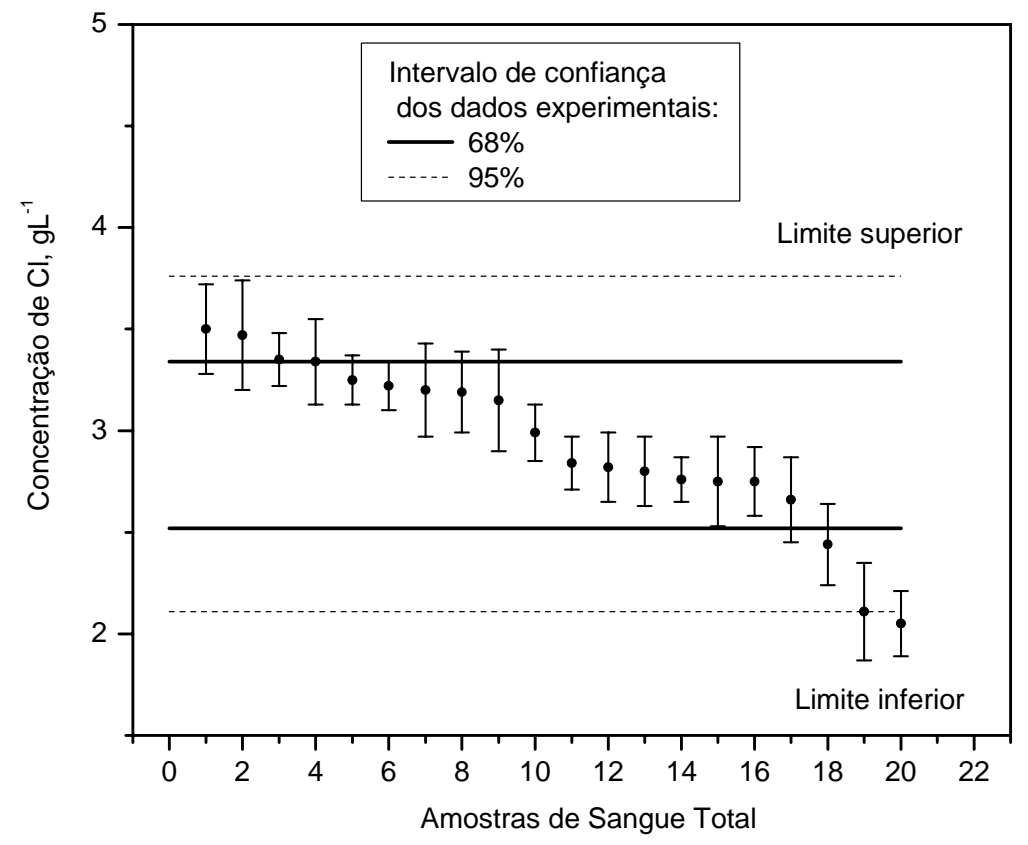

FIGURA 15 - Concentração de $\mathrm{Cl}$ em amostras de sangue total.

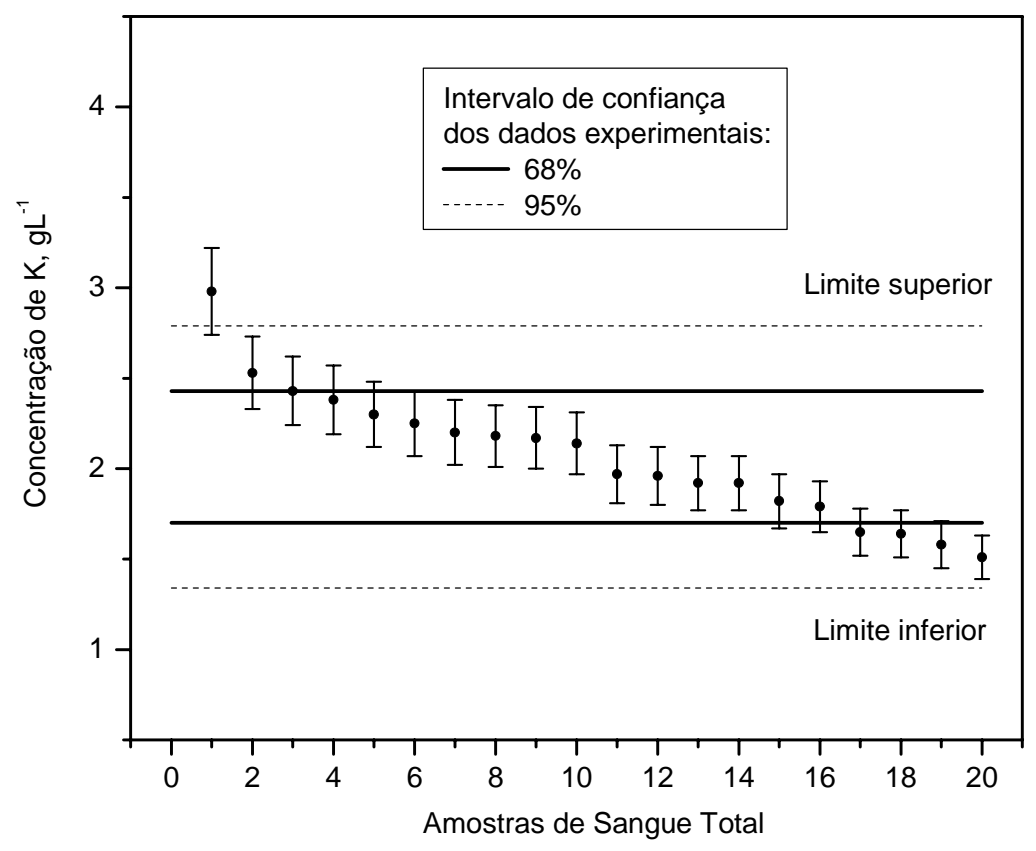

FIGURA 16 - Concentração de K em amostras de sangue total. 


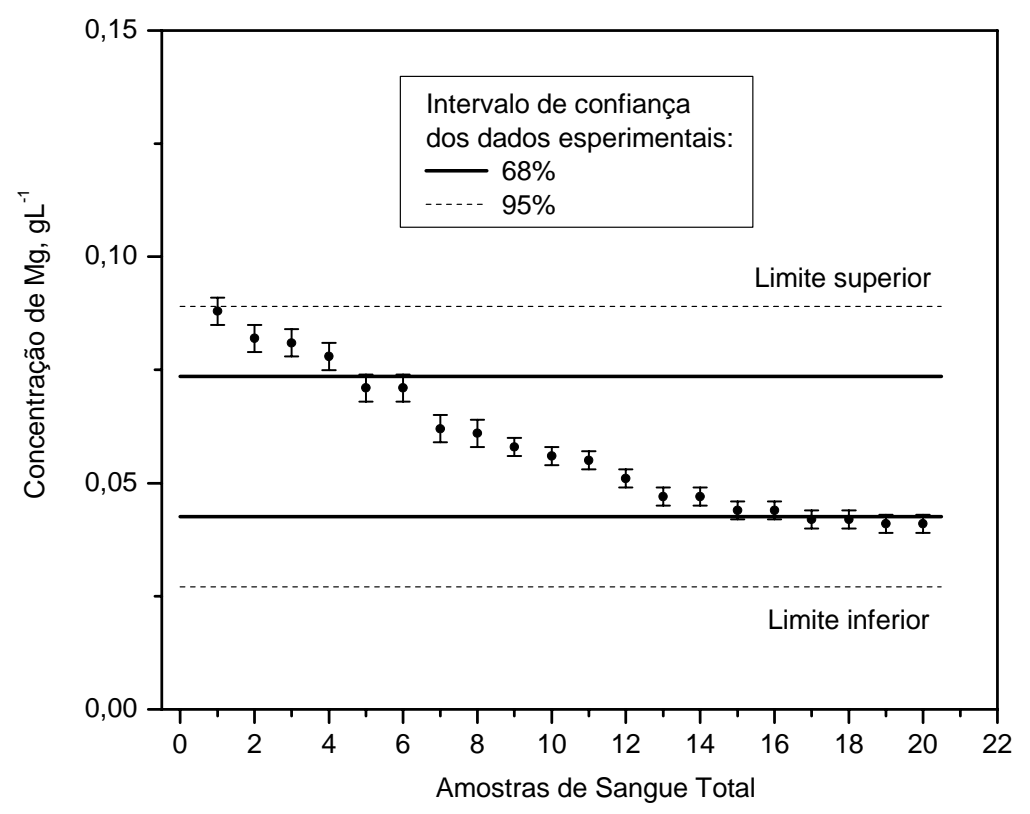

FIGURA 17 - Concentração de Mg em amostras de sangue total.

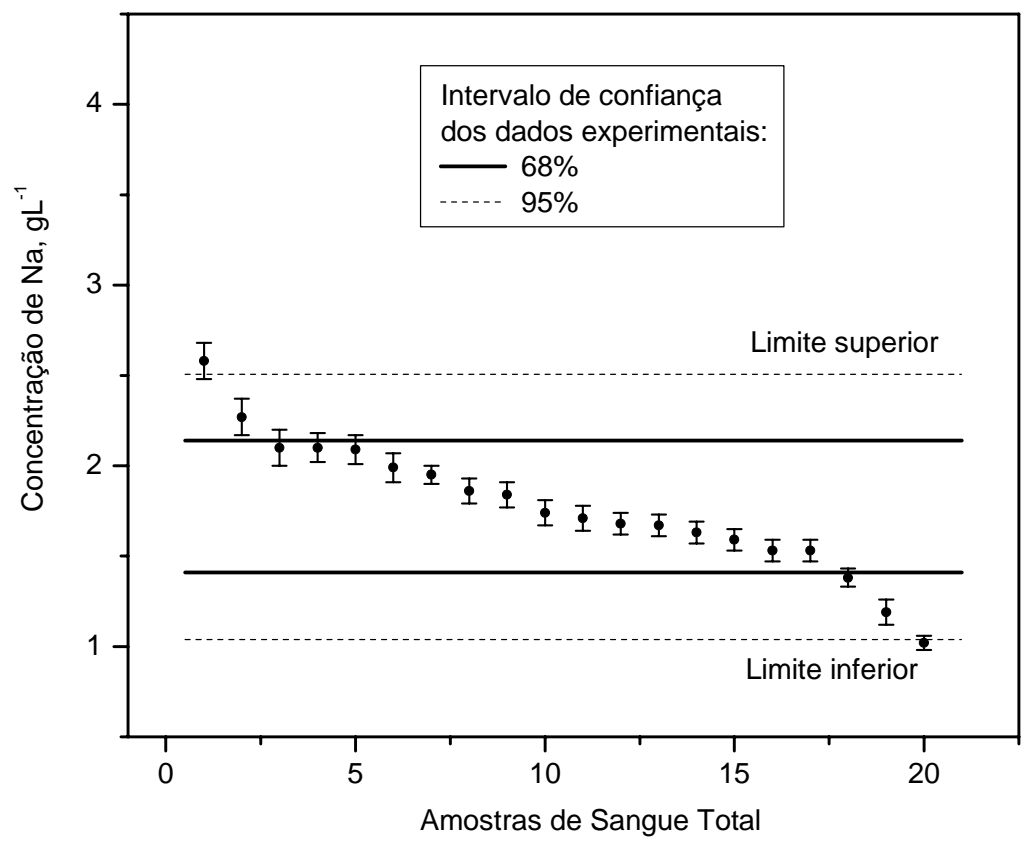

FIGURA 18 - Concentração de $\mathrm{Na}$ em amostras de sangue total. 


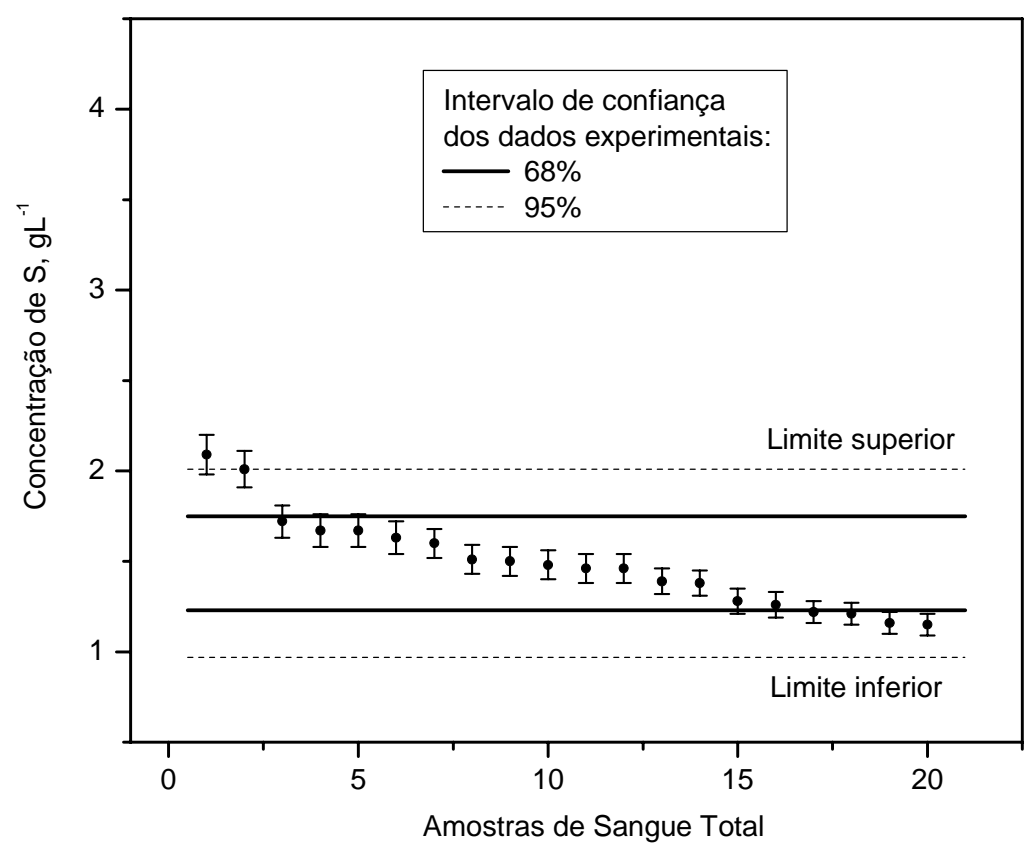

FIGURA 19 - Concentração de S em amostras de sangue total.

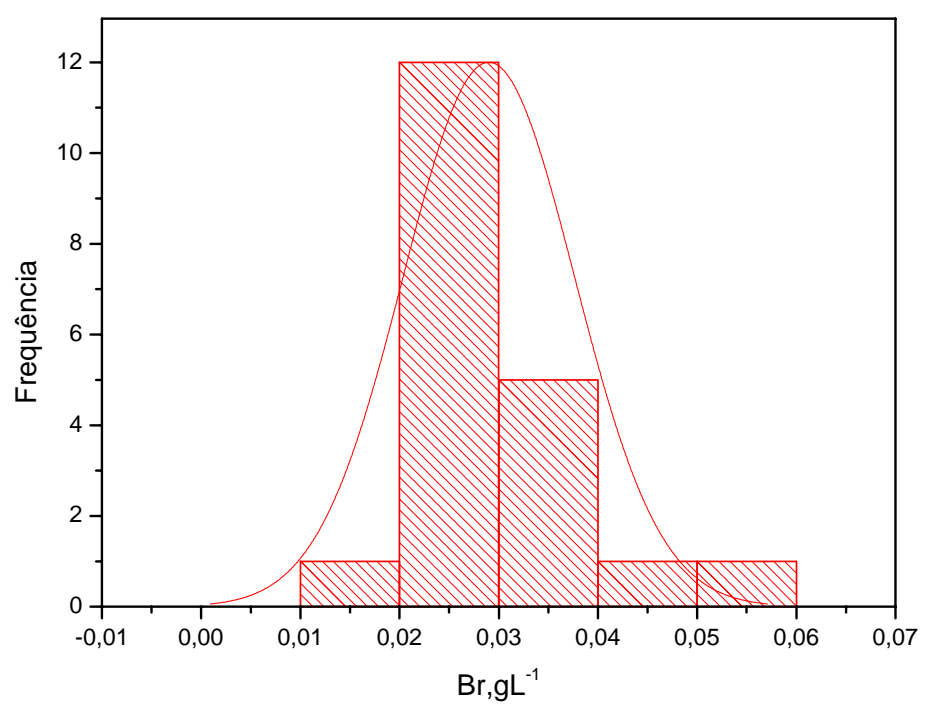

FIGURA 20 - Histograma das concentrações de $\mathrm{Br}$ em sangue total de Hamster e ajuste da função gaussiana. 


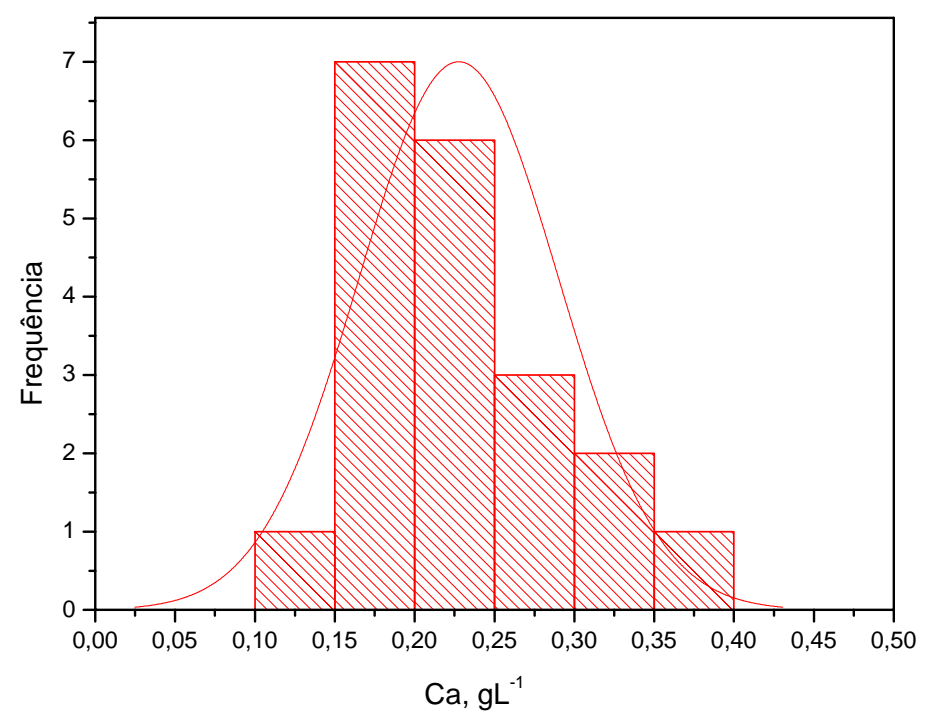

FIGURA 21 - Histograma das concentrações de Ca em sangue total de Hamster e ajuste da função gaussiana.

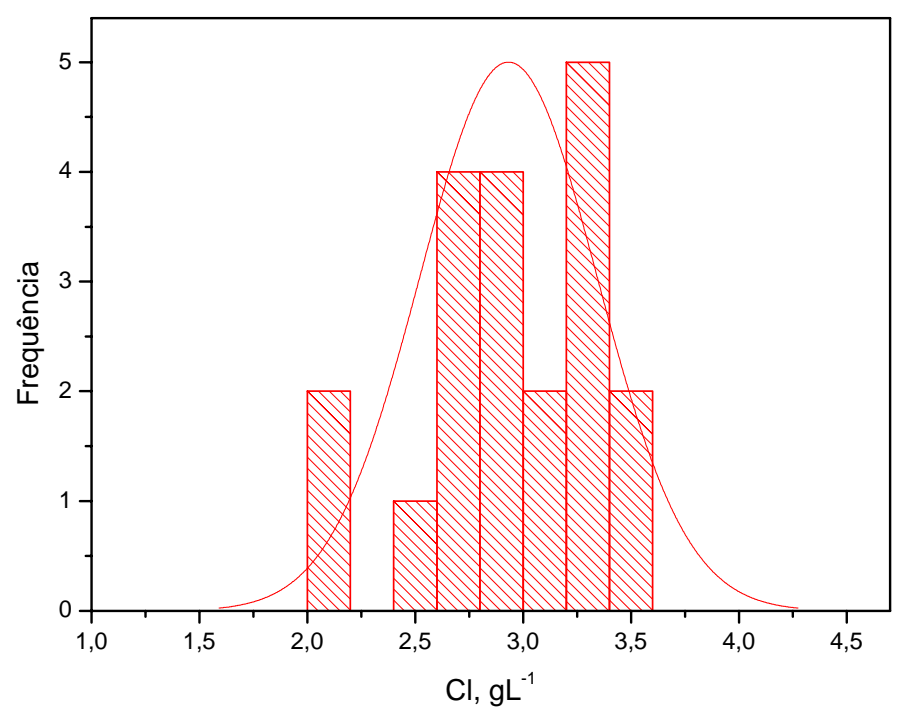

FIGURA 22 - Histograma das concentrações de $\mathrm{Cl}$ em sangue total de Hamster e ajuste da função gaussiana. 


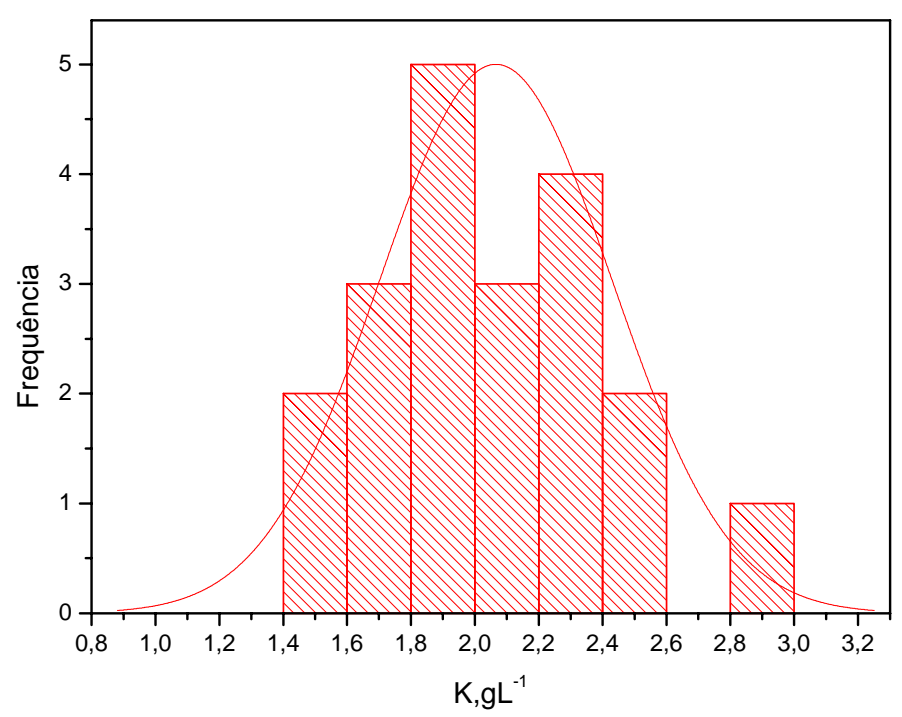

FIGURA 23 - Histograma das concentrações de K em sangue total de Hamster e ajuste da função gaussiana.

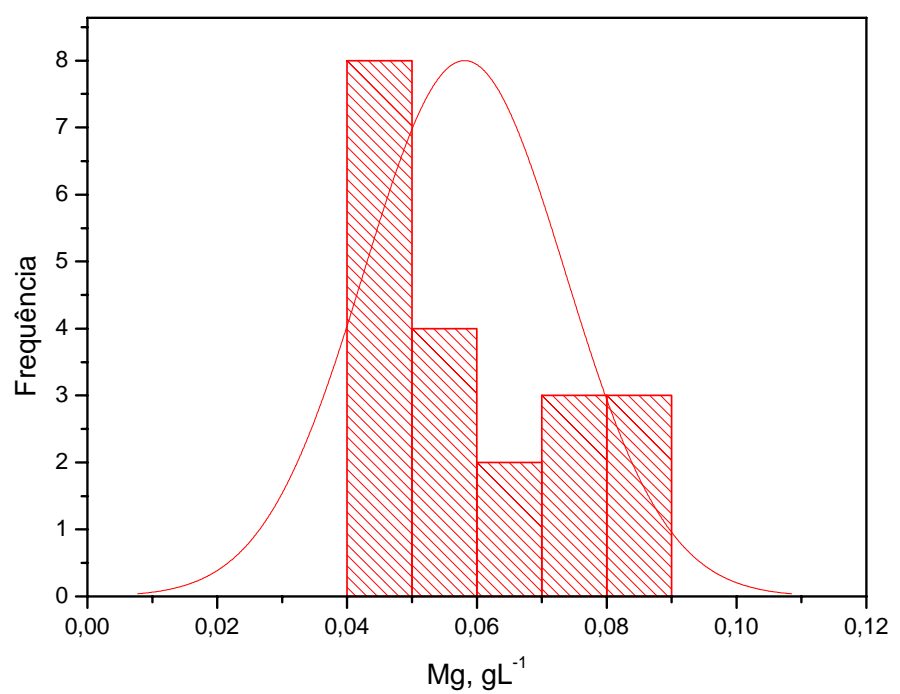

FIGURA 24 - Histograma das concentrações de Mg em sangue total de Hamster e ajuste da função gaussiana. 


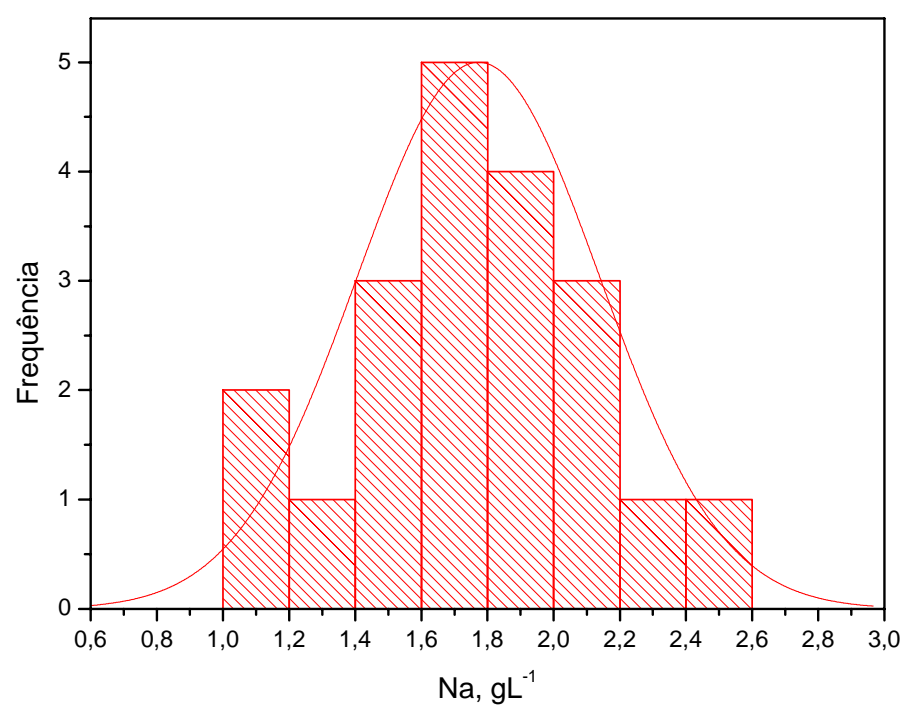

FIGURA 25 - Histograma das concentrações de Na em sangue total de Hamster e ajuste da função gaussiana.

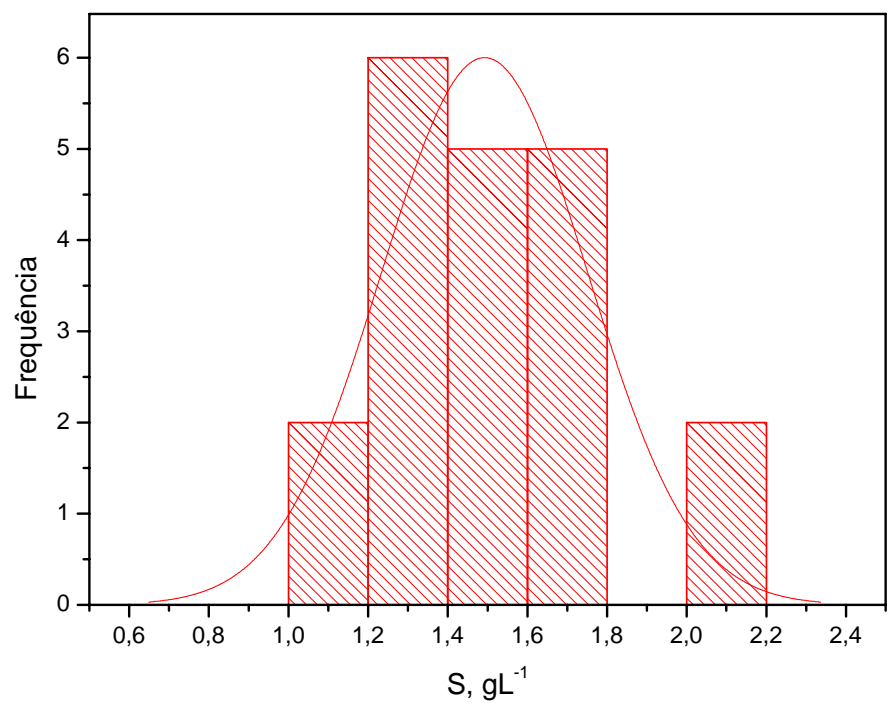

FIGURA 26 - Histograma das concentrações de S em sangue total de Hamster e ajuste da função gaussiana.

$\mathrm{Na}$ tabela 5 são apresentados os parâmetros estatísticos das distribuições para cada elemento (media, mediana, moda). Esses parâmetros permitem uma avaliação quanto a distribuição normal desses elementos no sangue (isto é: media $\sim$ mediana $\sim$ moda). Nas figuras 27-33 esses parâmetros são apresentados via Box-plot. 
TABELA 5 - Valores da média, mediana e moda das concentrações de $\mathrm{Br}, \mathrm{Ca}, \mathrm{Cl}, \mathrm{K}, \mathrm{Mg}$, $\mathrm{Na}$ e $\mathrm{S}$ obtidas pelo método semi - paramétrico de AAN.

\begin{tabular}{c|c|c|c|c}
\hline \hline ELEMENTO & $\begin{array}{c}\text { MÉDIA } \\
\mathrm{gL}^{-1}\end{array}$ & $\begin{array}{c}\text { MEDIANA } \\
\mathrm{gL}^{-1}\end{array}$ & $\begin{array}{c}\text { MODA } \\
\mathrm{gL}^{-1}\end{array}$ & $\begin{array}{c}\text { Desvio } \\
\text { padrão } \\
(68 \%)\end{array}$ \\
\hline \hline $\mathrm{Br}$ & 0,029 & 0,028 & $0,024^{*}$ & 0,009 \\
$\mathrm{Ca}$ & 0,23 & 0,21 & $0,24^{*}$ & 0,06 \\
$\mathrm{Cl}$ & 2,93 & 2,92 & 2,75 & 0,41 \\
\hline $\mathrm{K}$ & 2,07 & 2,06 & 1,92 & 0,36 \\
\hline $\mathrm{Mg}$ & 0,058 & 0,056 & $0,041^{*}$ & 0,016 \\
\hline $\mathrm{Na}$ & 1,77 & 1,73 & 2,10 & 0,37 \\
\hline $\mathrm{S}$ & 1,49 & 1,47 & $1,46^{*}$ & 0,26 \\
\hline \hline
\end{tabular}

* Distribuição com mais de um valor de moda.

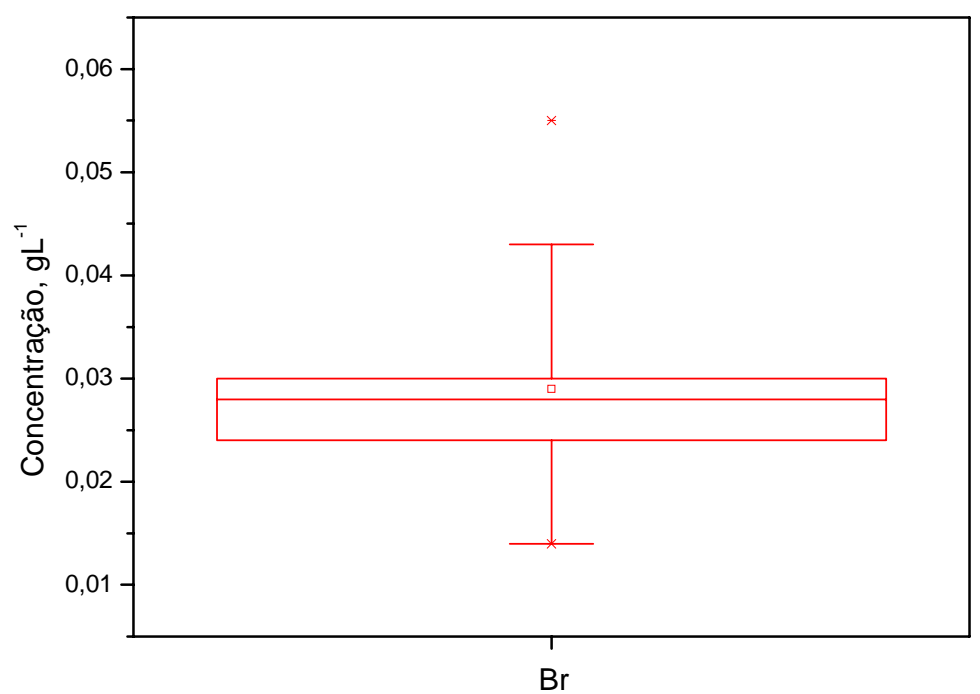

FIGURA 27 - Representação via Box-plot para Br. 


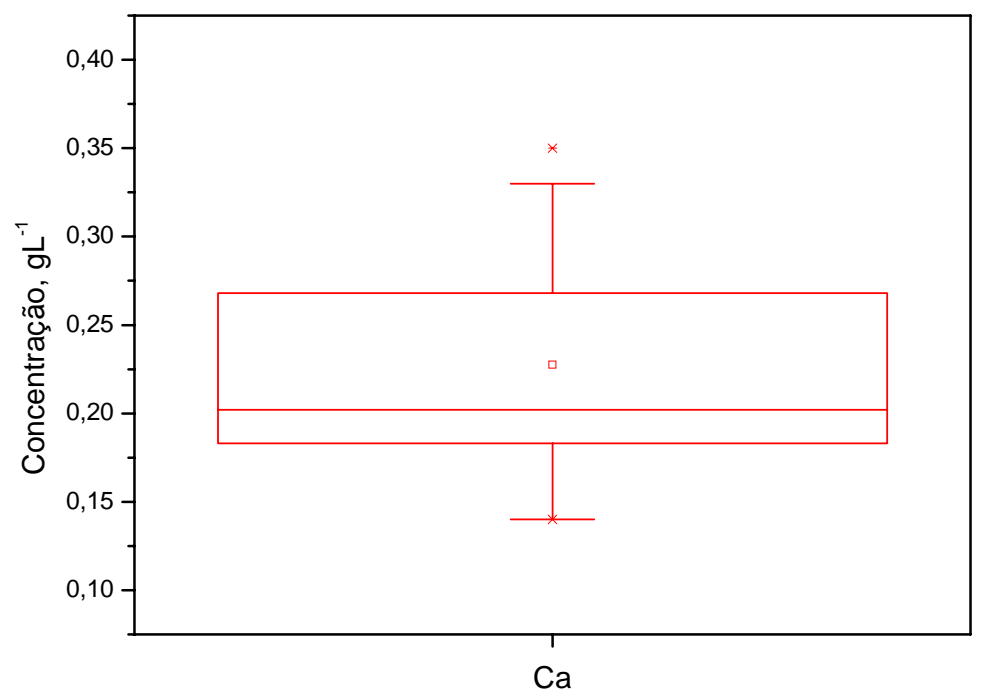

FIGURA 28 - Representação via Box-plot para Ca.

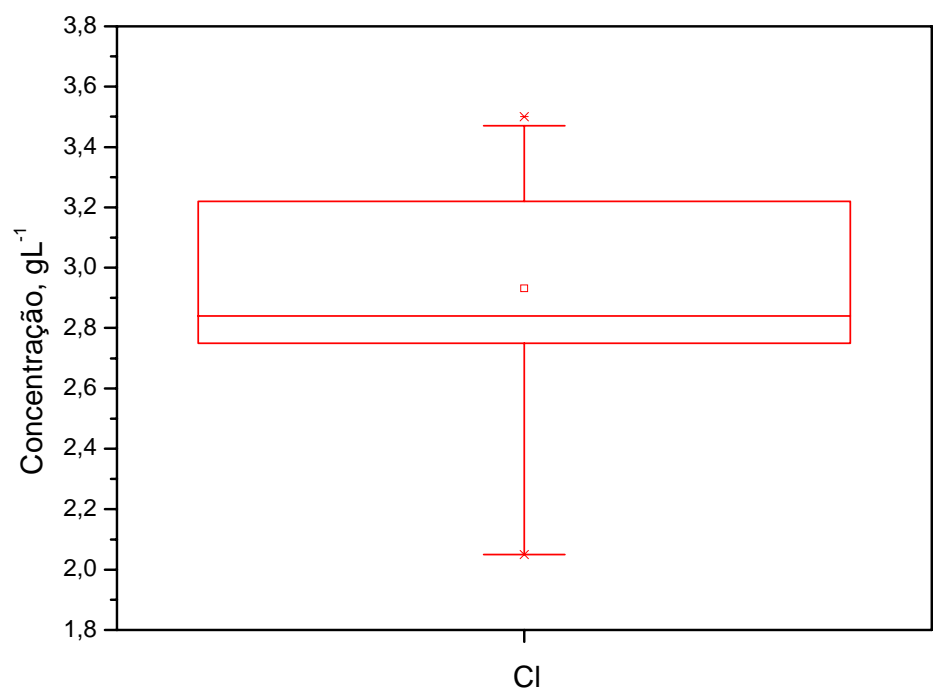

FIGURA 29 - Representação via Box-plot para Cl. 


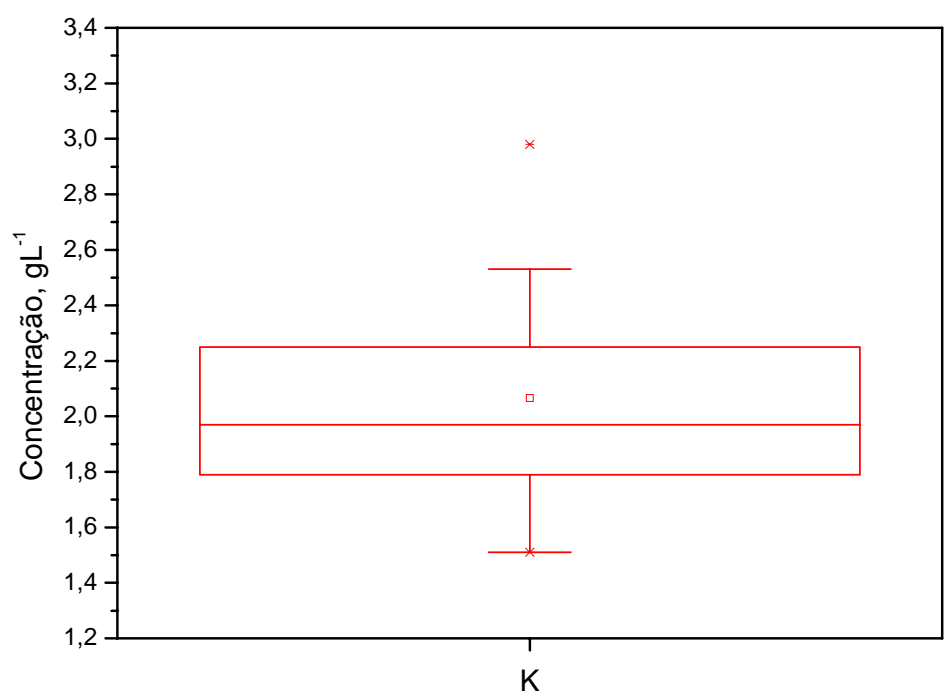

FIGURA 30 - Representação via Box-plot para K.

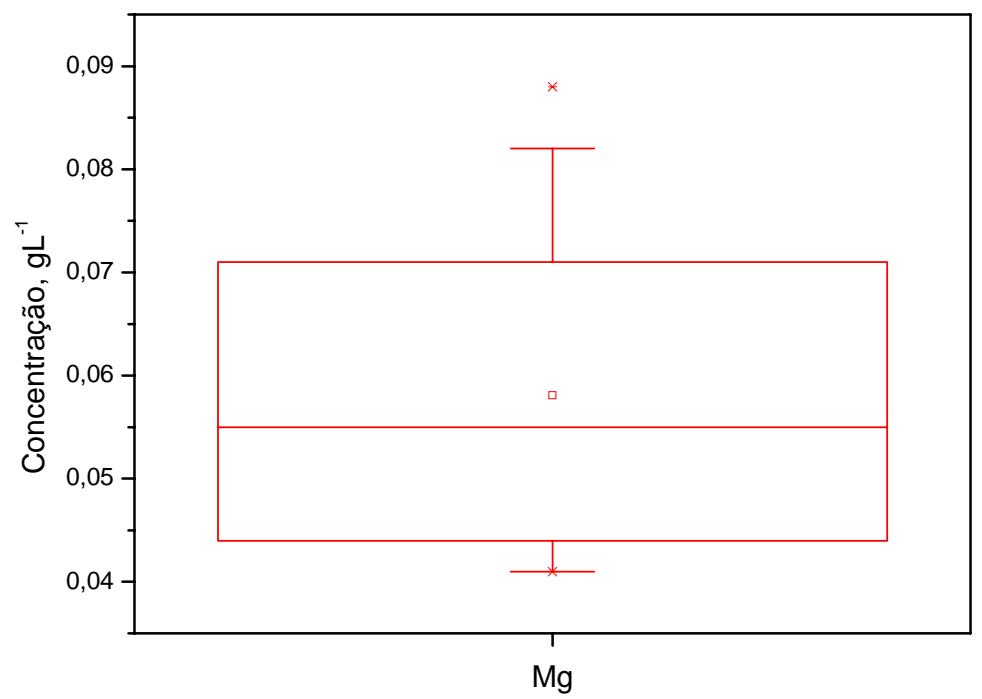

FIGURA 31 - Representação via Box-plot para Mg. 


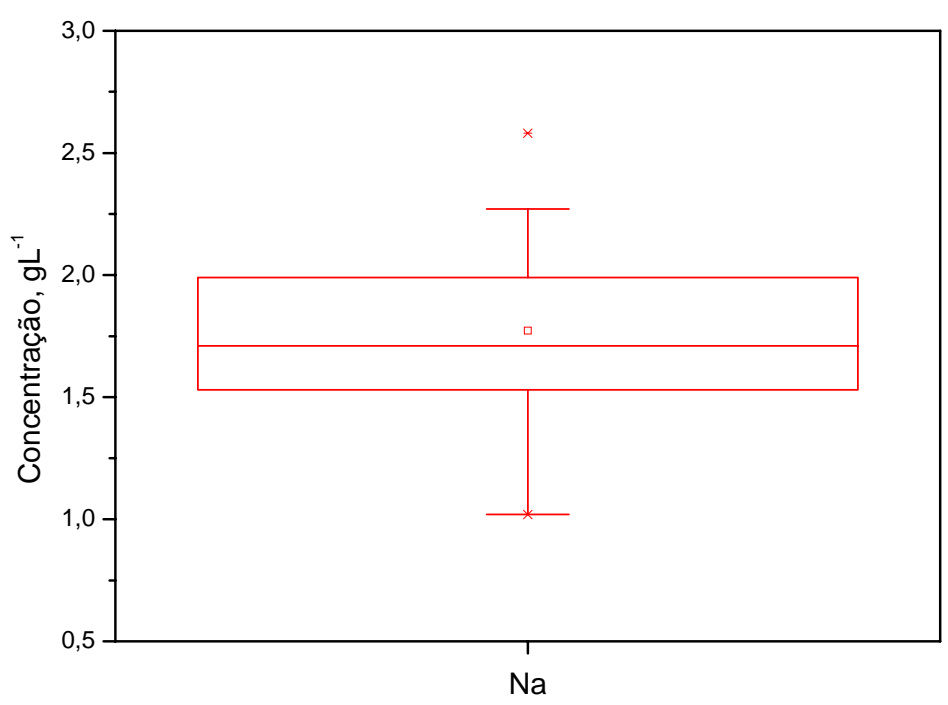

FIGURA 32 - Representação via Box-plot para Na.

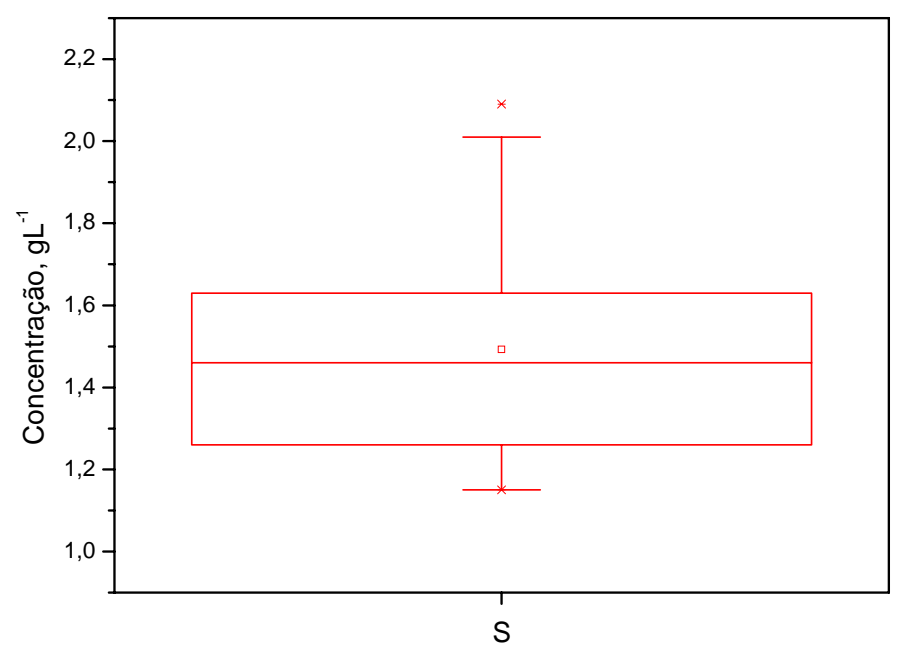

FIGURA 33 - Representação via Box-plot para S.

\subsection{Método Instrumental de AAN}

As concentrações de $\mathrm{Br}, \mathrm{Ca}, \mathrm{Cl}, \mathrm{K}, \mathrm{Mg}, \mathrm{Na}$ e $\mathrm{S}$ em amostras de sangue total de Hamster Dourado são apresentadas na Tabela 6. Os resultados foram obtidos pela média 
das análises em duplicatas. Os resultados obtidos via método semi - paramétrico foram incluídos para comparação.

As figuras 34 - 39 ilustram as concentrações de $\mathrm{Br}, \mathrm{Ca}, \mathrm{Cl}, \mathrm{K}, \mathrm{Mg}$ e $\mathrm{Na}$, respectivamente, das amostras de sangue total do Hamster Dourado, onde o intervalo de referência obtido no presente estudo foi incluído considerando-se \pm 1 e \pm 2 DP (Desvio Padrão).

Nas figuras 40 - 47 são apresentados os histogramas com as curvas gaussianas para os elementos medidos.

TABELA 6 - Resultado das análises bioquímicas em sangue de Hamster Dourado pela técnica Instrumental (AANI) e Semi-Paramétrica (AAN SP).

\begin{tabular}{|c|c|c|}
\hline $\begin{array}{c}\text { Elementos } \\
\left(\mathrm{gL}^{-1}\right)\end{array}$ & $\begin{array}{c}\text { AANI } \\
\text { Média } \pm \text { 1DP } \\
\text { (n) }\end{array}$ & $\begin{array}{c}\text { AAN SP } \\
\text { Média } \pm \text { 1DP } \\
\text { (n) }\end{array}$ \\
\hline $\mathrm{Br}$ & $\begin{array}{c}0,020 \pm 0,006 \\
\text { (20) }\end{array}$ & $\begin{array}{c}0,029 \pm 0,009 \\
\text { (20) }\end{array}$ \\
\hline $\mathrm{Ca}$ & $\begin{array}{c}0,19 \pm 0,07 \\
(17)\end{array}$ & $\begin{array}{c}0,23 \pm 0,06 \\
(20)\end{array}$ \\
\hline $\mathrm{Cl}$ & $\begin{array}{c}3,12 \pm 0,51 \\
(20)\end{array}$ & $\begin{array}{c}2,93 \pm 0,41 \\
(20)\end{array}$ \\
\hline $\mathrm{K}$ & $\begin{array}{c}2,26 \pm 0,39 \\
(20)\end{array}$ & $\begin{array}{c}2,07 \pm 0,36 \\
(20)\end{array}$ \\
\hline $\mathrm{Mg}$ & $\begin{array}{c}0,067 \pm 0,016 \\
\text { (20) }\end{array}$ & $\begin{array}{c}0,058 \pm 0,016 \\
\text { (20) }\end{array}$ \\
\hline $\mathrm{Na}$ & $\begin{array}{c}2,00 \pm 0,41 \\
(20)\end{array}$ & $\begin{array}{c}1,77 \pm 0,37 \\
(20)\end{array}$ \\
\hline $\mathrm{S}$ & $\begin{array}{c}1,01 \pm 0,28 \\
(5)\end{array}$ & $\begin{array}{c}1,49 \pm 0,26 \\
(20)\end{array}$ \\
\hline
\end{tabular}

n: número de amostras analisadas 


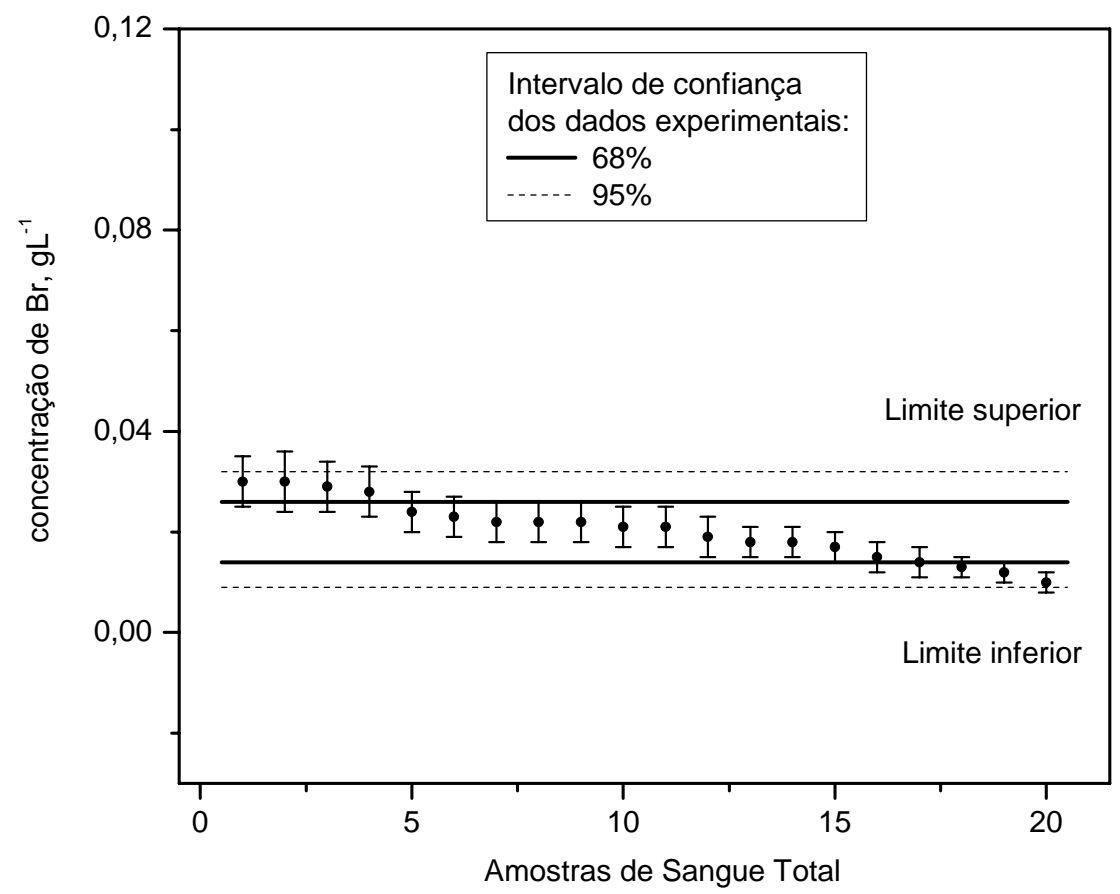

FIGRURA 34 - Concentração de Br em amostras de sangue total de Hamster Dourado pela técnica de AANI.

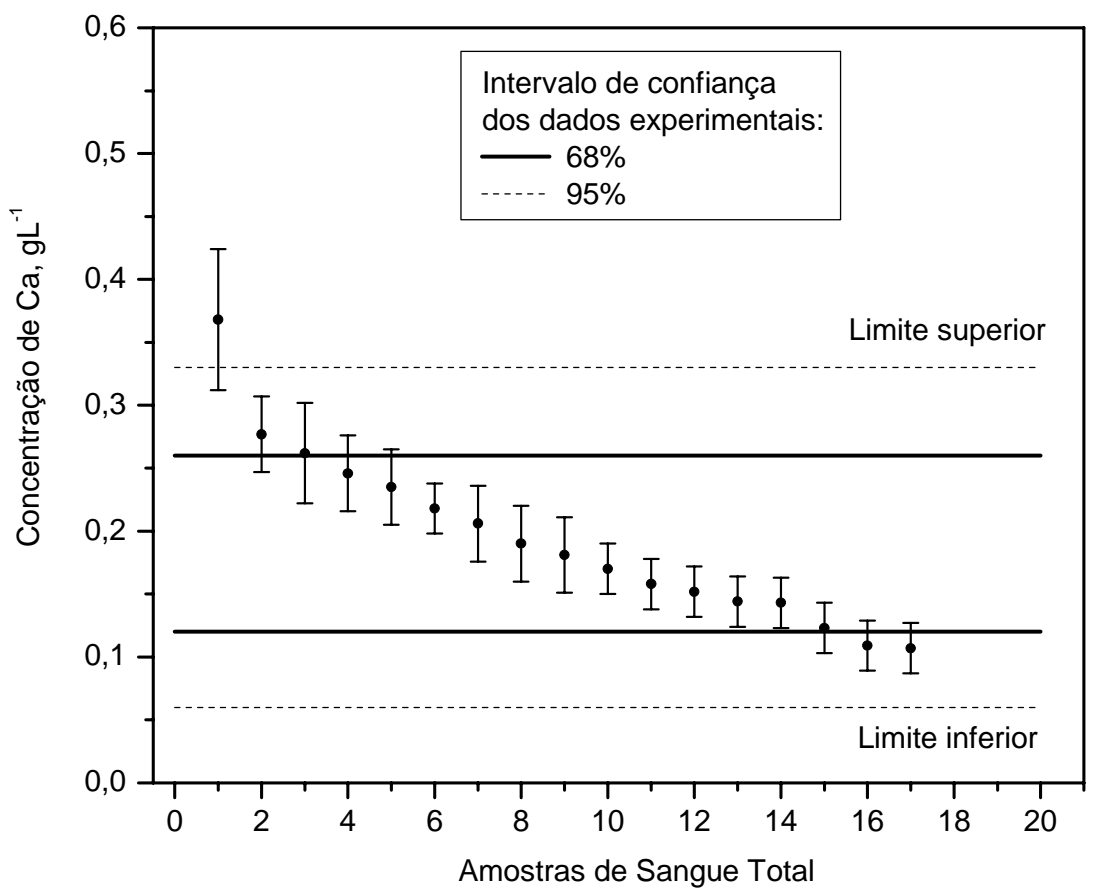

FIGURA 35 - Concentração de Ca em amostras de sangue total de Hamster Dourado pela técnica de AANI. 


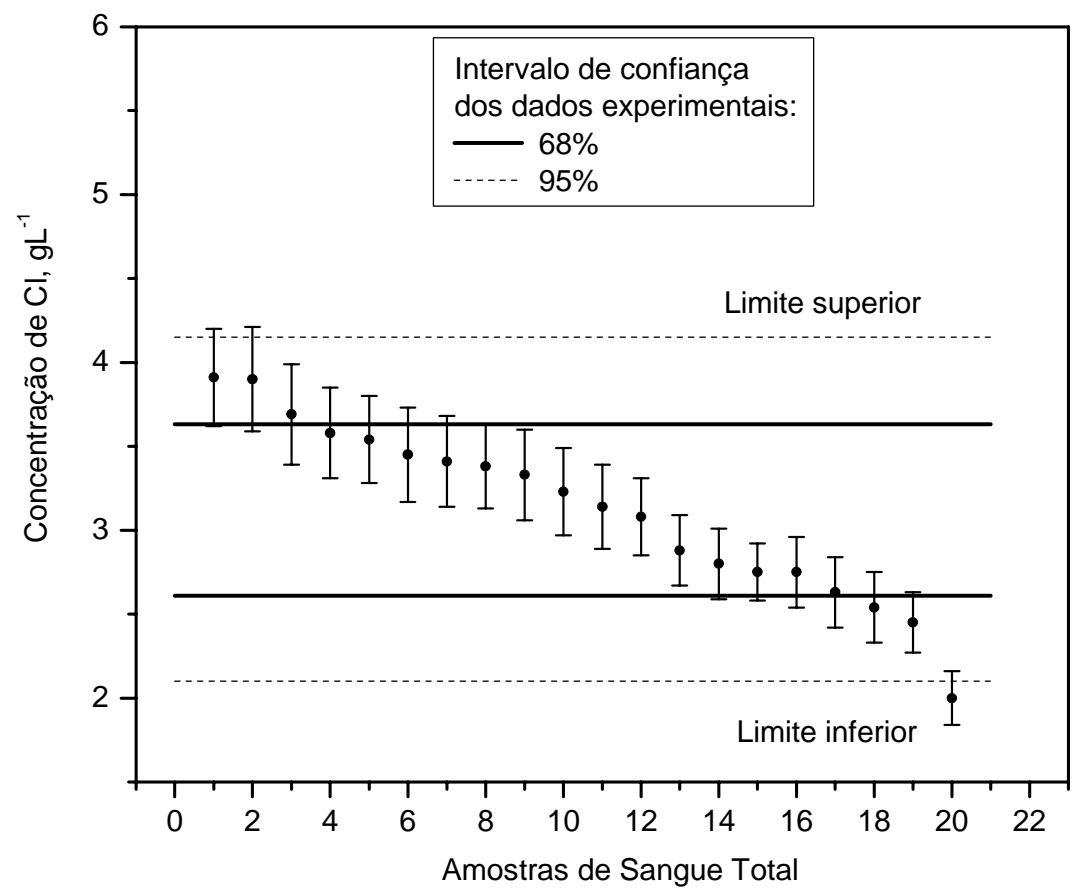

FIGURA 36 - Concentração de $\mathrm{Cl}$ em amostras de sangue total de Hamster Dourado pela técnica de AANI.

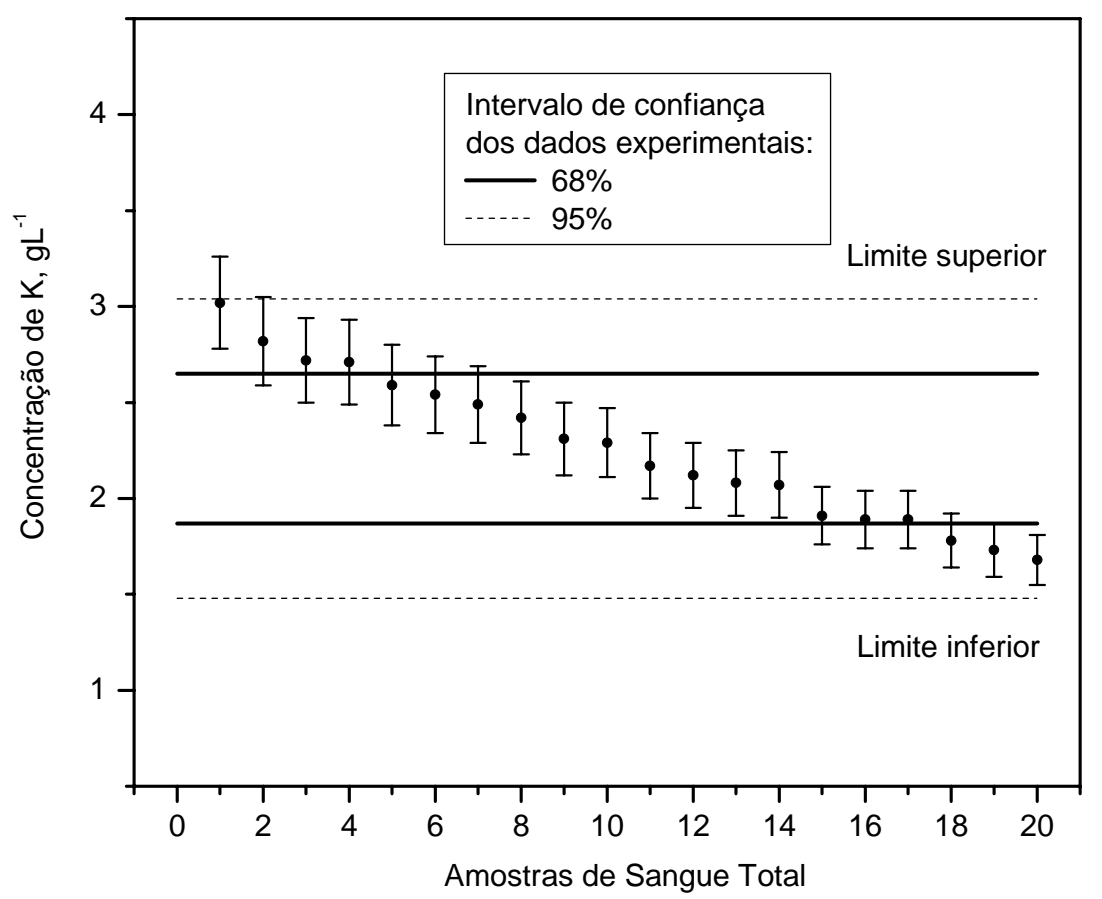

FIGURA 37 - Concentração de K em amostras de sangue total de Hamster Dourado pela técnica de AANI. 


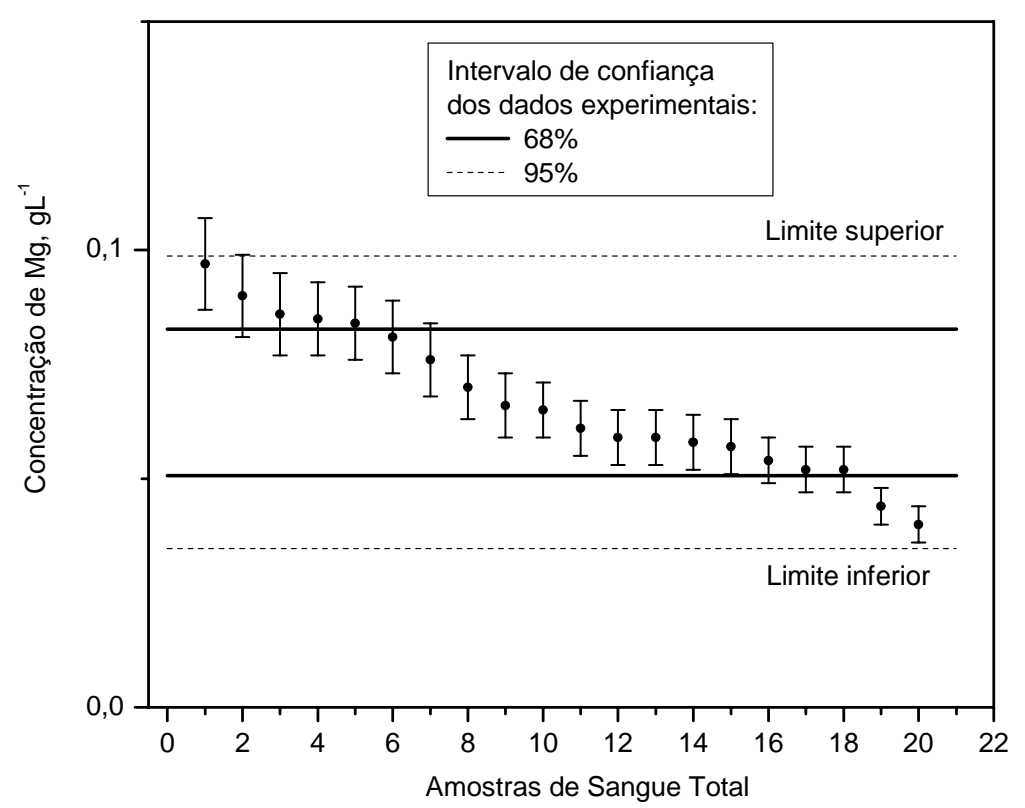

FIGURA 38 - Concentração de Mg em amostras de sangue total de Hamster Dourado pela técnica de AANI.

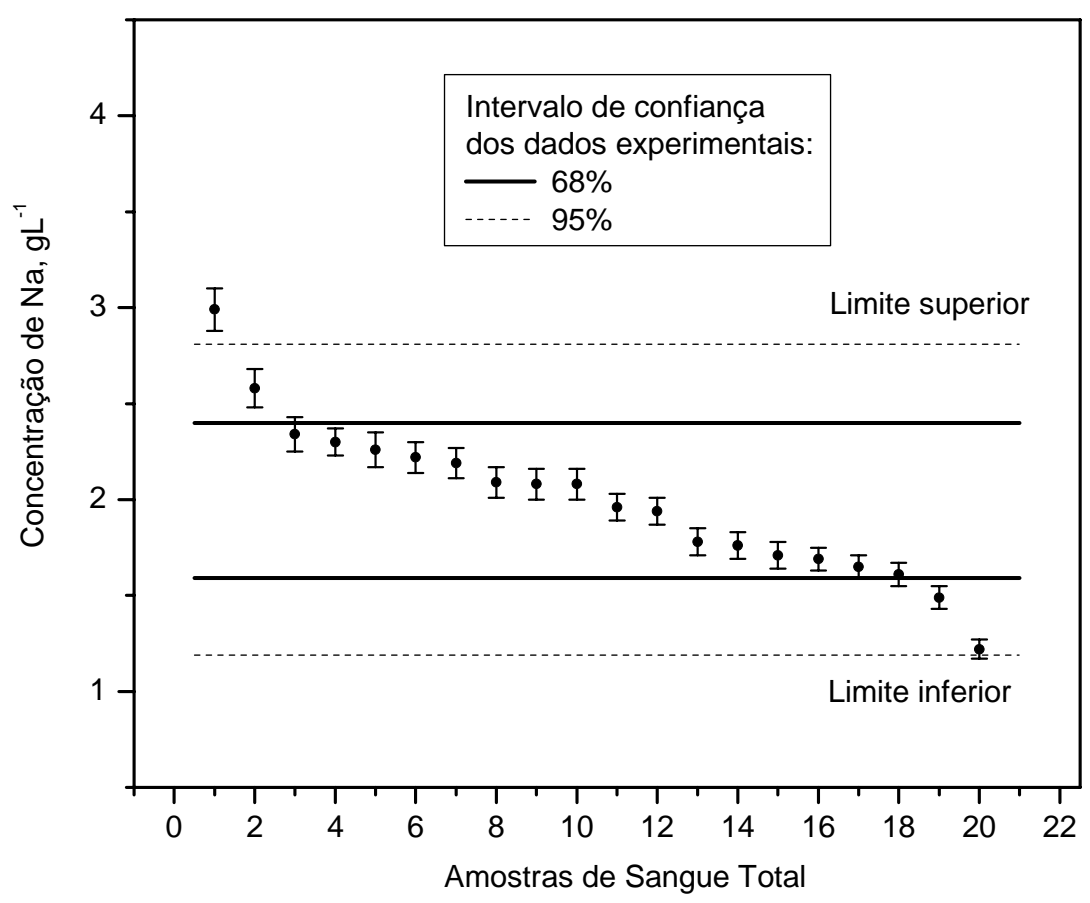

FIGURA 39 - Concentração de Na em amostras de sangue total de Hamster Dourado pela técnica de AANI. 


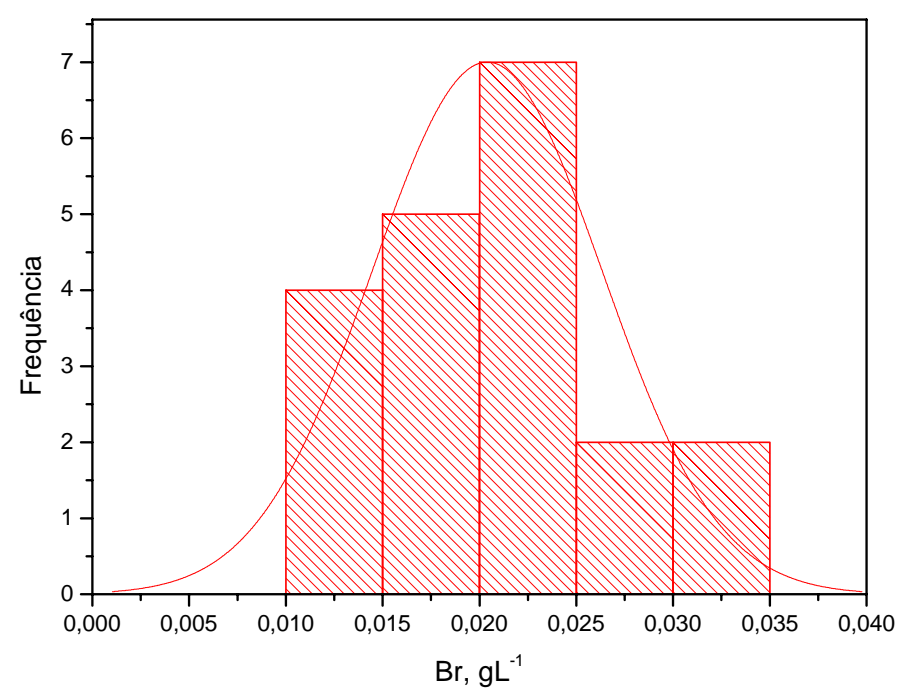

FIGURA 40 - Histograma das concentrações de $\mathrm{Br}$ em sangue total de Hamster e ajuste da função gaussiana obtidos pela técnica de AANI.

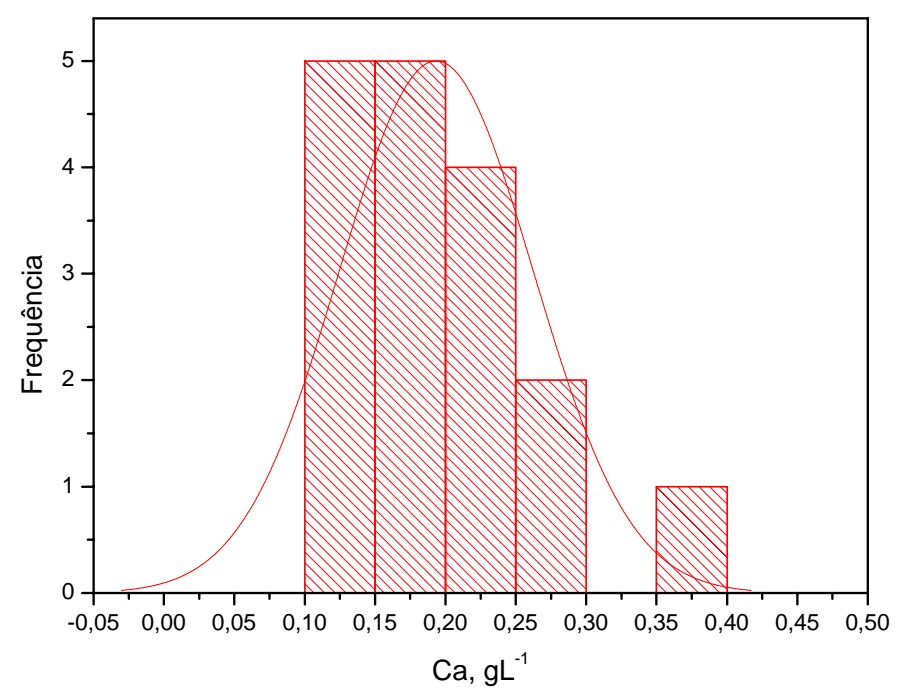

FIGURA 41 - Histograma das concentrações de Ca em sangue total de Hamster e ajuste da função gaussiana obtidos pela técnica de AANI. 


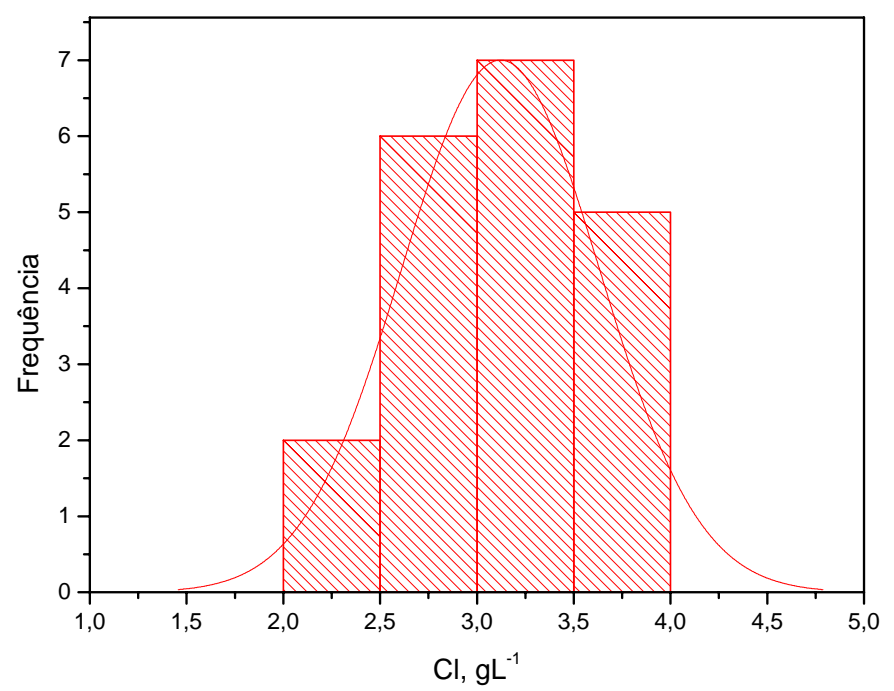

FIGURA 42 - Histograma das concentrações de $\mathrm{Cl}$ em sangue total de Hamster e ajuste da função gaussiana obtidos pela técnica de AANI.

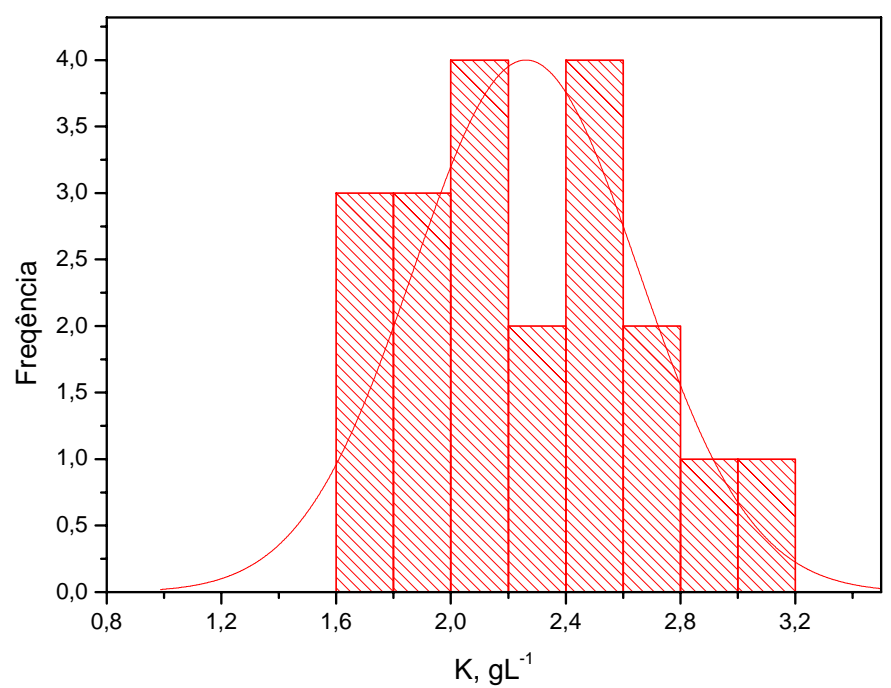

FIGURA 43 - Histograma das concentrações de K em sangue total de Hamster e ajuste da função gaussiana obtidos pela técnica de AANI. 


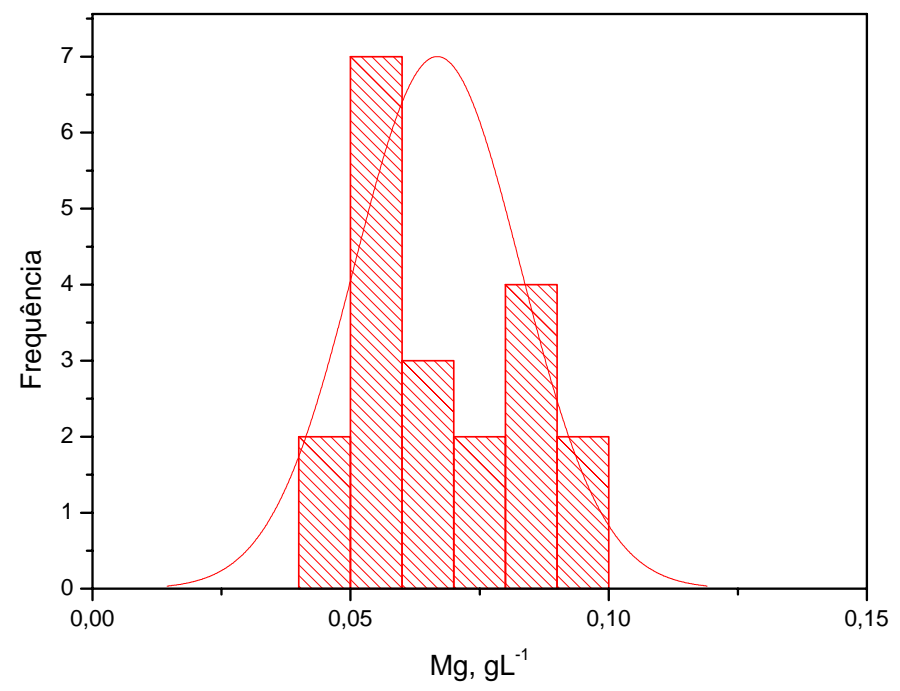

FIGURA 44 - Histograma das concentrações de Mg em sangue total de Hamster e ajuste da função gaussiana obtidos pela técnica de AANI.

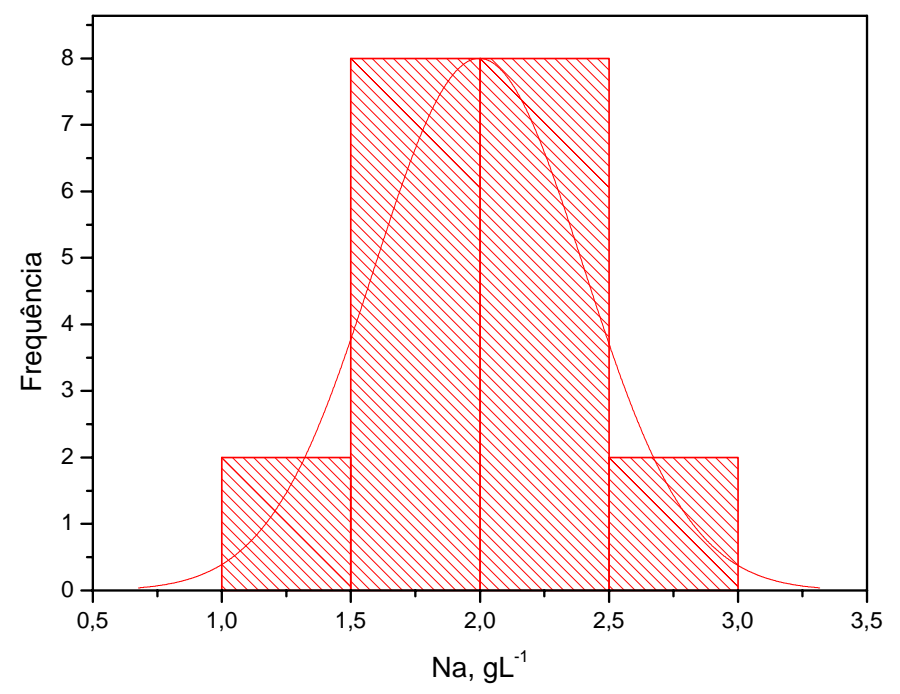

FIGURA 45 - Histograma das concentrações de Na em sangue total de Hamster e ajuste da função gaussiana obtidos pela técnica de AANI. 


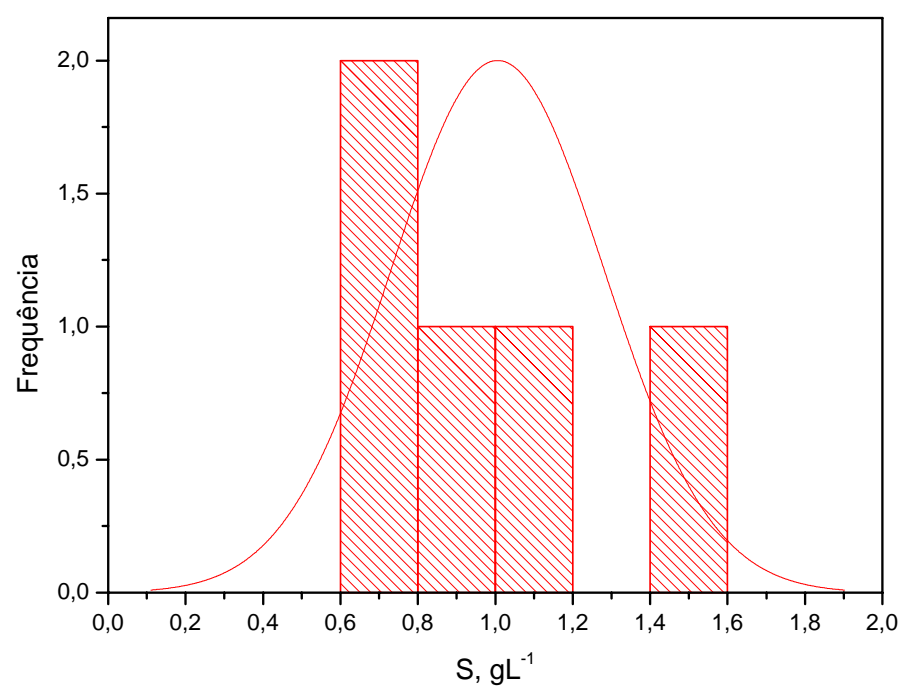

FIGURA 46 - Histograma das concentrações de S em sangue total de Hamster e ajuste da função gaussiana obtidos pela técnica de AANI.

Na tabela 7 são apresentados os parâmetros estatísticos das distribuições para cada elemento e nas figuras 47 - 52 esses parâmetros são apresentados via Box-plot.

TABELA 7 - Valores da média, mediana e moda das concentrações do $\mathrm{Br}, \mathrm{Ca}, \mathrm{Cl}, \mathrm{K}, \mathrm{Mg}$ e Na obtidas pelo método instrumental.

\begin{tabular}{c|c|c|c|c}
\hline \hline ELEMENTO, & $\begin{array}{c}\text { MÉDIA } \\
\mathrm{gL}^{-1}\end{array}$ & $\begin{array}{c}\text { MEDIANA } \\
\mathrm{gL}^{-1}\end{array}$ & $\begin{array}{c}\text { MODA } \\
\mathrm{gL}^{-1}\end{array}$ & $\begin{array}{c}\text { Desvio } \\
\text { padrão } \\
(68 \%)\end{array}$ \\
\hline \hline $\mathrm{Br}$ & 0,020 & 0,021 & $0,021^{*}$ & 0,006 \\
$\mathrm{Ca}$ & 0,19 & 0,18 & --- & 0,07 \\
\hline $\mathrm{Cl}$ & 3,12 & 3,19 & 2,75 & 0,51 \\
\hline $\mathrm{K}$ & 2,26 & 2,23 & 1,89 & 0,39 \\
\hline $\mathrm{Mg}$ & 0,067 & 0,063 & --- & 0,016 \\
\hline $\mathrm{Na}$ & 2,00 & 2,02 & $2,08^{*}$ & 0,41 \\
\hline \hline
\end{tabular}

* Distribuição com mais de um valor de moda. 


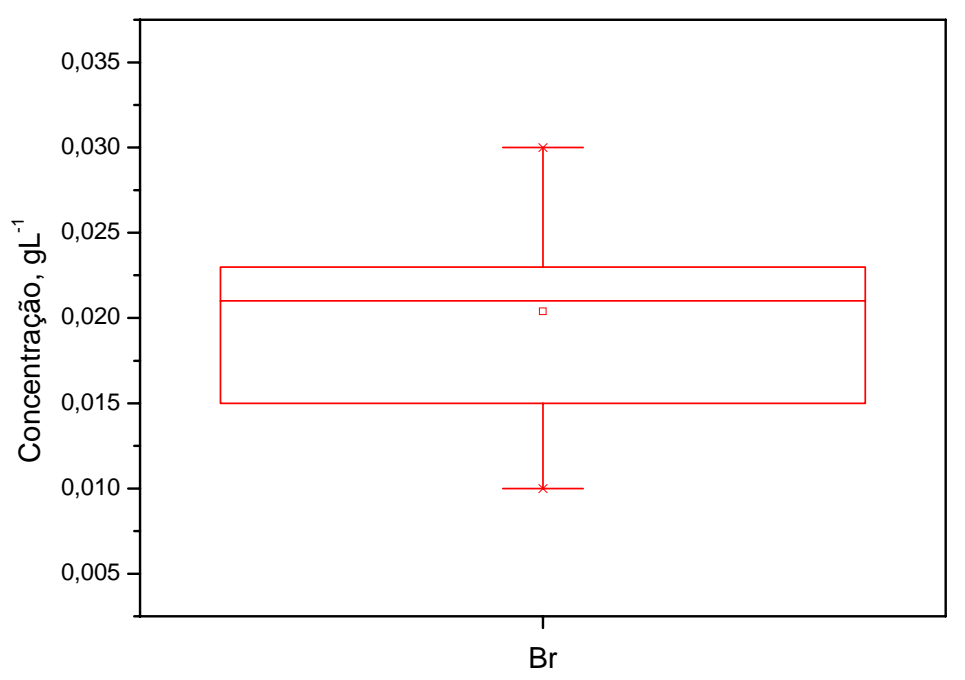

FIGURA 47 - Representação via Box-plot para Br pela técnica de AANI.

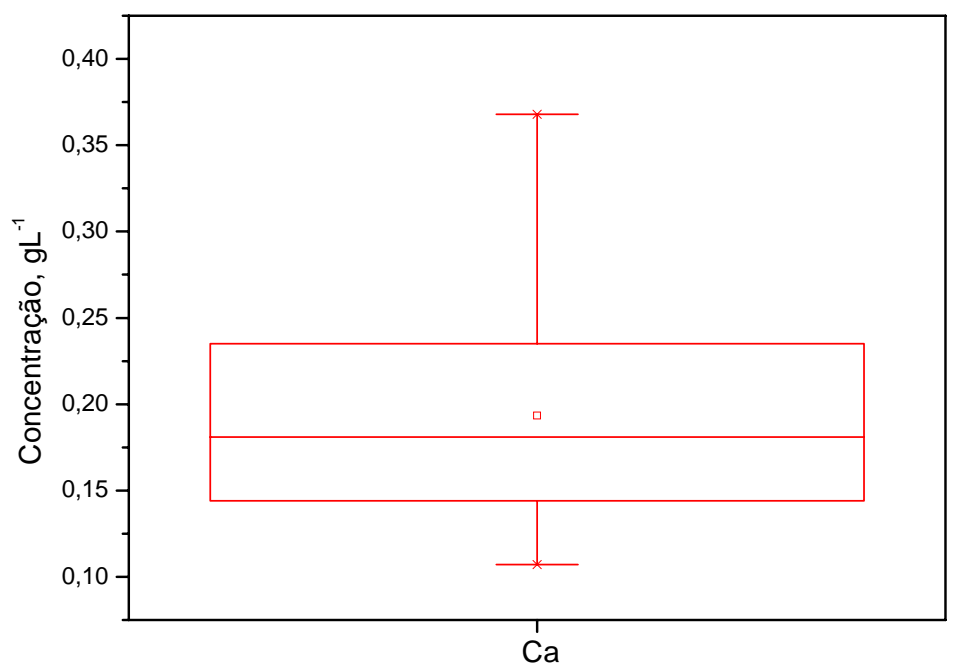

FIGURA 48 - Representação via Box-plot para Ca pela técnica de AANI. 


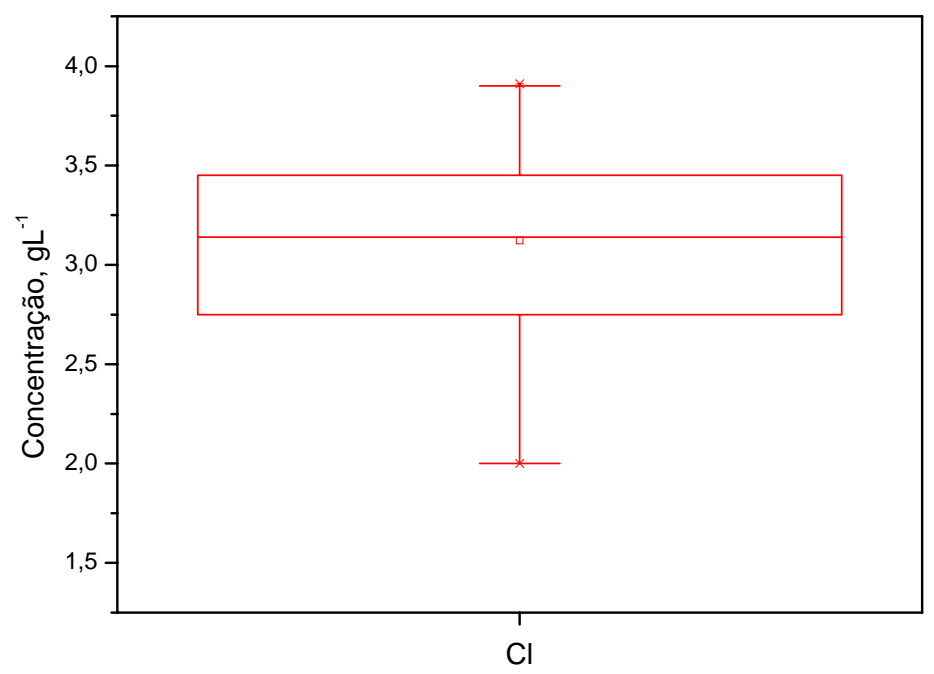

FIGURA 49 - Representação via Box-plot para $\mathrm{Cl}$ pela técnica de AANI.

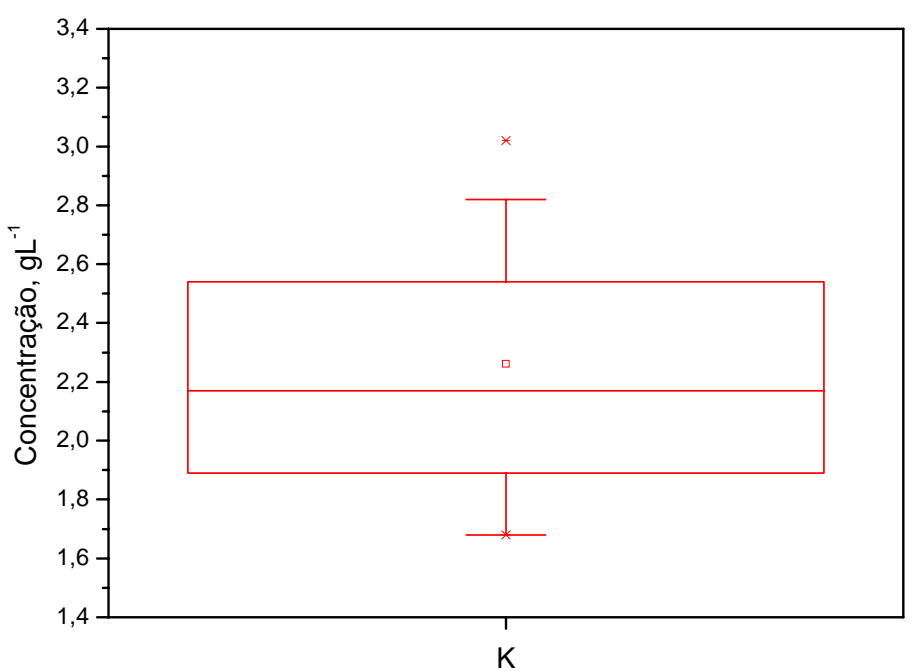

FIGURA 50 - Representação via Box-plot para K pela técnica de AANI. 


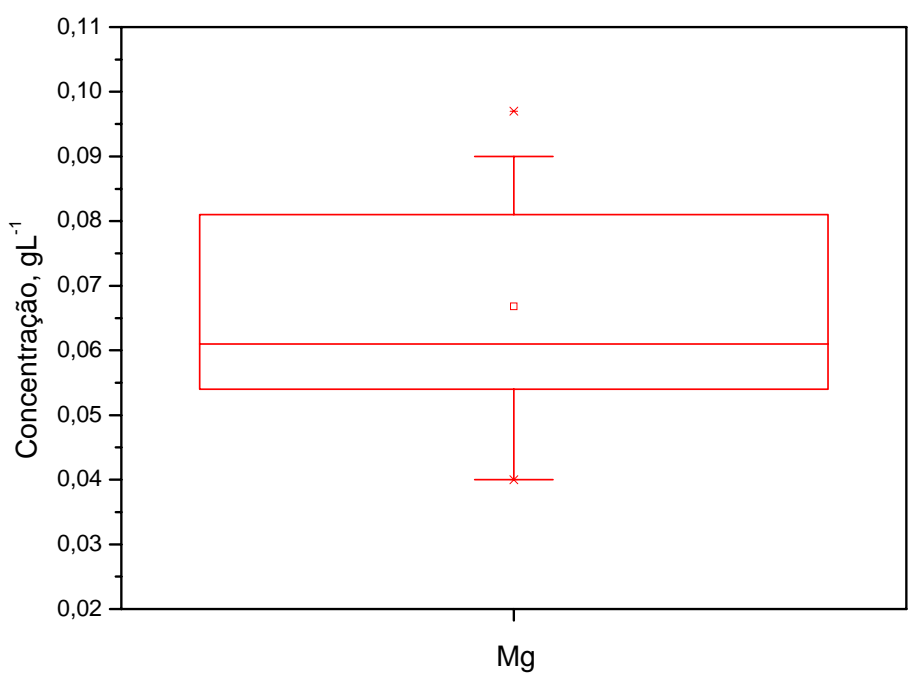

FIGURA 51 - Representação via Box-plot para Mg pela técnica de AANI.

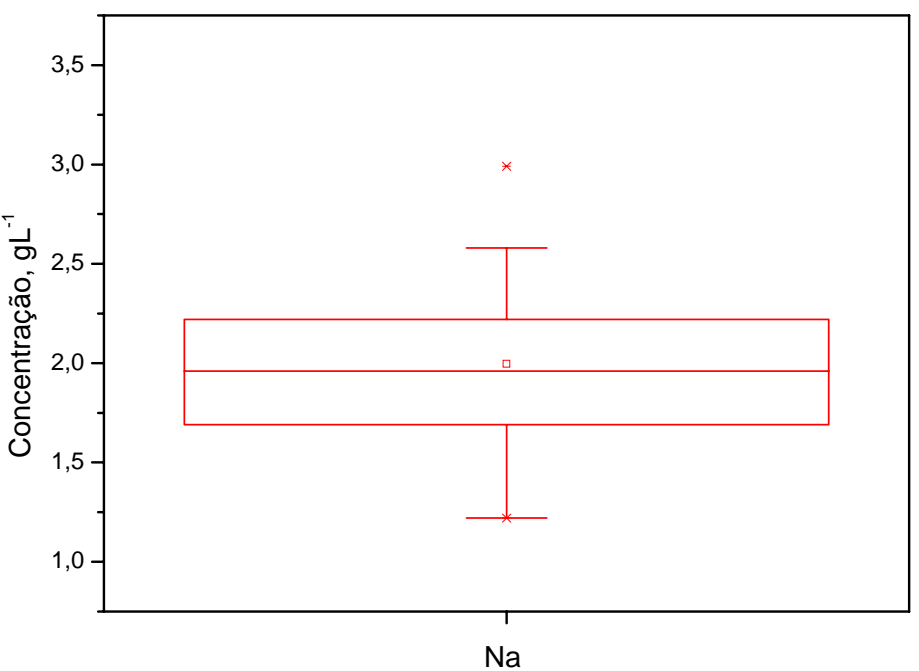

FIGURA 52 - Representação via Box-plot para Na pela técnica de AANI. 


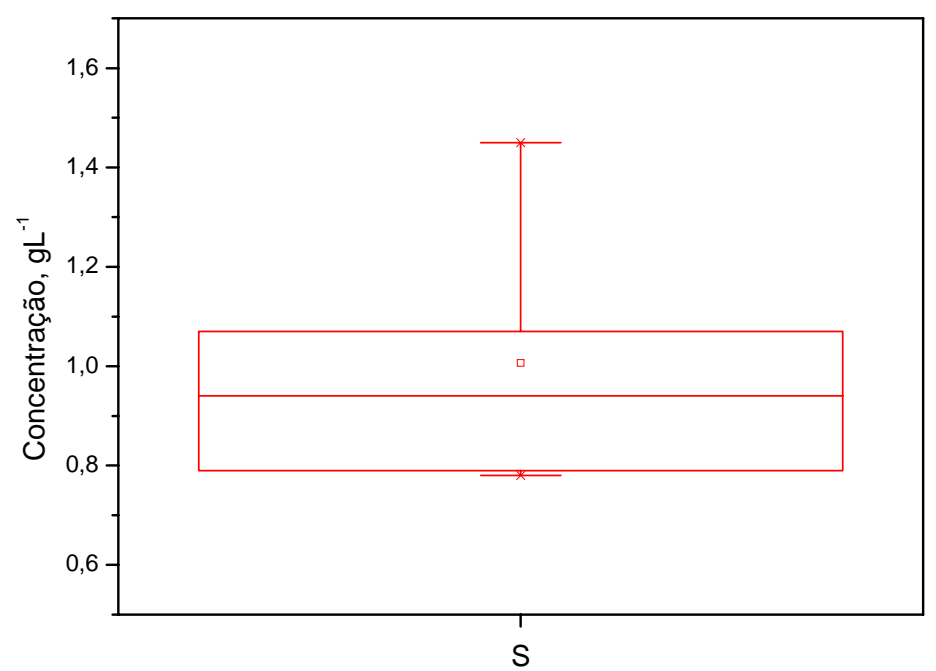

FIGURA 53 - Representação via Box-plot para S pela técnica de AANI. 


\section{CAPÍTULO 8. DISCUSSÃO}

\subsection{ANÁLISE COMPARATIVA ENTRE OS MÉTODOS}

Quando os procedimentos semi - paramétrico e instrumental de AAN foram comparados (TABELA 6) pode-se observar que os resultados são compatíveis para o intervalo de confiança de $68 \%$. Nas figuras 54 a 60 é possível visualizar essa concordância: são apresentados os valores da concentração para os elementos medidos pelo procedimento instrumental considerando-se o intervalo de confiança de $\pm 1 \mathrm{DP}$ obtido via procedimento semi- paramétrico .

Para o S, só foi possível determinar a concentração pelo método instrumental para 5 amostras; isso deve - se à meia-vida curta do isótopo de enxofre ativado ${ }^{37} \mathrm{~S}, \mathrm{~T}_{1 / 2} \sim 5$ minutos) e ao tempo de espera ( $\mathrm{T}_{\mathrm{e}}=2$ minutos), necessário para manipulação dos materiais irradiados, o que faz com que os mesmos decaiam substancialmente, inviabilizando a aquisição para a amostra e padrão com boa estatística. Embora o tempo de irradiação possa ser alterado (aumentado) existe um limite em termos de "tempo de irradiação - taxa de exposição", em análises de meia - vida curta, que torna inviável sua execução. Neste caso é usual o emprego de solução padrão do elemento a ser analisado, ou a realização de uma separação radioquímica das meias vidas mais longas, ou o emprego do método SP AAN (adotado no presente estudo). 


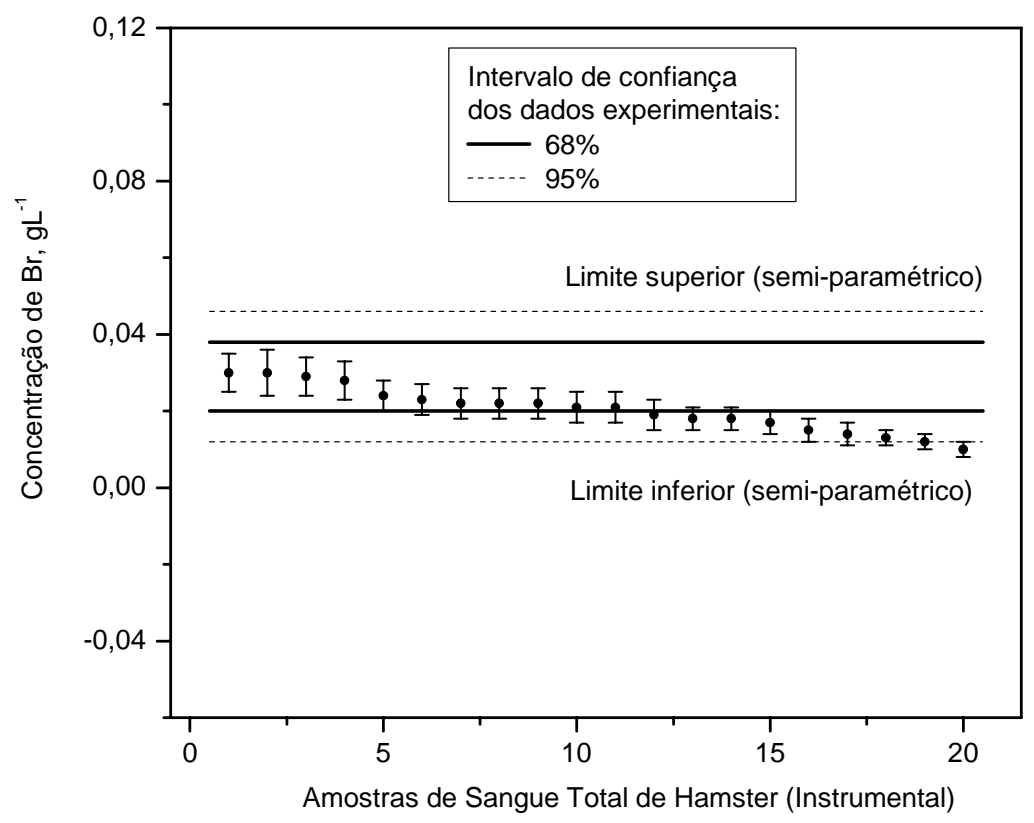

FIGURA 54 - Concentração de $\mathrm{Br}$ em amostras de sangue total de Hamster Dourado via método instrumental, comparada com o intervalo de confiança de $\mathrm{Br}$ via método semiparamétrico.

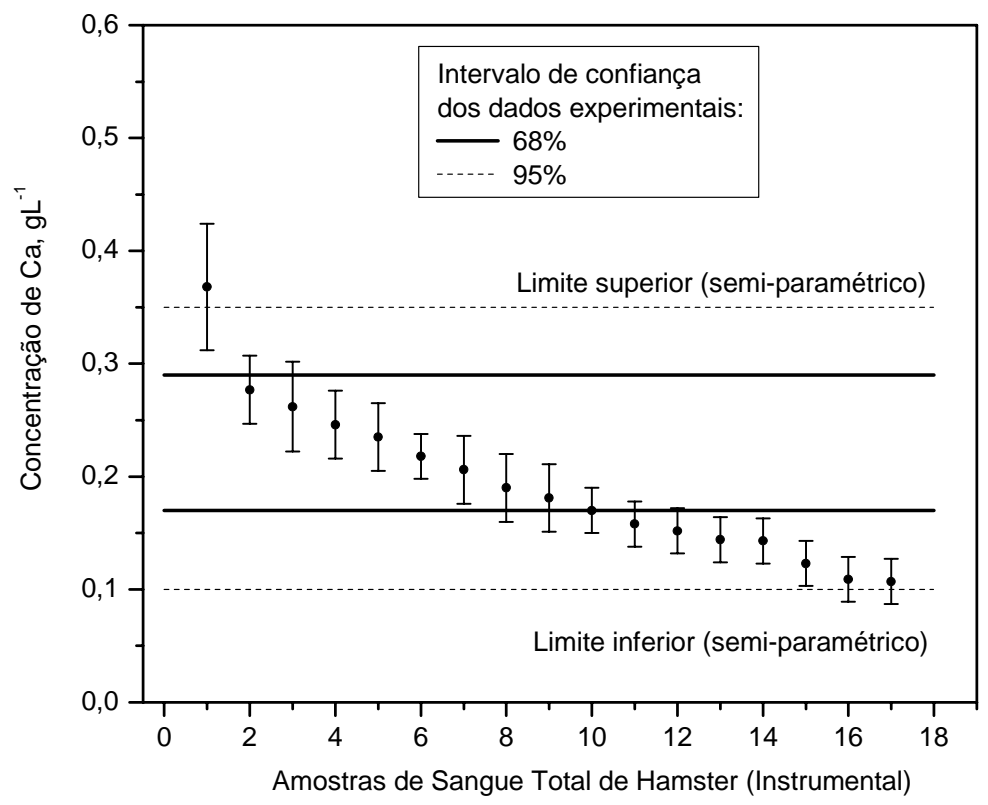

FIGURA 55 - Concentração de Ca em amostras de sangue total de Hamster Dourado via método instrumental, comparada com o intervalo de confiança de $\mathrm{Ca}$ via método semiparamétrico. 


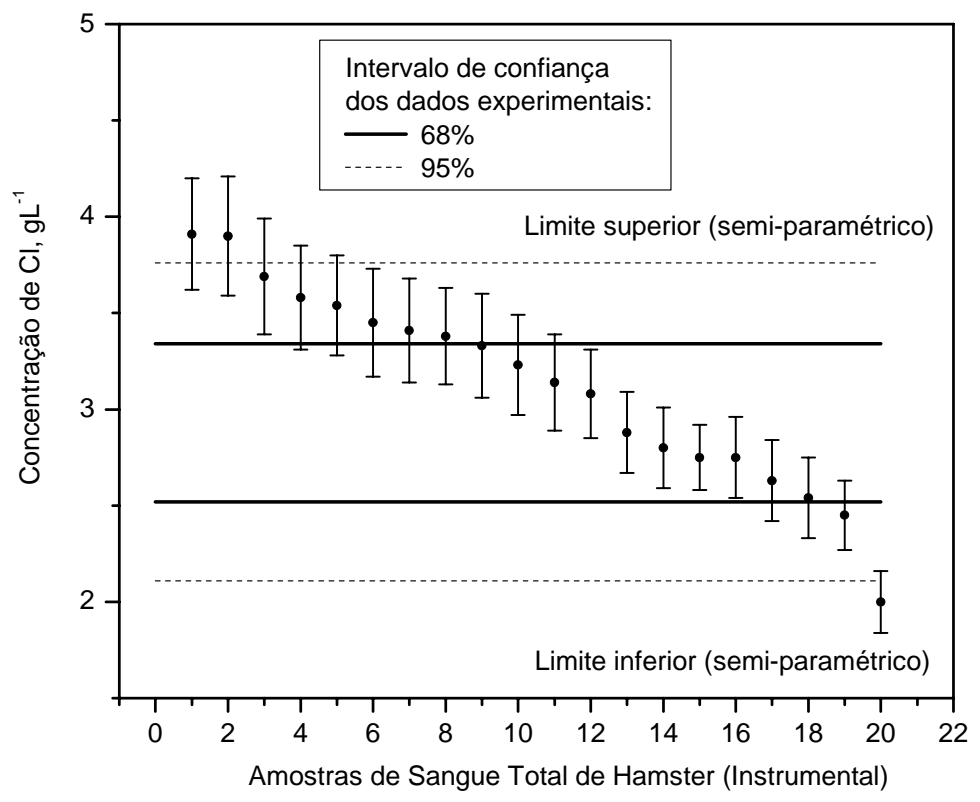

FIGURA 56 - Concentração de $\mathrm{Cl}$ em amostras de sangue total de Hamster Dourado via método instrumental, comparada com o intervalo de confiança de $\mathrm{Cl}$ via método semiparamétrico.

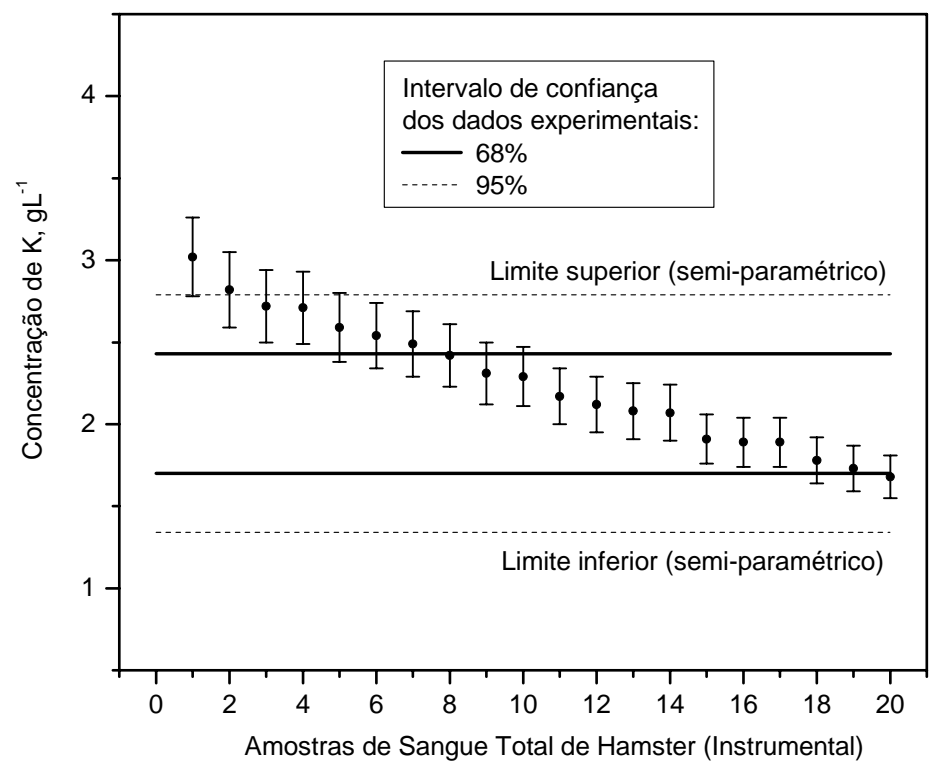

FIGURA 57 - Concentração de K em amostras de sangue total de Hamster Dourado via método instrumental, comparada com o intervalo de confiança de $\mathrm{K}$ via método semiparamétrico. 


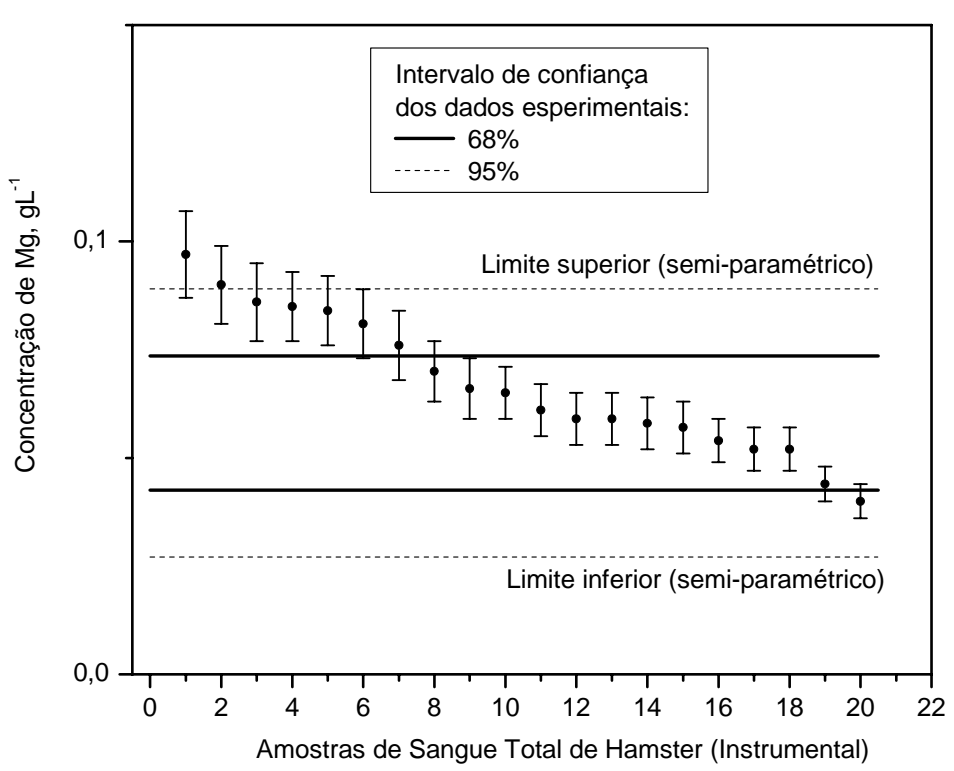

FIGURA 58 - Concentração de Mg em amostras de sangue total de Hamster Dourado via método instrumental, comparada com o intervalo de confiança de $\mathrm{Mg}$ via método semiparamétrico.

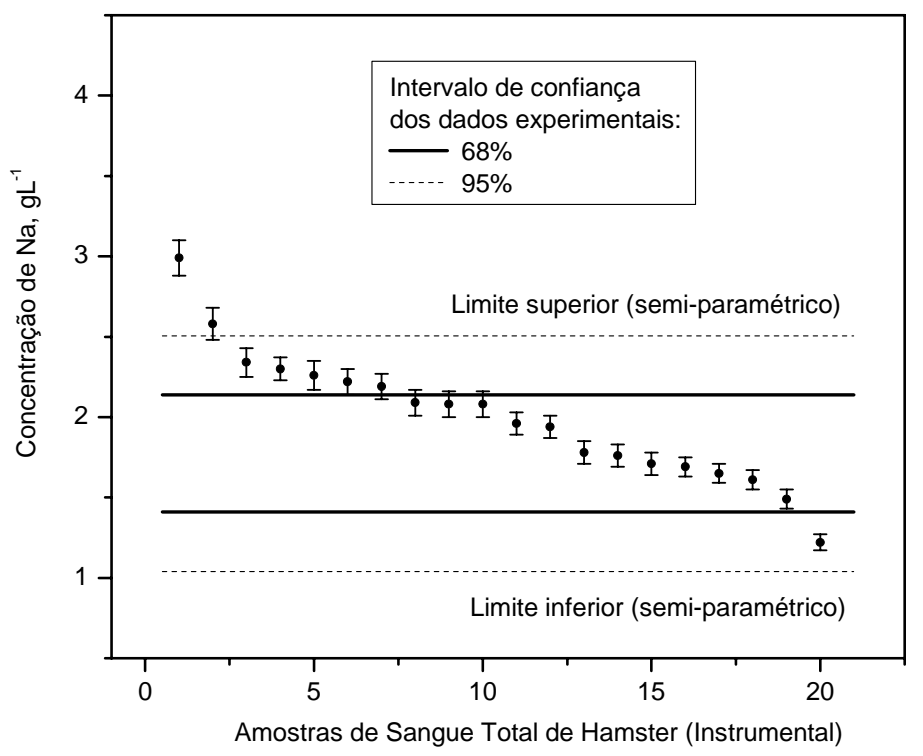

FIGURA 59 - Concentração de $\mathrm{Na}$ em amostras de sangue total de Hamster Dourado, comparada com o intervalo de confiança de $\mathrm{Na}$ via método semi-paramétrico. 


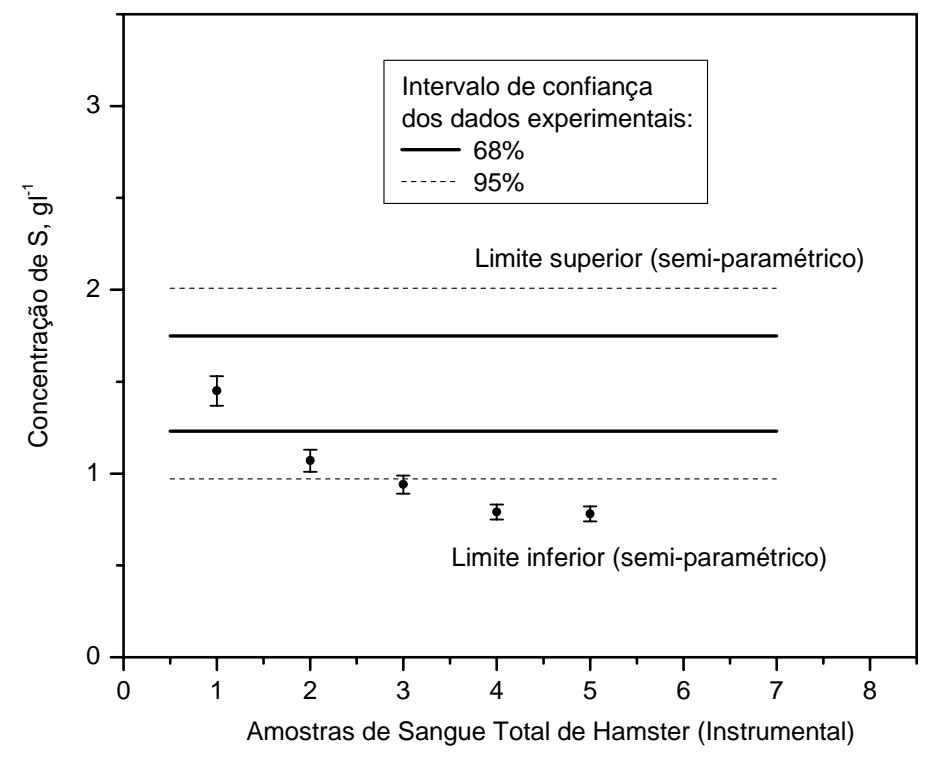

FIGURA 60 - Concentração de S em amostras de sangue total de Hamster Dourado via método instrumental, comparada com o intervalo de confiança de $\mathrm{S}$ via método semiparamétrico

\subsection{ANÁLISE COMPARATIVA: Hamster \& Humanos}

Os valores das concentrações obtidas no presente estudo, para $\mathrm{Br}, \mathrm{Cl}, \mathrm{K}$ e $\mathrm{Na}$ em sangue total de Hamster Dourado, permitem uma comparação com as estimativas em sangue de humanos, ambos obtidos pelo procedimento semi - paramétrico de AAN. Esta comparação é apresentada nas Figuras 61 a 64, respectivamente, onde o intervalo de referência adotado corresponde os valores obtidos para humanos [27], evidenciando as similaridades desses elementos no sangue desta espécie e de humanos.

Para os demais elementos $(\mathrm{Ca}, \mathrm{Mg}$ e $\mathrm{S})$ só foi possível realizar uma comparação em termos de "valores de mínimo e de máximo" disponíveis na literatura para sangue total de humanos. Estes dados são apresentados na tabela 4 e sugerem que as estimativas para Hamster encontram-se um pouco acima da estimativa para humanos: enquanto o limite superior para Ca em sangue de Hamster $\left(0,29 \mathrm{gL}^{-1}\right)$ é compatível dentro de 1DP com o valor máximo estabelecido para $\mathrm{Ca}\left(0,26 \mathrm{gL}^{-1}\right)$ em sangue humano [29], para o limite inferior, mesmo considerando o intervalo de confiança de $95 \%\left(0,11 \mathrm{gL}^{-1}\right)$ adotado na 
pratica clínica, o valor mínimo estabelecido para humanos é uma ordem de grandeza menor [29]; para $\mathrm{Mg}$, o que se observa é que os valor de máximo em humanos $\left(0,045 \mathrm{gL}^{-1}\right)$ [30] encontra-se próximo ao limite inferior em Hamster $\left(0,042 \mathrm{gL}^{-1}\right)$ considerando 1DP; da mesma forma para $\mathrm{S}$, o que se observa é que os valores de máximo em humanos $\left(0,74 \mathrm{gL}^{-1}\right)$ [29] encontra-se próximo ao limite inferior em Hamster somente quando se considera o intervalo de confiança de $99 \%\left(0,71 \mathrm{gL}^{-1}-2,27 \mathrm{gL}^{-1}\right)$.

O mesmo comportamento é observado quando a comparação envolve os resultados obtidos pela técnica AANI.

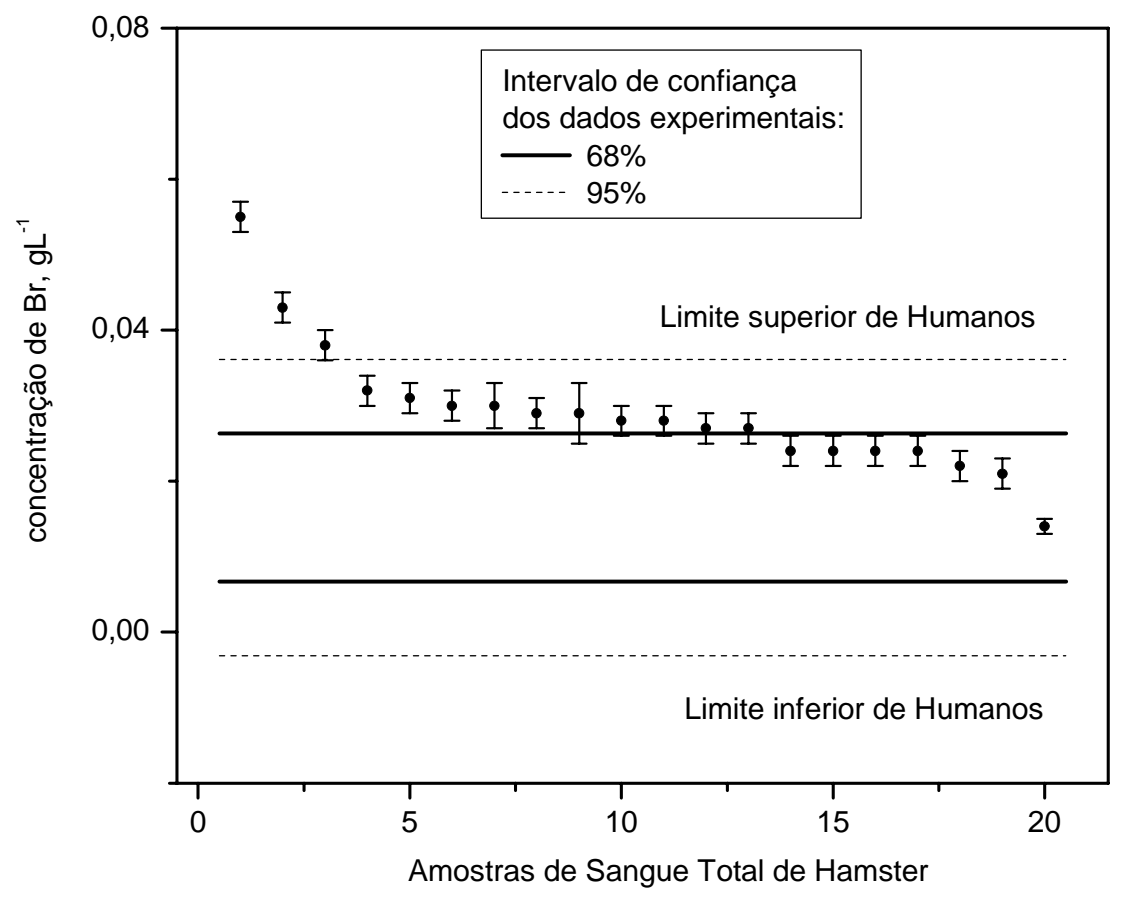

FIGURA 61 - Concentração de Br em amostras de sangue total de Hamster Dourado 


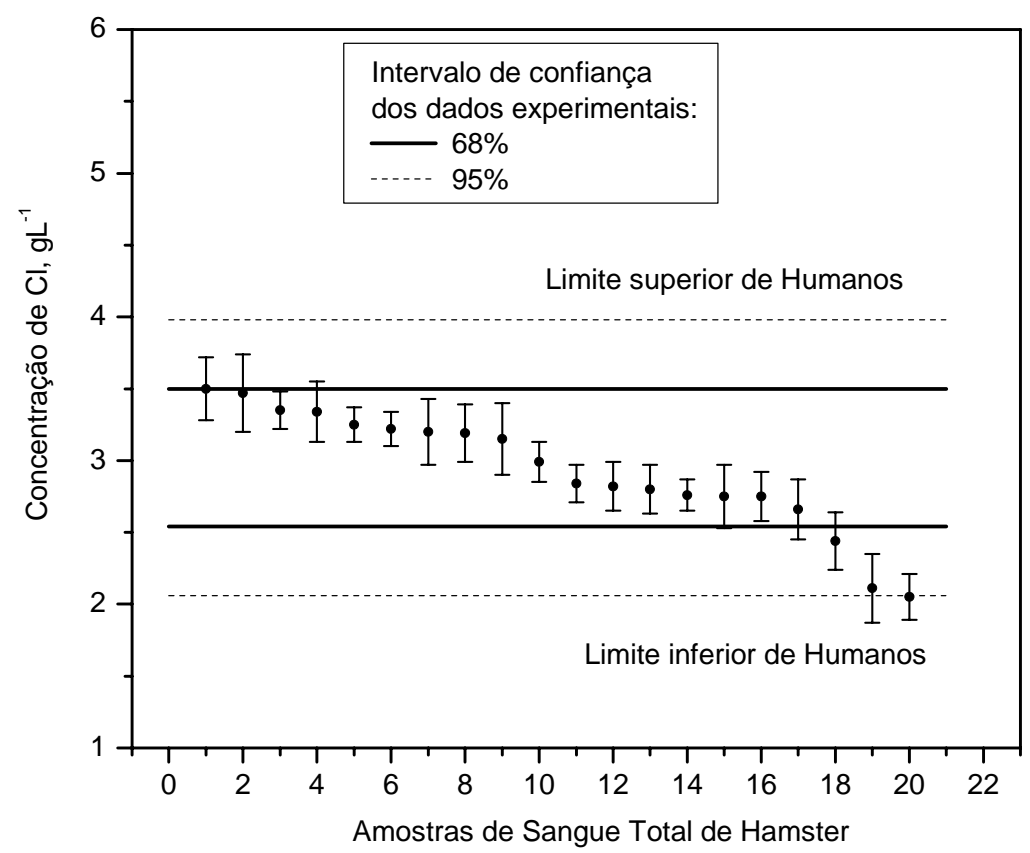

FIGURA 62 - Concentração de $\mathrm{Cl}$ em amostras de sangue total de Hamster Dourado

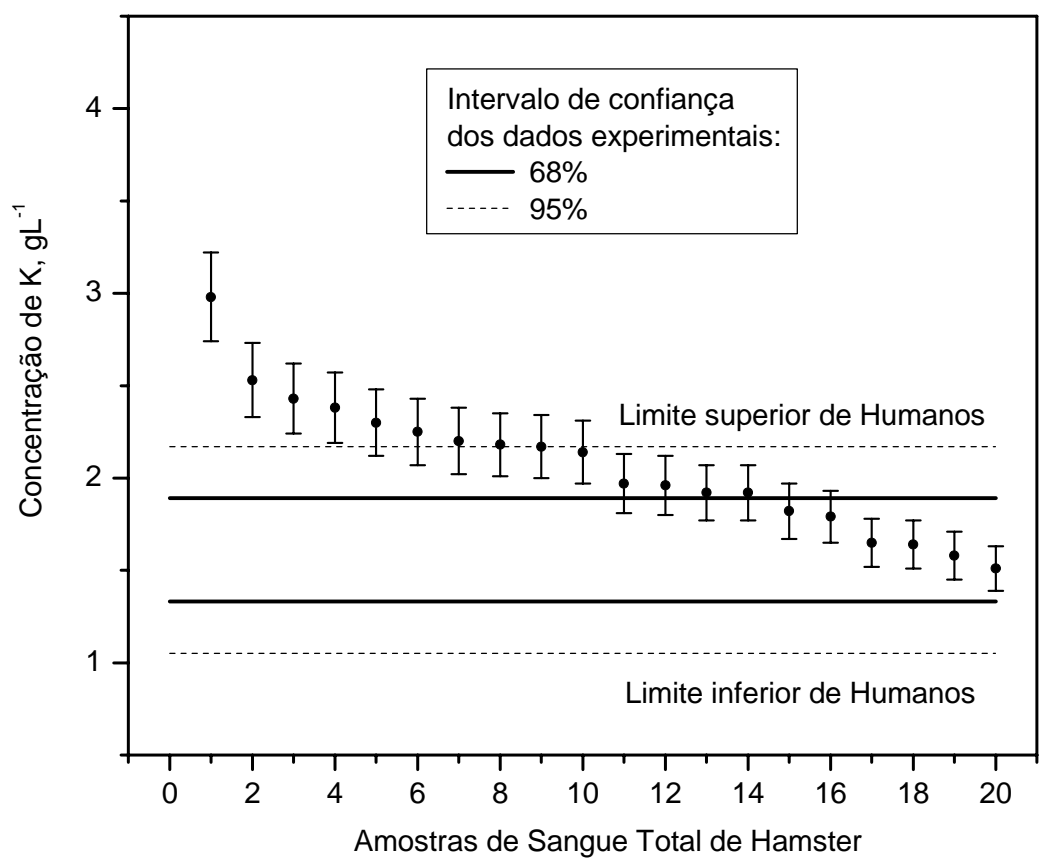

FIGURA 63 - Concentração de K em amostras de sangue total de Hamster Dourado 


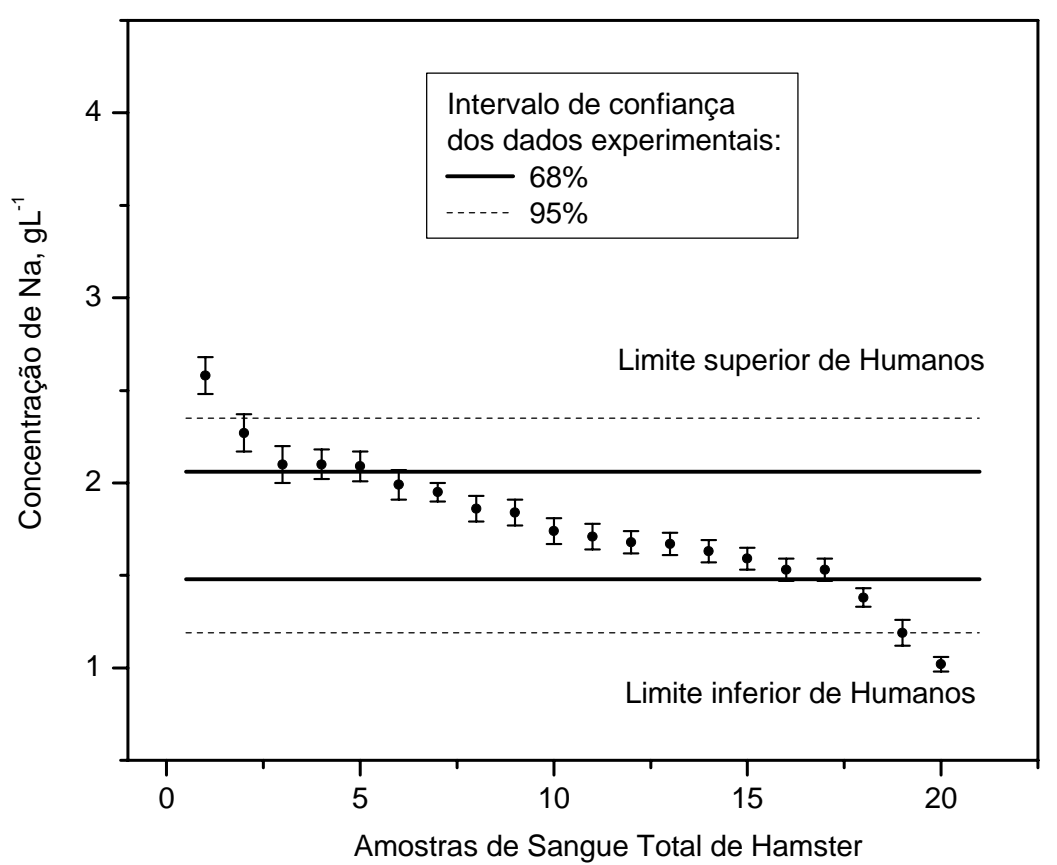

FIGURA 64 - Concentração de Na em amostras de sangue total de Hamster Dourado 


\section{CAPÍTULO 9. CONCLUSÕES}

Os resultados obtidos no presente estudo evidenciam as similaridades/discrepâncias entre os constituintes majoritários de sangue total entre esta espécie de rato e o homem.

Esses dados compõem informações valiosas para a bioquímica clínica pelo papel desses eletrólitos no metabolismo e nas patologias associadas.

A técnica de AAN para caracterização do tecido sanguíneo deste animal de experimentação mostrou-se ferramenta ágil e precisa, tanto para uso em medicina veterinária para prática clínica como em patologia clínica e áreas afins, pois o pesquisador poderá otimizar sua pesquisa, em tempo e em custo, selecionando o animal (espécime) que melhor se adapta ao experimento.

A técnica ANN pode ser empregada como procedimento analítico alternativo, em bioquímica clínica, quando o material biológico é escasso.

O emprego dos procedimentos semi - paramétrico e/ou instrumental de AAN apresentam simplificações e vantagens comparativamente aos procedimentos convencionais para prática clínica, tais como:

- utilização de sangue total, em pequena quantidade (100 $\mu \mathrm{L})$ comparativamente ao procedimento convencional (1 a $2 \mathrm{~mL}$ de soro/análise);

- agilidade: elimina a etapa de obtenção de soro;

- redução nos custos dispensa o uso de reagente e permite a obtenção simultânea de vários elementos (procedimento AAN SP);

- facilidades no armazenamento e transporte das amostras de sangue: em função do procedimento de preparo da amostra não há necessidade de refrigeração podendo ser armazenada por longos períodos, pois só depende da durabilidade do papel;

- por se tratar de métodos não destrutivo pode-se, ainda, repetir a análise após o término de sua atividade residual ( $\sim 72$ horas); 
- o descarte da amostra não necessita de nenhum tratamento :pode ser incinerada e descartada como rejeito hospitalar

As duas técnicas utilizadas foram compatíveis na determinação dos elementos. Entretanto, utilizando-se o procedimento semi- paramétrico foi possível medir simultaneamente a concentração dos elementos $\mathrm{Br}, \mathrm{Ca}, \mathrm{Cl}, \mathrm{Mg}, \mathrm{K}, \mathrm{Na}$ e $\mathrm{S}$ simplificando o procedimento experimental no laboratório; além disso, a determinação do enxofre, de meia vida curta ( $\mathrm{T}_{1 / 2} \sim 5$ minutos) é praticável sem a necessidade da realização de separação radioquímica.

Embora as incertezas possam ser menores utilizando o procedimento Instrumental de Ativação, pois são expressas principalmente em função das incertezas associadas ao padrão, na pratica clínica da ordem de 5 a 10\% são adotadas em função da combinação eletrolítico\& método analítico empregado.

\subsection{Perspectivas}

Realizar medidas com solução padrão de enxofre com objetivo de complementar a medida INAA em sangue total de Hamster. Com este procedimento experimental espera-se diminuir a taxa de exposição a radiação, na manipulação das amostras, logo após a irradiação, tornando viável o uso do procedimento comparativo de AAN.

Dar continuidade as análises: obtenção da concentração de ferro e iodo, também relevantes em bioquímica clínica; para esta análise é necessário coletar amostra de $500 \mu \mathrm{L}$ e irradiação de $4 \mathrm{hs}$ em fluxo de nêutrons térmicos da ordem de $10{ }^{12} \mathrm{n} \cdot \mathrm{cm}^{-2} \cdot \mathrm{s}^{-1}$.

Pretende-se avaliar a presença dos elementos $\mathrm{Br}, \mathrm{Ca}, \mathrm{Cl}, \mathrm{K}, \mathrm{Mg}, \mathrm{Na}$ e $\mathrm{S}$ na ração utilizada.

Submeter as amostras (utilizadas no presente estudo) a outros procedimentos analíticos: atualmente encontra-se em fase de teste a análise de amostras de sangue total por fluorescência de Raio X. 


\section{Anexo 1 : Cálculo das áreas dos fotopicos}

Para esta tarefa foi utilizado o programa IDFIX [31] que permite ajuste de um fotopico utilizando uma função gaussiana.

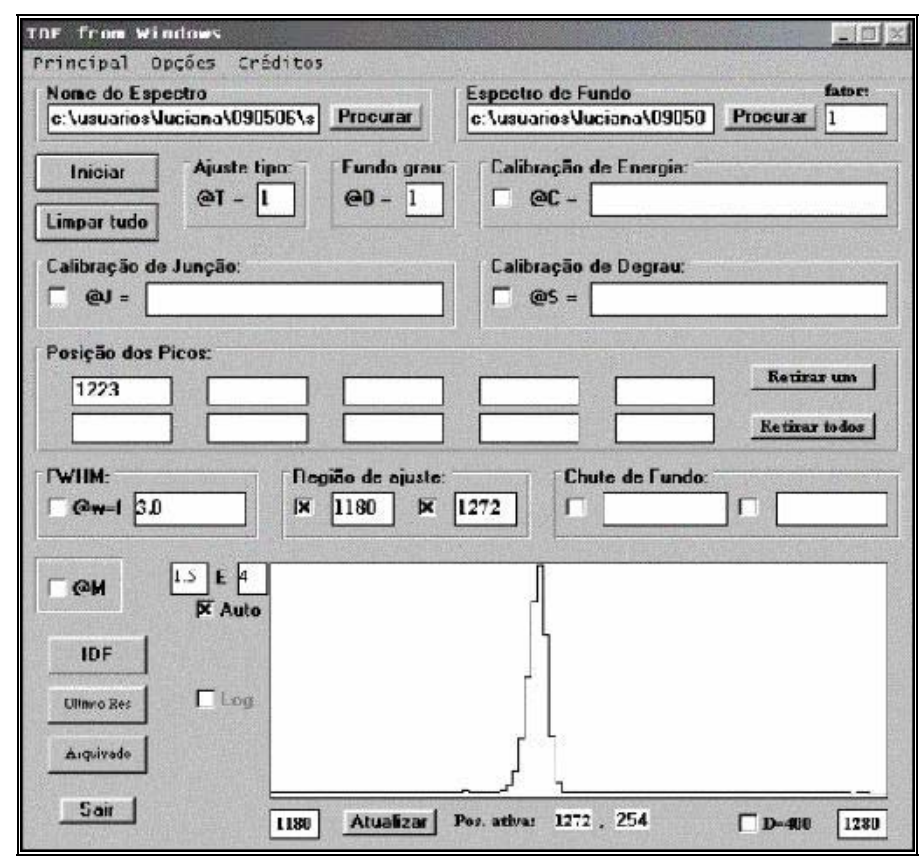

Seleção do pico para se calcular sua área.

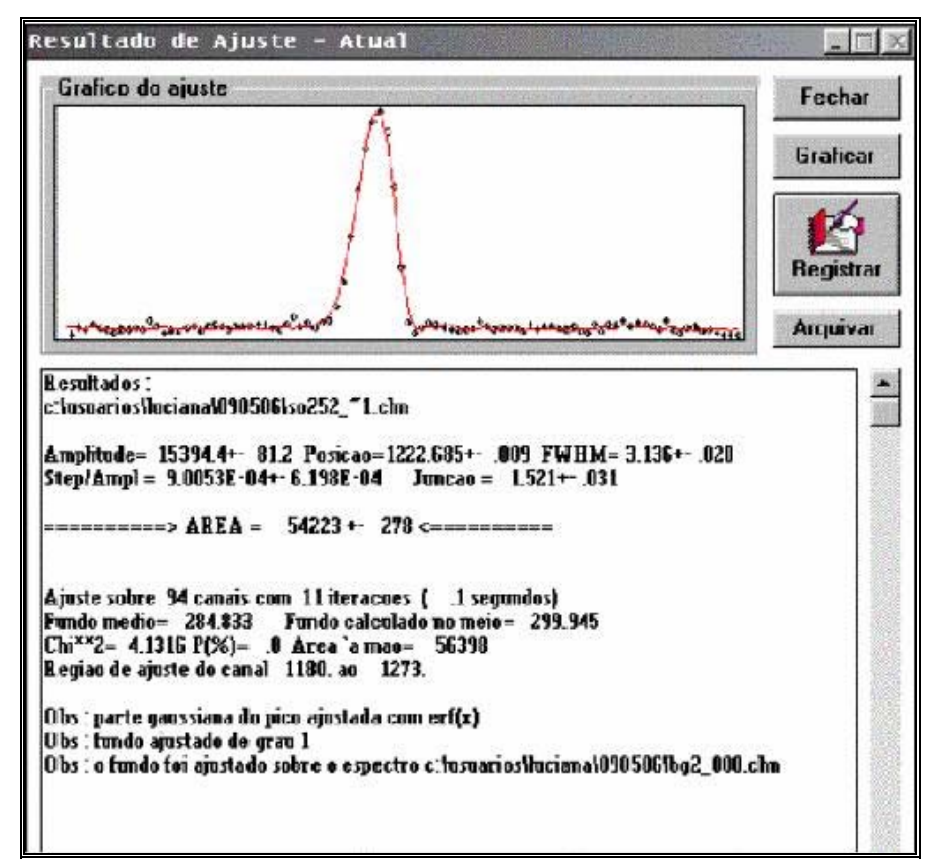




\section{Anexo 2 : Cálculo da concentração dos elementos e do fluxo}

Para esta tarefa foi utilizado o programa Ativação [32] que calcula o fluxo de nêutrons e a concentração do elemento desejado.

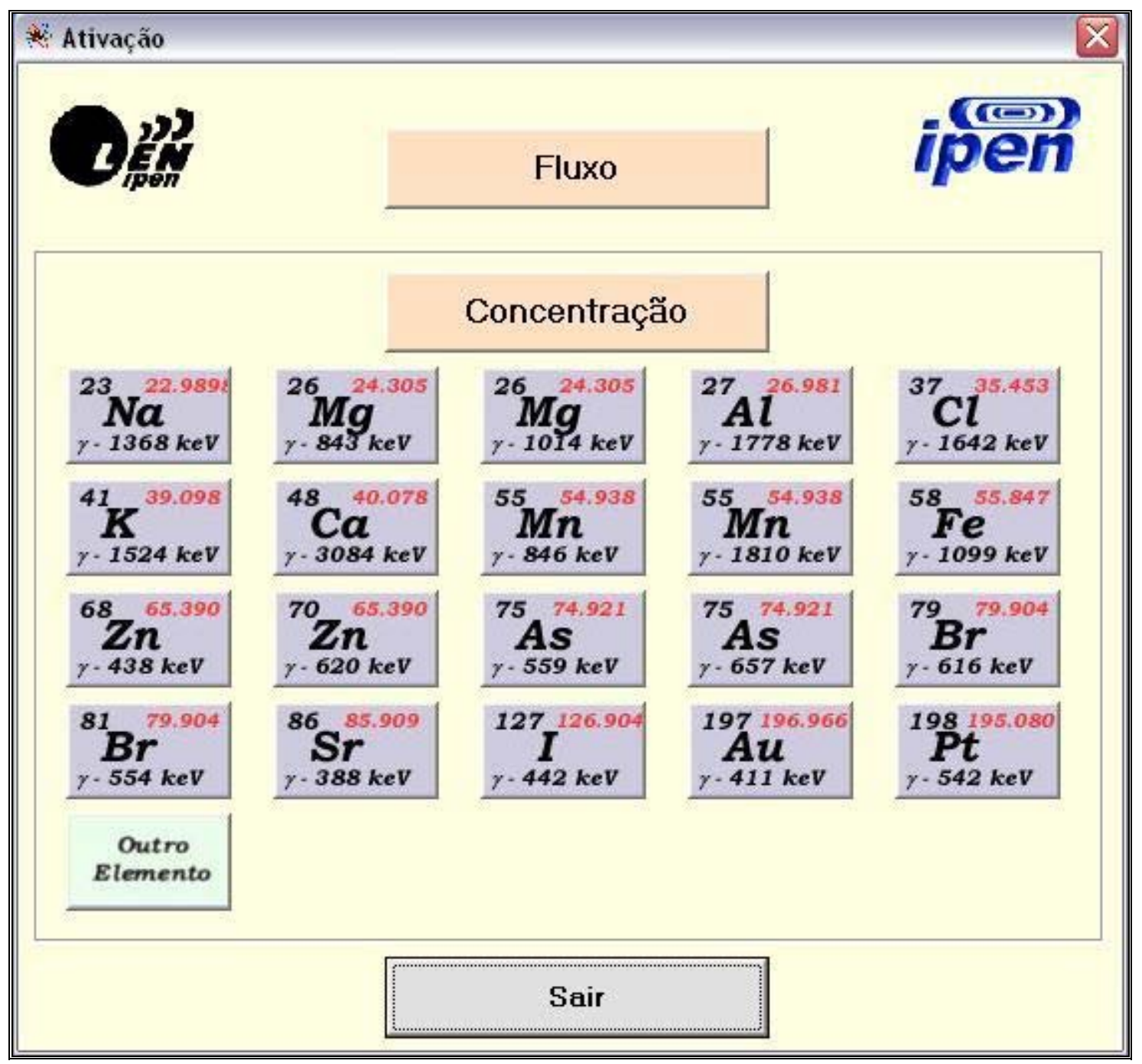




\section{Anexo 3 : Tela do software para cálculo do fluxo de nêutrons.}

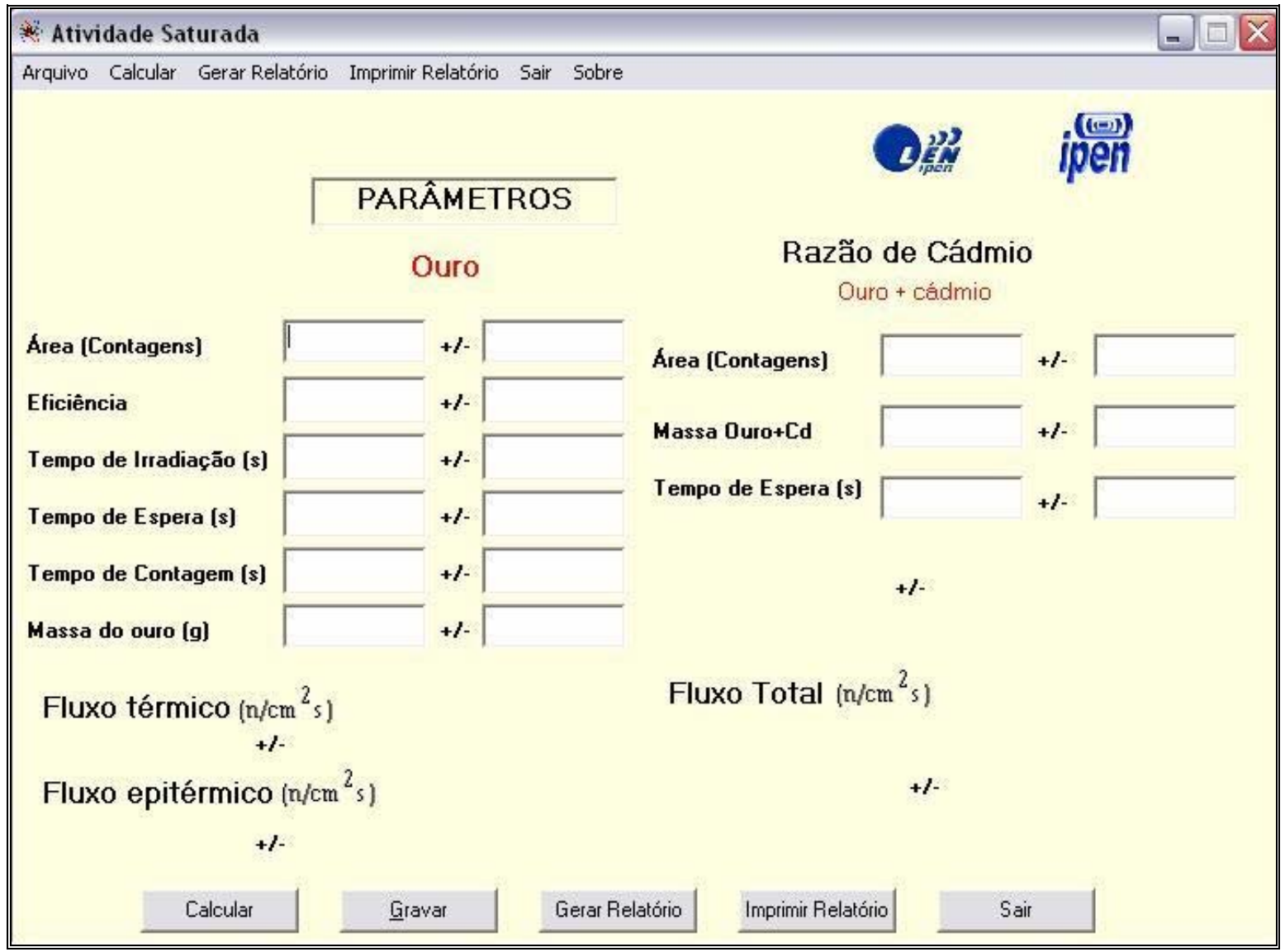




\section{Anexo 4 : Tela do software para cálculo da concentração}

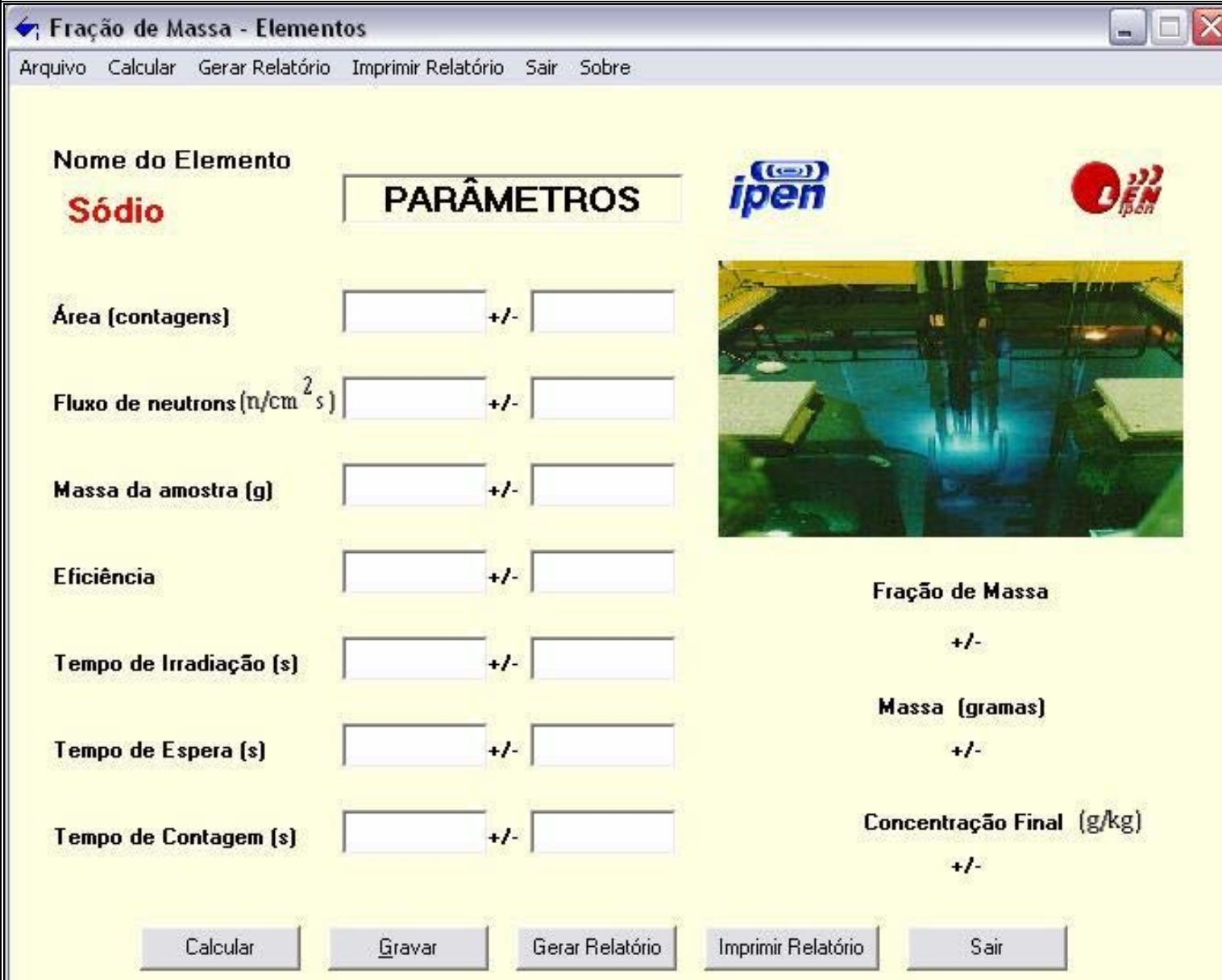




\section{REFERÊNCIAS BIBLIOGRÁFICAS}

[1] ZAMBONI, C.B.; MEDEIROS, I. M. M.A.; GENEZINI, F.A. Nuclear Methodology to Study Kidney Anomalies. V National Meeting on Nuclear Applications, Brasil, 2000.

[2] OLIVEIRA, L.C.; ZAMBONI, C. B.; ZAHN, G. S.; CESTARI, A. C.; DALAQUA JR. L.; MANSO, M. V. G.; FIGUEIREDO, A. M. G.; ARRUDA-NETO, J. T. Nuclear Methodology for Studyning Biological Functions of Mammalians Submitted to Uranium Ingestion. Rev. Bras. Pesq. Des. 4(2002)1035.

[3] FIGUEIREDO, A. M. G.;. SAIKI, M; ZAMBONI, C.B; OLIVEIRA, L. C; MEDEIROS, J. A. G. Comparasion of absolute NAA by using Cadmium Ration Technique with comparative NAA to determine trace elements in fiological samples aiming clinical analysis. V Latinamerican Symposium on Nuclear Physics, Santos, 2003.

[4] CESTARI, A. C; ZAMBONI, C. B; OLIVEIRA, L.C; GONÇALVES, O. D; MAGALHÃES, S. D; PEREZ, A. C. XRF and NAA Analysis of Trace Elements in Poultry Boné. V Latinamerican Symposium on Nuclear Physics, Santos, 2003.

[5] ZAMBONI, C. B.; FIGUEIREDO, A. M. G.; SAIKI, M.; CESTARI, A. C.; GUEVARA, M. V. M.; ARRUDA-NETO, J. T. Uranium incorporation investigation in Wistar rats boné. In: V Nationl Meeting on Nuclear Applications, Brasil, 2000.

[6] OLIVEIRA, L. C.; ZAMBONI, C. B.; FIGUEIREDO, A. M. G.; CESTARI, A. C.; ARRUDA-NETO, J. T. Nuclear methodology to perform clinical examination of urine. III Encontro Nacional de Biociências Nucleares, Brasil, 2001.

[7] OLIVEIRA, L. C.; ZAMBONI, C. B.; ZAHN, G. S.; RAELE, M. P.; MASCHIO, M. Use of Thermal Nêutrons to Perform Analyses in Body Organs of Small Sized Animals. Brazilian Journal of Physics. 34(2004)811.

[8] OLIVEIRA, L. C.; ZAMBONI, C. B.; GENEZINI, F. A.; FIGUEIREDO, A. M. G.; ZAHN, G. S. Use of Thermal Neutrons to Perform Clinical Analyses in Blood and Urine Samples. J. Radio anal. Nucl. Chem. 263(2005)783.

[9] ZAMBONI, C. B; ZAHN, G. S AND SANT'ANNA, O. A. Trace elements at whole blood of distinct mouse lines by using NAA. VI Latin American Symposium on Nuclear Physics and Applications, 2004, Pto. Iguazu, Argentina.

[10] ZAMBONI, C. B; MEDEIROS, I.M.M.A; MEDEIROS, J. A. G; SANT'Anna, O. A. Differences in Trace Element Concentrations in Whole Blood of Small Sized Animals using ANAA. International Nuclear Physics Conference, 2005, Santos, Brasil.

[11] OLIVEIRA, L. C; ZAMBONI, C. B; LINS, P. S; AZEVEDO, M. R.. The Chlorine reference value in whole blood using ANAA. Brazilian Journal of Physics. 35, $\mathrm{n}^{\mathrm{o}} 3 \mathrm{~b}, 793-$ 796,(2005). 
[12] ZAMBONI, C. B.; OLIVEIRA, L. C.; DALAQUA JR., L. Diagnostic Application of Absolute Nêutron Activation Analysis in Hematology. Americas Nuclear Energy Symposium ANES, Florida, 2004.

[13] OLIVEIRA, L. C; ZAMBONI, C. B. Realização de Análises Clínicas utilizando processo radioanalítico. $39^{\circ}$ Congresso Brasileiro de Patologia Clínica/Medicina Laboratorial, São Paulo, 2005.

[14] KOVACS, L; ZAMBONI, C. B; OLIVEIRA, L. C; SALVADOR, V. L. R. I; SATO, M; AZEVEDO, M. R A; in: Proc. MTAA-12, Tókio, Japão, 2007.

[15] FRÉJAVILLE, J.P.; KAMOUN, P. (eds) Guide des exames de laboratoire. Paris. Flammarion, 1981.

[16] SCHMIDT-NIELSEN, K.Fisiologia animal: adaptação e meio ambiente. Ed. Santos, São Paulo, 1996.

[17] BURTIS, C. A.; ASHWOOD, E. R. Tietz Fundamentos de Química Clínica. 4ª ed. Rio de Janeiro: ED. Guanabara Koogan, 1996. 836p.

[18] RIELLA, M. C.; Princícios de Nefrologia e Distúrbios Hidroeletrolíticos. $3^{\text {a }}$. ed Rio de Janeiro: Ed. Guanabara Koogan, 1996. 740p.

[19] SACKHEIM, G. I.; LEHMAN, D. D.Química e Bioquímica para Ciências Biomédicas. $8^{a}$ ed. ED. Manole. 2001 São Paulo. 644p.

[20] GODIM JR, RAYMUNDO M M. Pesquisa em saúde e os direitos dos animais. 2 ed. Porto Alegre: HPCA, 1997.

[21] BRITT D. Ethics, ethical committees and animal experimentation. Nature 311(1984)503

[22] PETROiAnU A. Aspectos éticos na pesquisa em animais. Acta Cir Brás 1996; 11:157-64.

[23] FOLK JR.,G.EDGAR. Hamster Guide. T.F.H. Publications. Neptune City, 1967.

[24] ZAMBONI, C. B. (Org.). Fundamentos da Física de nêutrons. 1. ed. Livraria da Física, São Paulo, 2007.

[25] INTERNATIONNAL ATOMIC ENERGY AGENCY. X-Ray and Gamma-Ray Standards for detector calibration. (IAEA - TECDOC - 619), Viena, 1991.

[26] BEVINGTON, P.R. Data Reduction and Error Analysis for the Physical Sciences, New York (1969).

[27] OLIVEIRA, L. C; ZAMBONI, C. B; MESA, J. Quantitative estimation of Br, Cl, K and $\mathrm{Na}$ in sample blood by NAA.. Journal of Radioanalitical and Nuclear Chemistry. 269, $3(2006) 541$. 
[28] ISO - GUM Organização Internacional para Padronização - Guia para Expressão de Incerteza de Medição.

[29] MOUSAVI-YEGANEH, S., EBRAHIMY-FAKLAR, F., ENAYATI, F. Nuclear instruments and Methods in Physics Research B, 3 (1984) 364.

[30] BESTMAN, A. D., BRYAN, G.K., N, WINEFORDNER, J.D. Microchemical Journal, 61(1999) 240.

[31] GOUFFON, P. Manual do programa Idefix. Universidade de São Paulo, Instituto de Física, Laboratório do Acelerador Linear, São Paulo, 1987.

[32] MEDEIROS, J. A. G; ZAMBONI, C. B; ZAHN, G. S; OLIVEIRA, L. C; DALAQUA $\mathrm{Jr}$, L. Software para realização de analises hematológicas utilizando processo radioanalítico. $39^{\circ}$ Congresso Brasileiro de Patologia Clínica / Medicina Laboratorial, São Paulo - SP, Brasil, 2005. 